NASA/TM-2011-216968

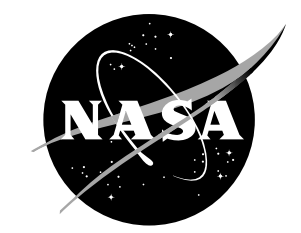

Mars Ascent Vehicle Gross Lift-off Mass Sensitivities for Robotic Mars Sample Return

Ian J. Dux

Glenn Research Center, Cleveland, Ohio

Joseph A. Huwaldt and R. Steve McKamey, P.E.

BD Systems, Inc., Huntsville, Alabama

John W. Dankanich

Gray Research, Inc., Cleveland, Ohio 


\section{NASA STI Program . . . in Profile}

Since its founding, NASA has been dedicated to the advancement of aeronautics and space science. The NASA Scientific and Technical Information (STI) program plays a key part in helping NASA maintain this important role.

The NASA STI Program operates under the auspices of the Agency Chief Information Officer. It collects, organizes, provides for archiving, and disseminates NASA's STI. The NASA STI program provides access to the NASA Aeronautics and Space Database and its public interface, the NASA Technical Reports Server, thus providing one of the largest collections of aeronautical and space science STI in the world. Results are published in both non-NASA channels and by NASA in the NASA STI Report Series, which includes the following report types:

- TECHNICAL PUBLICATION. Reports of completed research or a major significant phase of research that present the results of NASA programs and include extensive data or theoretical analysis. Includes compilations of significant scientific and technical data and information deemed to be of continuing reference value. NASA counterpart of peer-reviewed formal professional papers but has less stringent limitations on manuscript length and extent of graphic presentations.

- TECHNICAL MEMORANDUM. Scientific and technical findings that are preliminary or of specialized interest, e.g., quick release reports, working papers, and bibliographies that contain minimal annotation. Does not contain extensive analysis.

- CONTRACTOR REPORT. Scientific and technical findings by NASA-sponsored contractors and grantees.
- CONFERENCE PUBLICATION. Collected papers from scientific and technical conferences, symposia, seminars, or other meetings sponsored or cosponsored by NASA.

- SPECIAL PUBLICATION. Scientific, technical, or historical information from NASA programs, projects, and missions, often concerned with subjects having substantial public interest.

- TECHNICAL TRANSLATION. Englishlanguage translations of foreign scientific and technical material pertinent to NASA's mission.

Specialized services also include creating custom thesauri, building customized databases, organizing and publishing research results.

For more information about the NASA STI program, see the following:

- Access the NASA STI program home page at http://www.sti.nasa.gov

- E-mail your question via the Internet to help@ sti.nasa.gov

- Fax your question to the NASA STI Help Desk at $443-757-5803$

- Telephone the NASA STI Help Desk at 443-757-5802

- Write to: NASA Center for AeroSpace Information (CASI) 7115 Standard Drive Hanover, MD 21076-1320 
NASA/TM-2011-216968

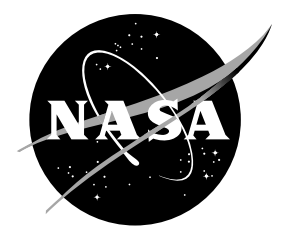

\section{Mars Ascent Vehicle Gross Lift-off Mass Sensitivities for Robotic Mars Sample Return}

Ian J. Dux

Glenn Research Center, Cleveland, Ohio

Joseph A. Huwaldt and R. Steve McKamey, P.E.

BD Systems, Inc., Huntsville, Alabama

John W. Dankanich

Gray Research, Inc., Cleveland, Ohio

National Aeronautics and

Space Administration

Glenn Research Center

Cleveland, Ohio 44135 
This report contains preliminary findings, subject to revision as analysis proceeds.

Trade names and trademarks are used in this report for identification only. Their usage does not constitute an official endorsement, either expressed or implied, by the National Aeronautics and Space Administration.

Level of Review: This material has been technically reviewed by technical management.

Available from

NASA Center for Aerospace Information 7115 Standard Drive

Hanover, MD 21076-1320
National Technical Information Service 5301 Shawnee Road Alexandria, VA 22312

Available electronically at http://www.sti.nasa.gov 


\section{Contents}

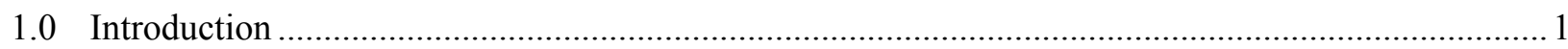

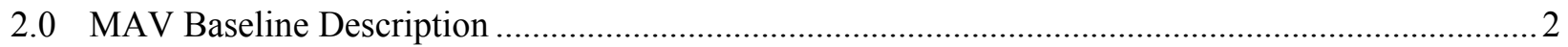

$2.1 \quad$ Top Level MAV Requirements.......................................................................................

2.2 MAV TSTO Ascent Trajectory Profile .................................................................................

2.3 TSTO Baseline Vehicle Design ......................................................................................

2.4 MAV SSTO Ascent Trajectory Profile ..............................................................................

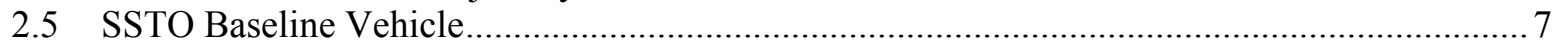

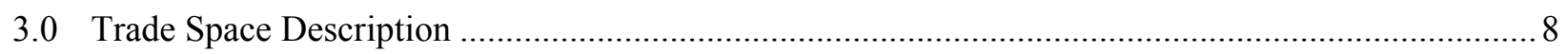

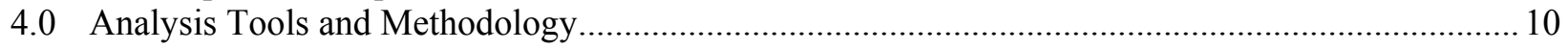

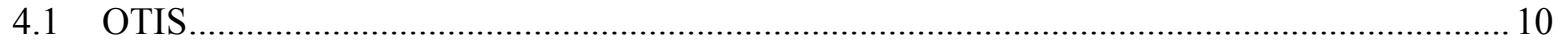

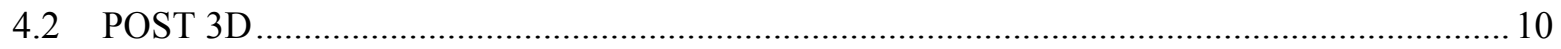

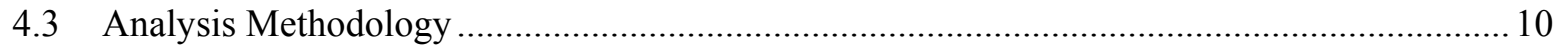

5.0 MAV Baseline Comparison ..................................................................................................... 11

5.1 TSTO POST and OTIS Trajectory Comparison ................................................................... 11

5.2 SSTO POST and OTIS Trajectory Comparison ……………………............................... 17

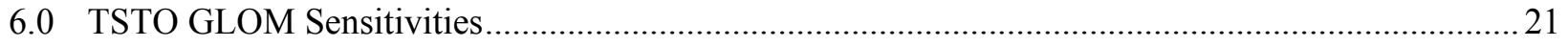

6.1 GLOM Sensitivity to Target Inclination, Launch Latitude, and Launch Elevation...................22

6.2 Sensitivity to Launch Azimuth and Launch Elevation ...........................................................2

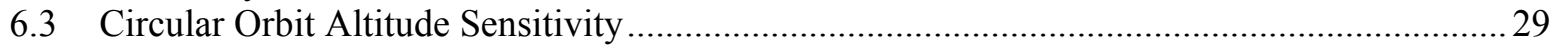

6.4 Vehicle Mass and Engine Parameter Sensitivities ....................................................................2 29

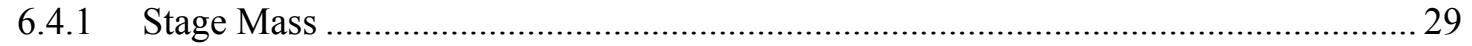

6.4.2 Engine Isp and Thrust ……………………………………………………….... 33

6.5 Verification of Combined TSTO Sensitivities …………………………………………….....36

6.6 Nominal Mission Availability for a MAV Designed for Off Nominal Launch
Conditions ................................................................................................................ 38

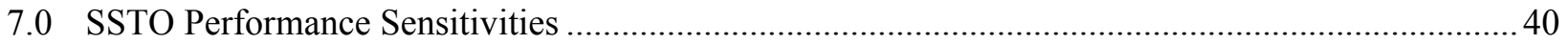

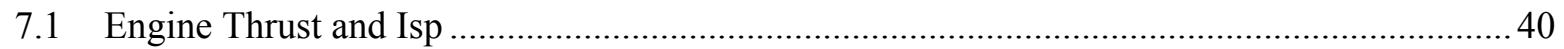

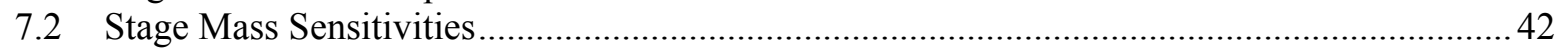

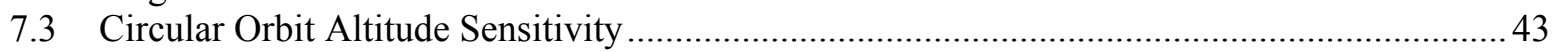

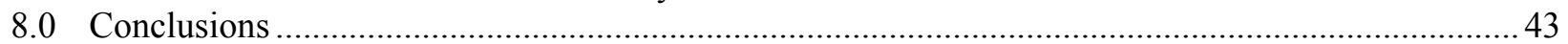

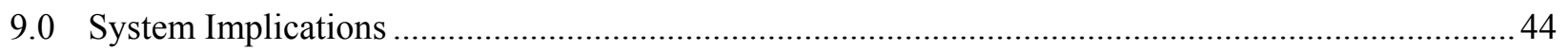

10.0 Future Work …………………………………………………………………………….... 44

Appendix A - Gross Lift-off Mass Sensitivities for Launch Elevations From $0^{\circ}$ to $90^{\circ}$ Targeting

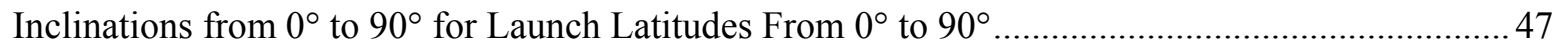

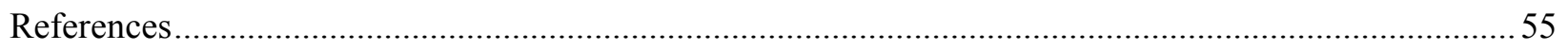

\section{List of Tables}

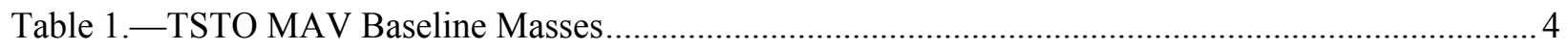

Table 2. - TSTO MAV Baseline Thrust and Isp …………............................................................. 4

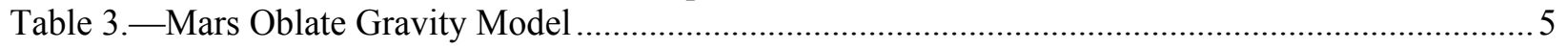

Table 4. - TSTO MAV Baseline Launch Site and Mission Assumptions .................................................... 5

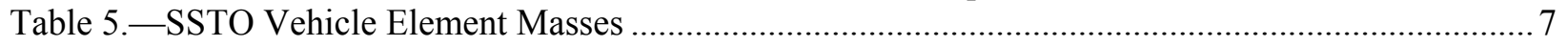

Table 6. -SSTO Engine Assumptions..........................................................................................

Table 7. - SSTO Launch and Mission Assumptions ……………………………………................... 7

Table 8. - Range of MAV Parameters Analyzed............................................................................. 9

Table 9. - Trajectory Target Parameters............................................................................................. 12

Table 10. - Comparison of OTIS and POST Baseline TSTO Baseline Trajectories .....................................13

Table 11._OTIS Constraints Necessary to Match POST SSTO Baseline.................................................... 18 
Table 12.-Comparison of OTIS and POST Baseline SSTO Baseline Trajectories ................................ 18

Table 13.-Eerification of Predicted TSTO GLOM Using TSTO Sensitivities ....................................... 37

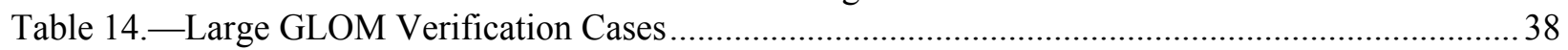

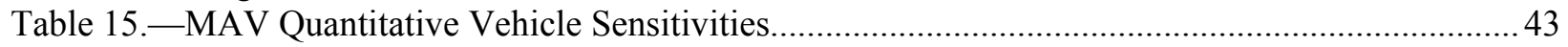

\section{List of Figures}

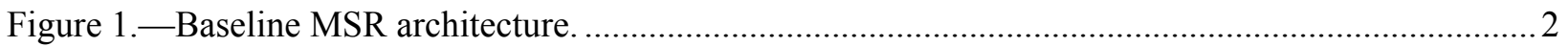

Figure 2.-MAV TSTO ascent operational concept.......................................................................... 4

Figure 3.-GLOM growth compared 2001 TSTO baseline for restricted control rates........................... 5

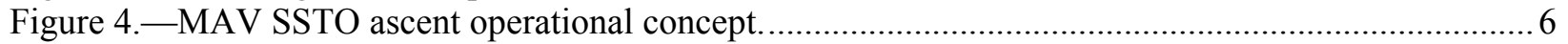

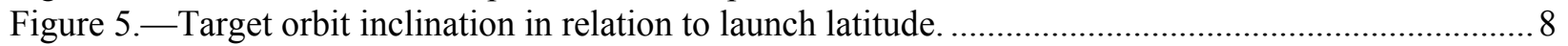

Figure 6.-MAV launch platform elevation and launch azimuth orientation. ........................................ 9

Figure 7.-Comparison of POST and OTIS MAV GLOM sensitivity data.......................................... 11

Figure 8. - Coordinate system used to define launch inertial Euler control angles................................ 12

Figure 9.-Launch inertial Euler control angle rotation sequence. ...................................................... 13

Figure 10.-Comparison geodetic altitude and inertial velocity histories for OTIS and POST

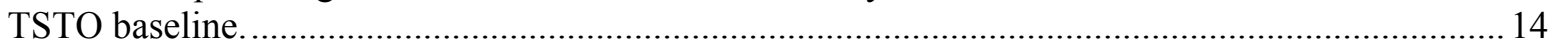

Figure 11.-Comparison of inertial Euler control angle history for OTIS and POST TSTO

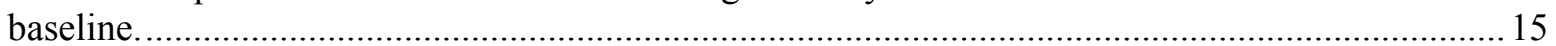

Figure 12.-Comparison of AOA history for OTIS and POST TSTO baseline.....................................15

Figure 13.-Comparison of dynamic pressure history for OTIS and POST TSTO baseline.................... 16

Figure 14.-OTIS inertial Euler pitch history comparison of wind modeling. ....................................... 16

Figure 15.- OTIS AOA history comparison of wind modeling effects................................................ 17

Figure 16.-Comparison of geodetic altitude and inertial velocity histories for POST and OTIS

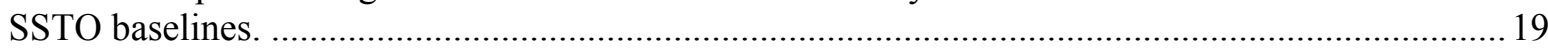

Figure 17.-Comparison of inertial Euler pitch control history for POST and OTIS SSTO

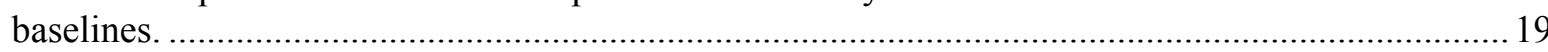

Figure 18.-Comparison of inertial Euler yaw control history for POST and OTIS SSTO

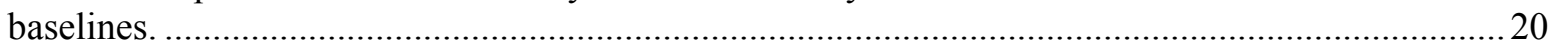

Figure 19.- Comparison of dynamic pressure history for POST and OTIS SSTO baselines...................20

Figure 20.-GLOM growth for an on-orbit inclination change necessary to reach inclinations

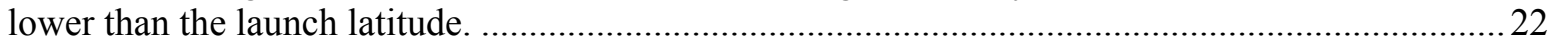

Figure 21. - GLOM sensitivity for all launch elevations and target orbit inclinations at a launch

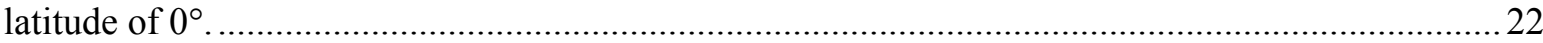

Figure 22.-GLOM sensitivity for selected elevations and target orbit inclinations at a launch

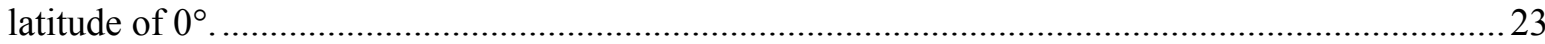

Figure 23.- Slope of GLOM change per degree of inclination for a launch latitude of $0^{\circ}$ at

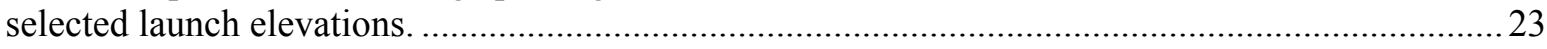

Figure 24.- GLOM sensitivity for all launch latitudes to target orbit inclinations greater than the

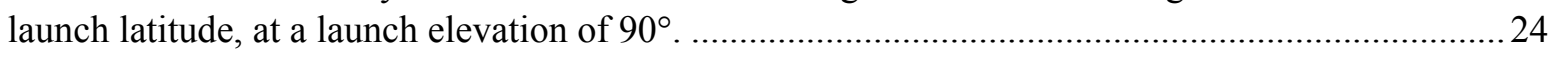

Figure 25.- GLOM sensitivity for all launch latitudes to target orbit inclinations greater than the

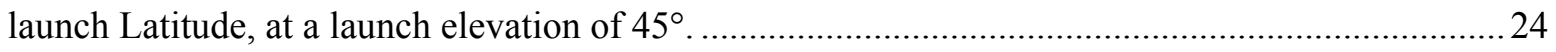

Figure 26.- Impact of control continuity on TSTO GLOM sensitivity of a vertical launch

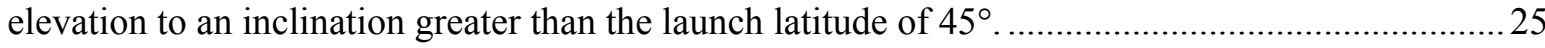

Figure 27.- Impact of wind modeling on TSTO GLOM sensitivity of a vertical launch elevation

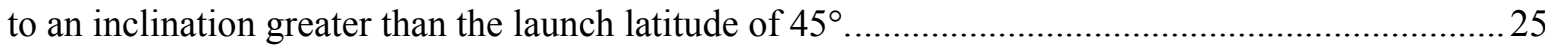

Figure 28.- Impact of control rate limit on TSTO GLOM sensitivity of a vertical launch

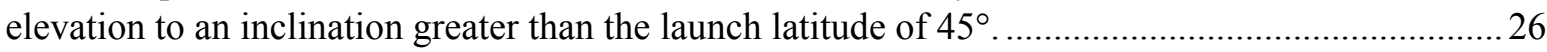


Figure 29.-GLOM delta for off optimal launch azimuths based on vertical launch with GLOM of $272.6 \mathrm{~kg}$.

Figure 30.-GLOM delta for off optimal launch azimuths based on $45^{\circ}$ elevation launch with GLOM of $265.8 \mathrm{~kg}$.

Figure 31. - GLOM delta for off optimal launch azimuths using varying control rate limits, based on a GLOM of $272.6 \mathrm{~kg}$. .28

Figure 32.-GLOM delta for off optimal launch azimuths without second stage control continuity, based on a GLOM of $272.6 \mathrm{~kg}$. 29

Figure 33.- TSTO GLOM sensitivity to circular orbit altitude. 30

Figure 34.- TSTO GLOM sensitivity to second stage mass variation for a fixed first stage mass. ...........31

Figure 35.- TSTO GLOM sensitivity to first stage mass variation for a fixed second stage mass. .......... 31

Figure 36.- Second stage dry mass sensitivity at varying values of Isp ............................................. 32

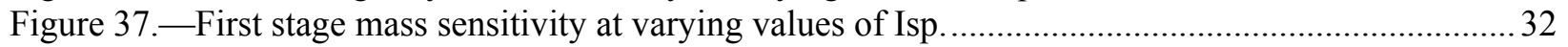

Figure 38.-TSTO GLOM sensitivity to Isp, constant for both stages. ................................................. 33

Figure 39.- - TSTO GLOM sensitivity to second sage thrust, first stage thrust held constant................... 34

Figure 40.- TSTO GLOM sensitivity to first stage thrust, second stage thrust held constant.................. 34

Figure 41.-TSTO delta GLOM difference for off azimuth launches using optimal thrust, based

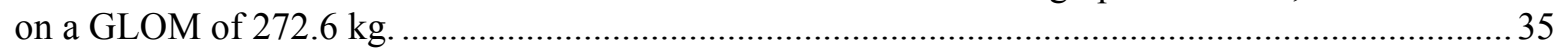

Figure 42.-TSTO delta GLOM difference for off azimuth launches using a representative liquid

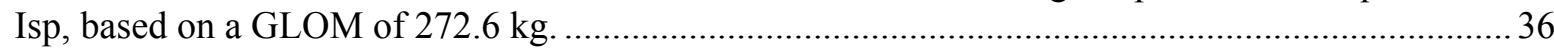

Figure 43.- Geodetic altitude and inertial velocity of large GLOM MAV, flown on a nominal

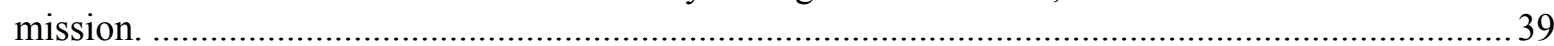

Figure 44.--Inertial Euler pitch history of large GLOM MAV, flown on a nominal mission..................39

Figure 45.- - Inertial Euler yaw history of large GLOM MAV, flown on a nominal mission. .................. 40

Figure 46.- SSTO GLOM sensitivity to thrust with and without wind modeling. ................................ 41

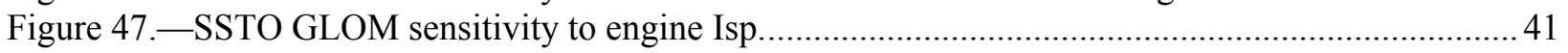

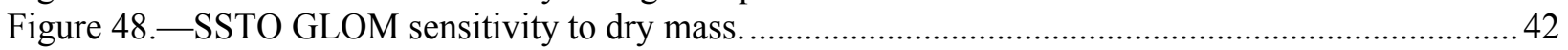

Figure 49.- SSTO GLOM sensitivity to circular orbit altitude. ....................................................... 42

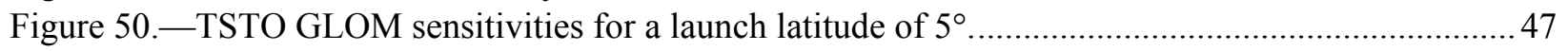

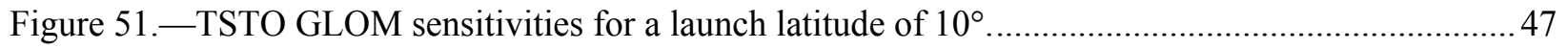

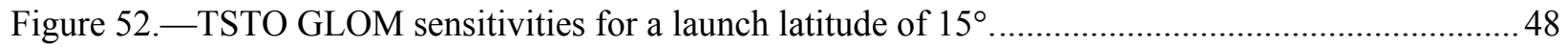

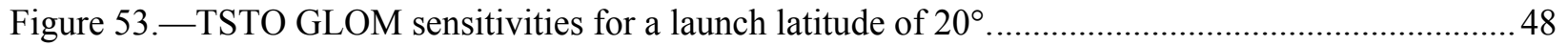

Figure 54.- TSTO GLOM sensitivities for a launch latitude of $25^{\circ}$........................................................49

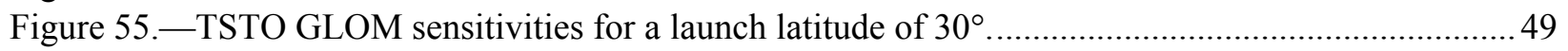

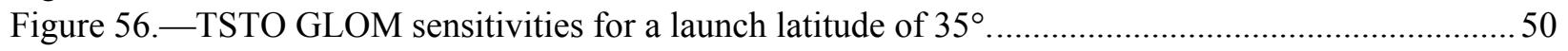

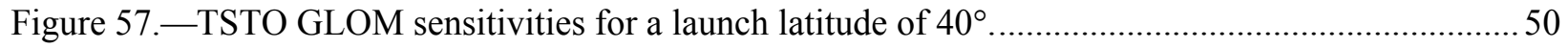

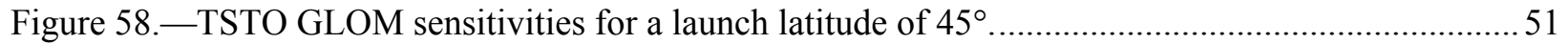

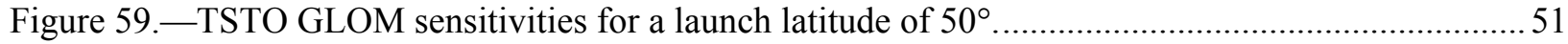

Figure 60.-TSTO GLOM sensitivities for a launch latitude of $55^{\circ}$......................................................52

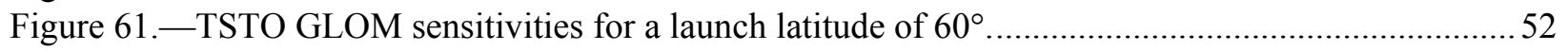

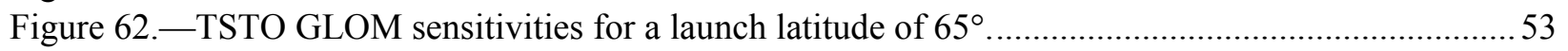

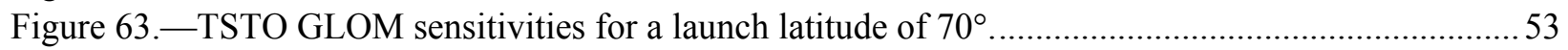

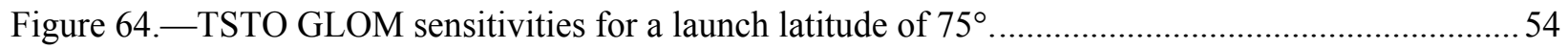





\title{
Mars Ascent Vehicle Gross Lift-off Mass Sensitivities for Robotic Mars Sample Return
}

\author{
Ian J. Dux \\ National Aeronautics and Space Administration \\ Glenn Research Center \\ Cleveland, Ohio 44135 \\ Joseph A. Huwaldt and R. Steve McKamey, P.E. \\ BD Systems, Inc. \\ Huntsville, Alabama 35806 \\ John W. Dankanich \\ Gray Research, Inc. \\ Cleveland, Ohio 44135
}

\begin{abstract}
The Mars ascent vehicle is a critical element of the robotic Mars Sample Return (MSR) mission. The Mars ascent vehicle must be developed to survive a variety of conditions including the trans-Mars journey, descent through the Martian atmosphere and the harsh Martian surface environments while maintaining the ability to deliver its payload to a low Mars orbit. The primary technology challenge of developing the Mars ascent vehicle system is designing for all conditions while ensuring the mass limitations of the entry descent and landing system are not exceeded.

The NASA In-Space Propulsion technology project has initiated the development of Mars ascent vehicle technologies with propulsion system performance and launch environments yet to be defined. To support the project's evaluation and development of various technology options the sensitivity of the Mars ascent vehicle gross lift-off mass to engine performance, inert mass, target orbits, and launch conditions has been completed with the results presented herein.
\end{abstract}

\subsection{Introduction}

For decades NASA and the science community have been working towards a robotic Mars Sample Return (MSR) mission. There have been numerous studies to evaluate MSR mission architectures, technology needs and development plans, and top-level mission requirements (Refs. 1 to 4). The Mars program has divided the MSR mission into three phases, each requiring a separate launch from Earth. The first launch consists of a lander and rover to perform sample collection and caching. This is followed by the launch of the Mars orbiter, which acts as the Earth return vehicle. The final phase of the mission is the launch of the second lander containing the Mars ascent vehicle (MAV). A notional depiction of the MSR architecture is included in Figure 1 and shows the potential for the order of the last two launches to change as mission planning continues. The first of these missions, the sample collection and caching, is scheduled as a joint NASA/ESA 2018 mission. Currently, the orbiter and lander missions are tentatively planned for 2022 and 2024, respectively. The MSR mission is one of the most challenging robotic missions ever attempted due to large number of system elements and technology development risks. One of the largest technology development risks for the MSR mission is the MAV.

NASA's In-Space Propulsion Technology (ISPT) project has recently been assigned the development of the MAV technologies with a requirement to perform multiple terrestrial flight demonstrations prior to the MSR preliminary design review (PDR). The MAV and its associated landing platform element PDR is expected to occur in 2018. To meet this technology readiness date, the ISPT project released a MAV 


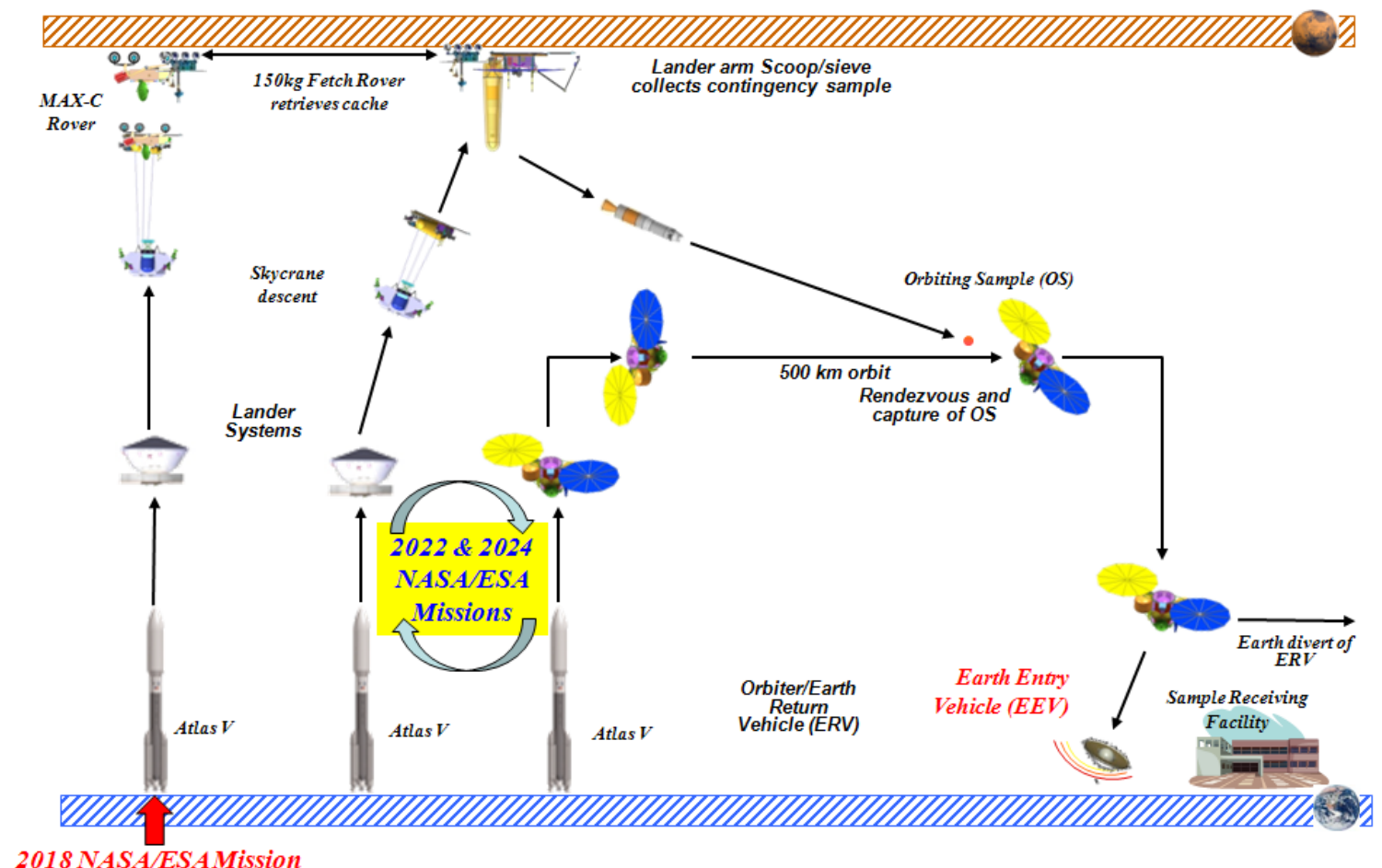

Figure 1.-Baseline MSR architecture.

Request for Information in December of 2008, and released a solicitation for the MAV propulsion system development in February of 2009. These awards will begin with system studies for various MAV propulsion concepts followed by a down select for the propulsion system development and demonstration.

The critical metric for the MAV is the landed mass required to complete its mission. The landed mass is limited due to the use of the Mars Science Laboratory (MSL) Skycrane, in the baseline entry descent and landing (EDL) system, to provide the final propulsive descent (Ref. 5). As a result of the landed mass restrictions, the objective is to minimize the Gross Lift-Off Mass (GLOM) of the MAV system.

MAV propulsion concepts being considered include solid, liquid, hybrid systems with state-of-the-art propellants and numerous subsystem architectures. These various concepts all have GLOM implications on the MAV system. The MSR science team is also still evaluating potential landing sites and evaluating landing accuracy of the EDL system. The landing site latitude, surface gradient, MAV launch platform orientation, MAV angle of elevation at launch, and other parameters all impact the MAV GLOM. To understand the primary MAV GLOM sensitivities to the MAV performance characteristics and landing site requirements, an extensive parametric trade has been completed and the results are presented herein.

\subsection{MAV Baseline Description}

\subsection{Top Level MAV Requirements}

The fundamental requirement for a successful MAV mission is the delivery of $5 \mathrm{~kg}$ of payload, which includes samples of the Martian surface as well as the sample containment system, to orbit. This requirement can be accomplished using a wide variety of engine and vehicle assumptions that fall into two major categories. First is a family of in-line two-stage vehicle designs to reach orbit known as two stage to orbit (TSTO) solutions. TSTO concepts use two separate propulsion systems with the first stage jettisoned before the second stage is used. The other major category of vehicle designs uses only a single stage with a restartable propulsion system and is referred to as a single stage to orbit (SSTO) solution. SSTO vehicle concepts do not jettison any part of the stage during ascent with considerations given to both restartable liquid and hybrid engines as well as timed solid rocket motor designs. 
To allow for a stable orbit at Mars, the MAV must be able to place the sample into a $500 \mathrm{~km}$ circular orbit, with dispersions no greater than $\pm 100 \mathrm{~km}$ (Ref. 6). The inclination of the rendezvous orbit has yet to be established and will ultimately depend on the largest landing latitude that the EDL system can guarantee for the MAV. This is due to the assumption that the target orbit inclination of the MAV will be greater than the launch site latitude. The vehicle must be capable of achieving its target inclination within $\pm 0.2^{\circ}$ (Ref. 6).

The MAV must be designed to accommodate a wide variety of launch conditions due to the inability of the EDL system to precisely land at a predetermined location with desired launch orientation. At the time of this analysis, the MAV was targeted to land at Martian latitudes within $45^{\circ}$ of the equator, resulting in the assumption of a $45^{\circ}$ baseline launch latitude. Additional analysis of the EDL system indicates that launch latitudes of no greater than $30^{\circ}$ could be provided to the MAV, however this information could not be included in this assessment. The current GLOM results, although baselined for a $45^{\circ}$ latitude launch, encompass launches from any latitude less than or equal to $45^{\circ}$.

Uncertainty in landing location also necessitates that the MAV be capable of launching from a wide range of launch orientations. The results presented show the performance impact of a requirement to land on slopes of up to $20^{\circ}$ from horizontal and guarantee a launch within $30^{\circ}$ of the targeted launch elevation (Ref. 6). In addition to the launch elevation of the MAV, the azimuth of the launch platform on the Mars surface may also be uncontrolled. This could result in a launch into a nonoptimal launch azimuth orientation resulting in an associated reduction in performance. Currently the precision with which the optimal launch azimuth could be maintained during EDL is unknown. Options exist to mitigate the performance impact due to launch azimuth variation, including tighter controls on the final portions of EDL to orient the lander along the optimal launch azimuth or the use of a turntable to rotate the MAV into an optimal launch orientation. The elevation and azimuth assumptions made are intended guide decisions on the necessary lander capabilities. Eventually, these launch requirements will be traded at a system level against the MAV GLOM growth necessary to accommodate off-nominal launch conditions.

\subsection{MAV TSTO Ascent Trajectory Profile}

The MAV TSTO ascent profile is relatively simple and differs from most terrestrial launch vehicle profiles given that it does not use a continuous burn from surface to orbit. Instead two separate burns are used. The first burn starts at engine ignition (time $=0$ ) and begins a $0.2 \mathrm{sec}$ fixed attitude burn necessary to clear the launch platform. The first burn continues with an optimal pitch over maneuver. Depending on the controls being used, this maneuver could include optimal roll and yaw maneuvers in conjunction with pitch. Following the optimal control section of the burn, the aerodynamic angles (angle of attack, side slip and bank angle) are manipulated to put the vehicle in a zero aerodynamic angle orientation by the end of the first burn. After first stage burnout, the vehicle coasts to apoapsis, jettisoning the first stage and payload fairing before the start of the second stage burn. The current baseline assumption is that jettison occurs at an altitude of $200 \mathrm{~km}$, but realistically it can occur any time after leaving the Martian atmosphere (approximately $100 \mathrm{~km}$ above the Martian surface) and before second stage ignition with no penalty to performance. Just prior to reaching apoapsis, a significantly shorter second burn, using an optimized control profile, is performed to raise the periapsis altitude and circularize the orbit. A theoretical operational concept, with baseline times and Martian altitudes, can be found in Figure 2.

\subsection{TSTO Baseline Vehicle Design}

The TSTO vehicle concept used for this analysis is a based on a vehicle previously developed by the NASA MAV team in 2001 (Ref. 7). The system masses, as sized for this vehicle, are shown in Table 1 with the baseline thrust and Isp assumptions in Table 2. These assumptions result in a total vehicle GLOM of $267.5 \mathrm{~kg}$. The MAV solid rocket motor performance assumptions are consistent with the use of a stretched STAR 17A solid motor first stage and a stretched STAR 13A second stage. It is assumed for all studies, except for those involving stage masses, that propellant mass can be adjusted while holding dry mass static. 


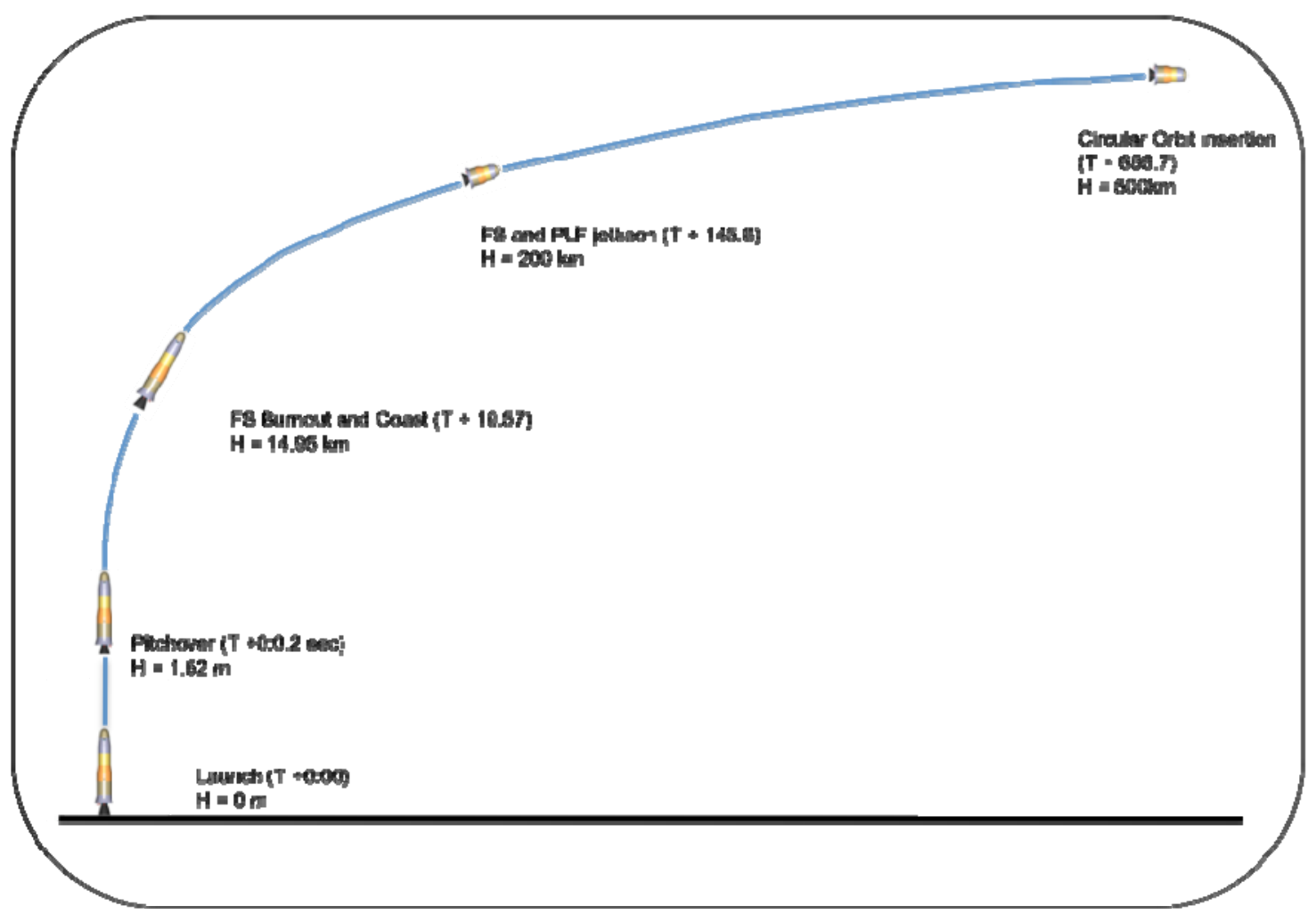

Figure 2.-MAV TSTO ascent operational concept.

TABLE 1.-TSTO MAV BASELINE MASSES

\begin{tabular}{|l|c|l|}
\hline \multicolumn{1}{|c|}{ MAV element } & $\begin{array}{c}\text { Mass, } \\
\mathrm{kg}\end{array}$ & \multicolumn{1}{c|}{ Description } \\
\hline Stage 1 dry & 27.7 & Motor casing, nozzle and interstage \\
\hline Stage 1 propellant & 158.6 & Solid propellant stretched Star 17A derivative \\
\hline Stage 2 dry & 38.4 & Motor casing, avionics, payload attach structure \\
\hline Stage 2 propellant & 34.7 & Solid propellant Star 13A derivative \\
\hline Payload fairing & 3.1 & PLF jettisoned with first stage at 200 km \\
\hline Payload & 5.0 & Sample and Container \\
\hline
\end{tabular}

TABLE 2.-TSTO MAV BASELINE

\begin{tabular}{|l|c|} 
THRUST AND ISP \\
\begin{tabular}{|l|c|}
\hline \multicolumn{1}{|c|}{ Engine parameter } & Value \\
\hline Stage 1 thrust $(\mathrm{N})$ & 21576.8 \\
\hline Stage 1 Isp $(\mathrm{s})$ & 285.7 \\
\hline Stage 1 exit area $\left(\mathrm{m}^{2}\right)$ & 0.032 \\
\hline Stage 2 thrust $(\mathrm{N})$ & 6318.9 \\
\hline Stage 2 Isp $(\mathrm{s})$ & 285.5 \\
\hline Stage 2 exit area $\left(\mathrm{m}^{2}\right)$ & 0.0093 \\
\hline
\end{tabular}
\end{tabular}

The Martian atmosphere and winds were modeled using a tabular representation of a mean Mars Global Reference Atmospheric Model (GRAM). Mars shape and gravity were specified using an oblate model with the constants listed in Table 3.

As the analysis to follow will show, mission and launch site assumptions have a large effect on the resulting vehicle GLOM. Therefore, it is necessary to identify the specific mission and launch site assumptions used in TSTO baseline such that the effects of the vehicle sensitivities presented can be better understood. The baseline launch site location and launch site orientation assumptions are specified in Table 4 along with the target orbital parameters. 
TABLE 3.-MARS OBLATE GRAVITY MODEL

\begin{tabular}{|c|c|}
\hline Parameter & Value \\
\hline $\mathrm{J} 2$ & $1.96 \mathrm{e}-03$ \\
\hline $\mathrm{J} 3$ & 0.0 \\
\hline $\mathrm{J} 4$ & 0.0 \\
\hline Mars gravitational constant $\left(\mathrm{km}^{3} / \mathrm{s}^{2}\right)$ & 42828.3 \\
\hline Mars rotation rate $(\mathrm{rad} / \mathrm{s})$ & $0.71 \mathrm{e}-04$ \\
\hline Mars equatorial radius $(\mathrm{km})$ & 3393.9 \\
\hline Mars polar radius $(\mathrm{km})$ & 3376.8 \\
\hline
\end{tabular}

TABLE 4.-TSTO MAV BASELINE LAUNCH SITE AND MISSION ASSUMPTIONS

\begin{tabular}{|l|c|}
\hline \multicolumn{1}{|c|}{ Trajectory assumption } & Value \\
\hline Latitude (degrees) & 45.0 \\
\hline Longitude (degrees) & 0.0 \\
\hline Launch elevation angle (degrees) & 90.0 (Vertical) \\
\hline Launch azimuth (degrees) & 88.8 (Optimal) \\
\hline Target circular orbit altitude $(\mathrm{km})$ & 500 \\
\hline Target orbit inclination (degrees) & 45 \\
\hline
\end{tabular}

It is important to note that the 2001 TSTO vehicle assumes use of only pitch control with-in the plane of the launch azimuth, which is varied at the start of the problem to target a $45^{\circ}$ inclination. Additionally, there is no control rate limit imposed, which results in control rates of approximately $20^{\circ}$ per second. During this study, a concern was immediately raised that control rates of this magnitude were too large for a reasonable flight profile. A decision was made to limit all body control rates to $5^{\circ}$ per second, since previous experience has shown that body control rates larger than this may result in the vehicle exceeding structural limits or requiring additional vehicle structure (James McDuffie, personal communication, December 16, 2009). Figure 3 shows the effect on the baseline GLOM, $267.5 \mathrm{~kg}$, as the body pitch rate is constrained to various levels. The performance deltas in Figure 3 assume only pitch control, with launch azimuth optimized. Since the goal is to produce the lightest possible MAV to meet mission requirements, the $5 \mathrm{~kg}$ ( 2 percent) growth that results from a control rate change is not insignificant. The performance delta for control rate restrictions placed on out-of-pitch-plane control rates at a nonoptimal launch azimuth are larger and are addressed in Section 6.0.

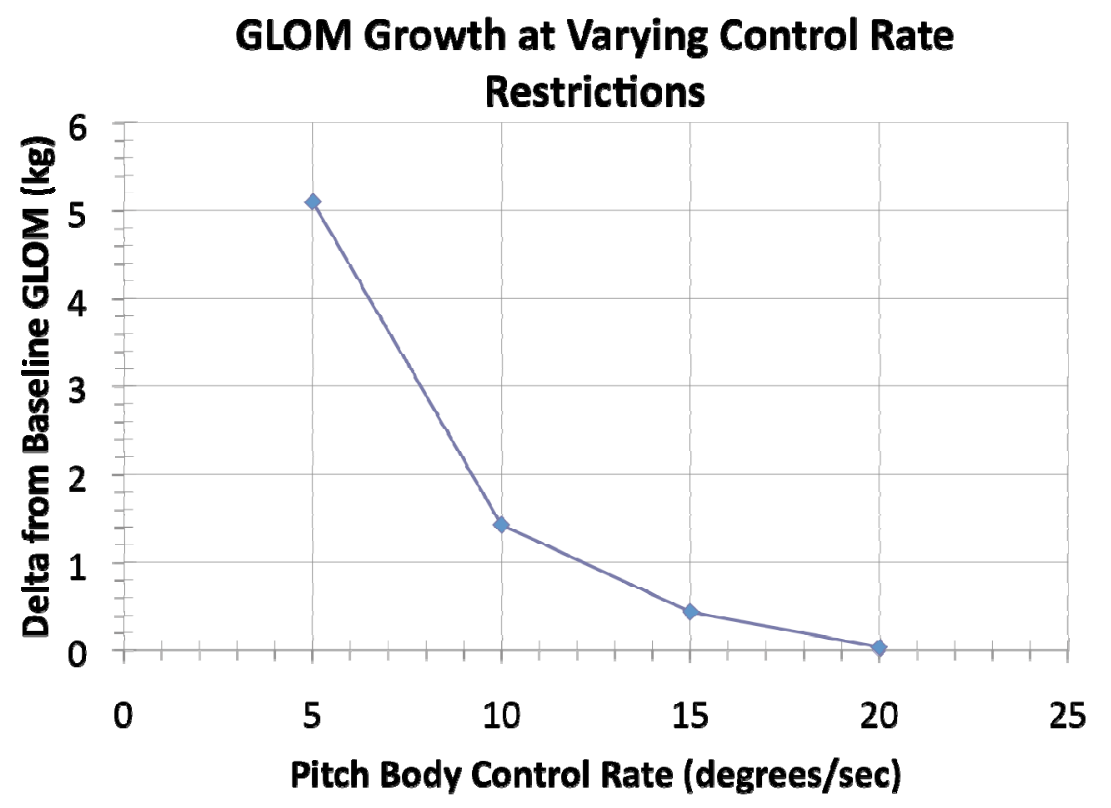

Figure 3.-GLOM growth compared 2001 TSTO baseline for restricted control rates. 


\subsection{MAV SSTO Ascent Trajectory Profile}

The SSTO MAV mission profile is similar to the TSTO trajectory in that it also uses two separate burns to reach orbit. The primary difference for the SSTO trajectory is that these burns are completed by the same stage. The first burn starts at engine ignition (time $=0$ ) and begins the $0.2 \mathrm{sec}$ vertical rise necessary to clear the launch platform. After vertical rise, the first burn continues with an optimal pitch over maneuver. Depending on the controls being used, this maneuver could include optimal roll and yaw maneuvers in conjunction with pitch over. Following the optimal control section of the burn, the aerodynamic angles (angle of attack, side slip, and bank angle) are varied to put the vehicle in a zero aerodynamic angle orientation by the end of the first burn. After burnout, the vehicle coasts to apoapsis, jettisoning the payload fairing before the start of the second stage burn. The current baseline assumption is that payload fairing jettison occurs at an altitude of $200 \mathrm{~km}$, but can realistically occur any time after leaving the Martian atmosphere (approximately $100 \mathrm{~km}$ above the Martian surface) and before the start of the second burn with no effect on performance. Just prior to reaching apoapsis, a significantly shorter second burn, with an optimized pitch profile, is performed by the same stage to raise periapsis altitude and circularize the orbit. A theoretical operation concept, with baseline times and altitudes, can be found in Figure 4.

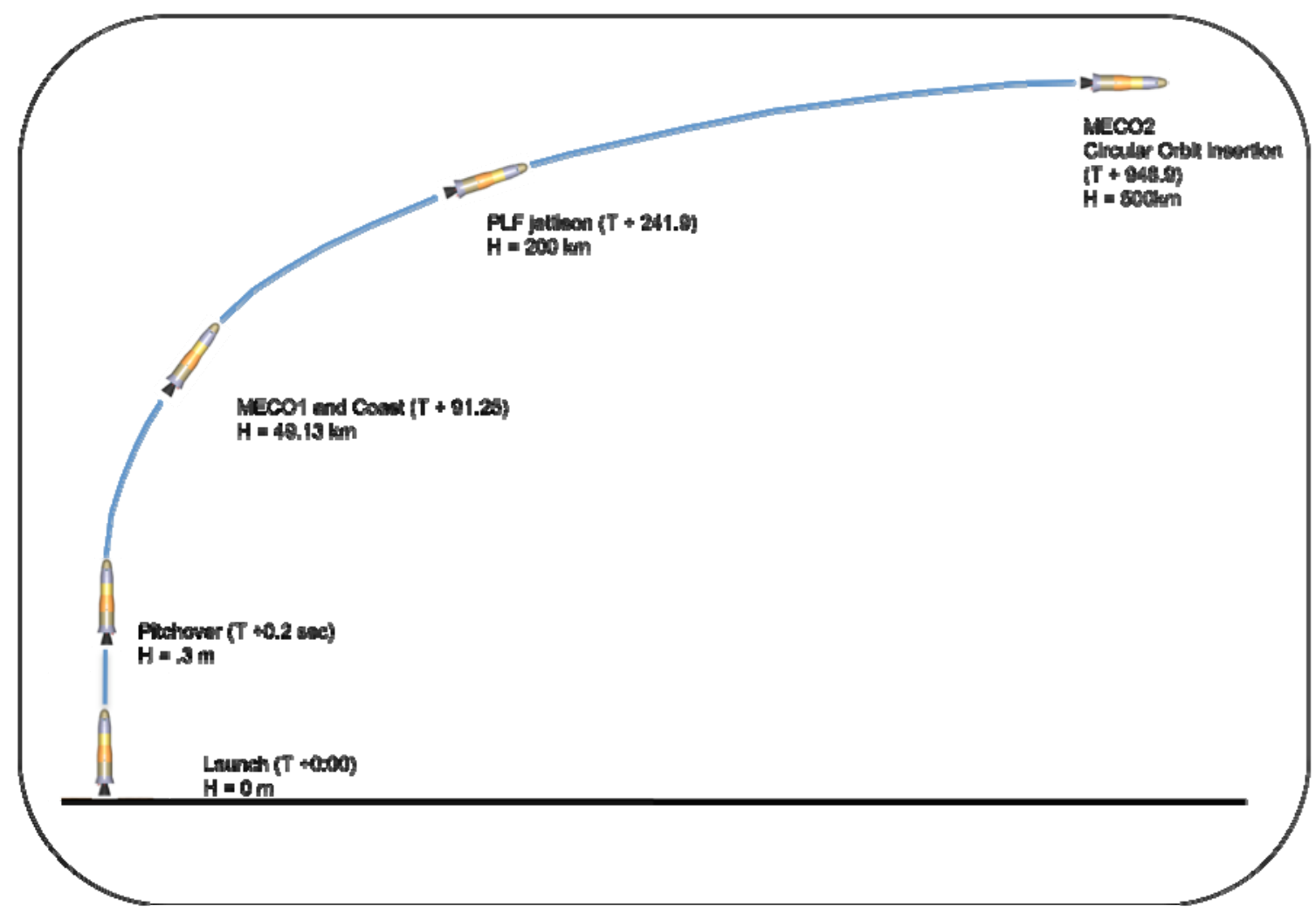

Figure 4.-MAV SSTO ascent operational concept. 


\subsection{SSTO Baseline Vehicle}

Differing from the TSTO vehicle concept, the SSTO concept was not based on an existing vehicle design. The SSTO baseline inert mass was assumed to be similar to the sum of the TSTO baseline inert stage masses with some mass savings due to the removal of systems duplicated on both TSTO stages. An Isp equal to the stretched Star 17A motor was assumed, with an optimized thrust level. The much lower thrust level allowed the SSTO vehicle to complete the MAV mission with much less propellant than would have been necessary at higher thrust levels. The SSTO baseline vehicle configuration, including the optimized engine thrust, is detailed in Table 5 and Table 6. The SSTO mission and launch site assumptions were identical to those used for the TSTO vehicle and are repeated in Table 7 with the vehicle launching from a vertical orientation.

The SSTO baseline used only pitch steering, with control rates limited to $5^{\circ}$ per second, while varying launch azimuth to target inclination. Models for the MAV aerodynamics, Mars Gravity and Mars atmosphere are identical to the TSTO vehicle baseline. Further discussion of the SSTO baseline trajectory assumptions is included in the Section 5.0.

TABLE 5.-SSTO VEHICLE ELEMENT MASSES

\begin{tabular}{|l|c|l|}
\hline MAV element & $\begin{array}{c}\text { Mass, } \\
\mathrm{kg}\end{array}$ & \multicolumn{1}{|c|}{ Description } \\
\hline Stage dry & 61.9 & $\begin{array}{l}\text { Motor casing, avionics, } \\
\text { payload attach structure }\end{array}$ \\
\hline Payload fairing & 3.1 & $\begin{array}{l}\text { PLF jettisoned with first } \\
\text { stage at 200 km }\end{array}$ \\
\hline Payload & 5.0 & Sample and container \\
\hline
\end{tabular}

TABLE 6.--SSTO ENGINE ASSUMPTIONS

\begin{tabular}{|l|c|}
\hline \multicolumn{1}{|c|}{ Engine parameter } & Value \\
\hline Thrust $(\mathrm{N})$ & 4425.7 \\
\hline Isp $(\mathrm{s})$ & 285.7 \\
\hline Exit area $\left(\mathrm{m}^{2}\right)$ & 0.032 \\
\hline
\end{tabular}

TABLE 7.- -SSTO LAUNCH AND MISSION ASSUMPTIONS

\begin{tabular}{|l|c|}
\hline \multicolumn{1}{|c|}{ Trajectory assumption } & Value \\
\hline Latitude (degrees) & 45.0 \\
\hline Longitude (degrees) & 0.0 \\
\hline Launch elevation angle (degrees) & 90.0 (Vertical) \\
\hline Launch azimuth (degrees) & 87.3 (Optimal) \\
\hline Target circular orbit altitude (km) & 500 \\
\hline Target orbit inclination (degrees) & 45 \\
\hline
\end{tabular}




\subsection{Trade Space Description}

The mission and launch assumptions of the MAV have a direct effect on the vehicle GLOM, primarily through the amount of propellant necessary to successfully reach orbit for each set of assumptions. Vehicle mass and engine performance assumptions also have an effect on MAV GLOM, through the mass of the components used as well as their effect on the amount of propellant needed to reach orbit.

To better understand the sensitivities to be discussed, Figure 5 depicts the assumed relationship between launch latitude and launch inclination with targeted inclination always assumed to be greater than or equal to the launch latitude. The orientation of the launch platform on the surface of Mars is also important to understand and is illustrated in Figure 6. The platform orientation is defined using two angles, the launch elevation angle, $90^{\circ}$ as shown, and the launch azimuth, measured clockwise from north. For each combination of launch latitude, targeted orbit inclination and launch elevation angle the optimal launch azimuth is calculated during analysis. The optimal launch azimuth corresponds to the minimum GLOM solution for each latitude and inclination combination. For the sensitivities presented here, it is more useful to express the simulated vehicle launch azimuth as the angle from the optimal launch azimuth, as defined in Figure 6. Further description and discussions of these values is found in Section 6.0, along with the sensitivity results.

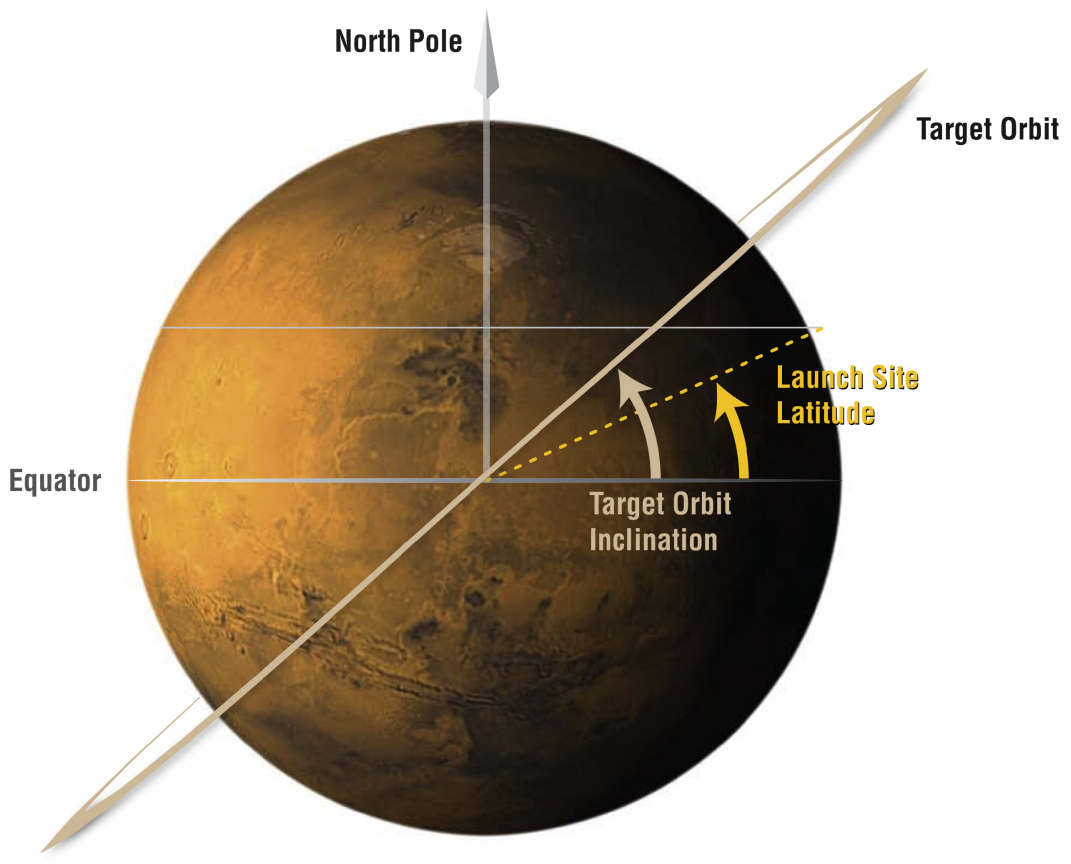

Figure 5.-Target orbit inclination in relation to launch latitude. 


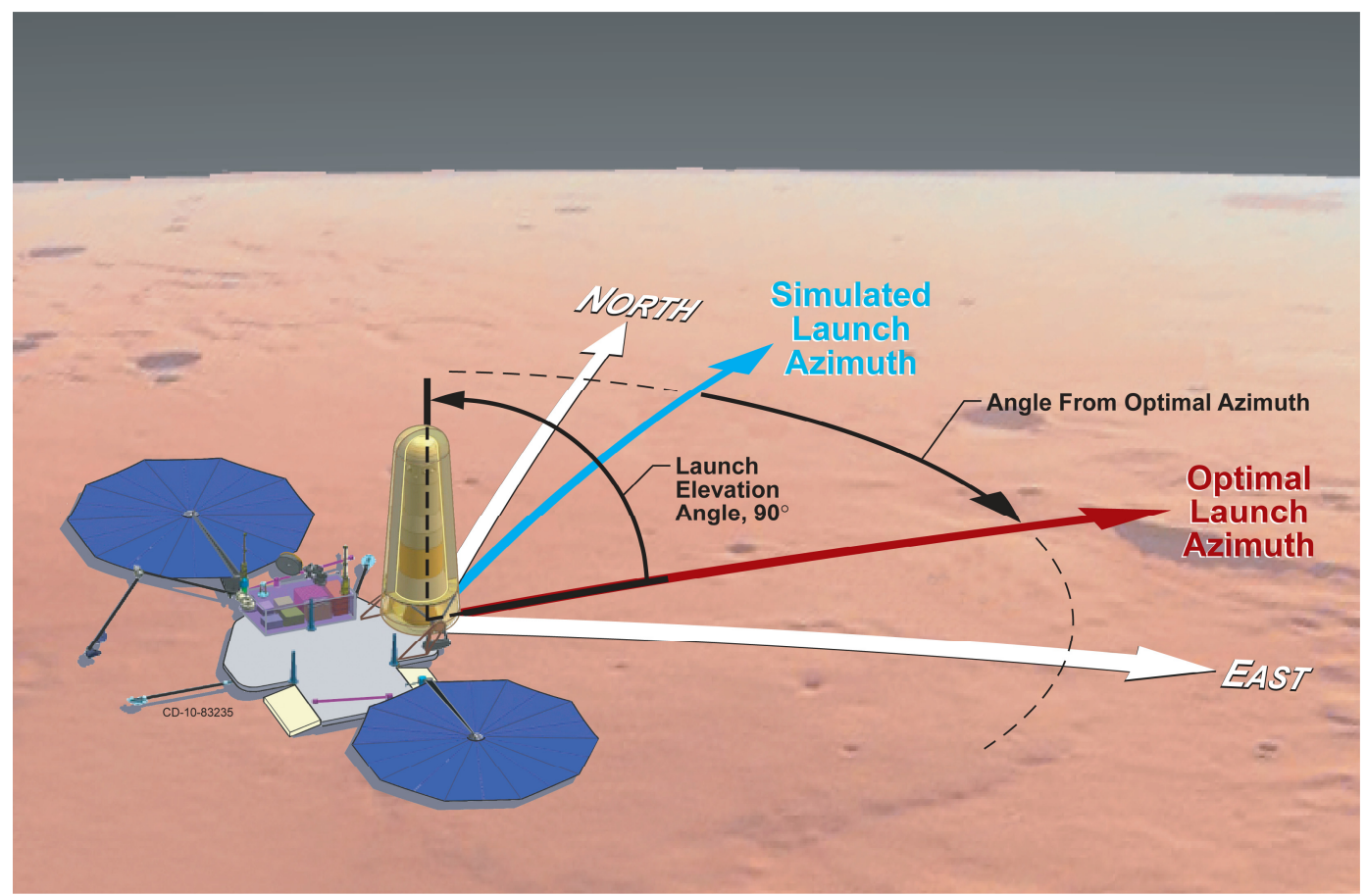

Figure 6.—MAV launch platform elevation and launch azimuth orientation.

TABLE 8.-RANGE OF MAV PARAMETERS ANALYZED

\begin{tabular}{|l|c|c|}
\hline \multicolumn{1}{|c|}{ Parameter } & Minimum & Maximum \\
\hline Launch latitude (degrees) & 0 & 90 \\
\hline Launch elevation (degrees) & 30 & 90 \\
\hline Angle from optimal launch azimuth (degrees) & 0 & 180 \\
\hline Engine Isp (s) & 255 & 355 \\
\hline Engine thrust (N) & Optimal & 21576.8 \\
\hline Total inert mass (kg) & 30 & 70 \\
\hline Target inclination $(\mathrm{deg})$ & 0 & 90 \\
\hline Target orbit altitude $(\mathrm{km})$ & 400 & 600 \\
\hline
\end{tabular}

The large trade space of mission, launch and vehicle assumptions that were analyzed for MAV GLOM sensitivities are listed, with ranges, in Table 8. It should be noted that this analysis looked only at northern latitudes but it is assumed, due to symmetry, that launches from southern latitudes would remain the same. To break down this vast trade space, the parameters were studied in several different ways.

First, assuming use of an optimal launch azimuth, a large matrix of MAV GLOM sensitivities were completed for all combinations of launch latitude, launch elevation, and targeted orbit inclination. Second, sensitivities for launches at a nonoptimal launch azimuth were run for all launch elevation angles at the baseline launch latitude of $45^{\circ}$ targeting a $45^{\circ}$ orbital inclination. Although only off-azimuth launches from $0^{\circ}$ to $180^{\circ}$ were analyzed, it is assumed due to symmetry that launch from $0^{\circ}$ to $-180^{\circ}$ would produce similar results. The remaining vehicle and mission sensitivities were run using the baseline launch and mission assumptions, including the use of an optimal launch azimuth at a vertical launch elevation, as listed in Table 4.

The previously developed TSTO MAV solid rocket concept is assumed to be the primary MAV baseline design for this analysis. Therefore, sensitivities to all parameters listed in Table 8 were run with vehicle assumptions consistent with the TSTO baseline vehicle. This included a range of vehicle sensitivities large enough to show how GLOM would change if using a liquid engine instead of the solid motor design. A subset of vehicle and mission sensitivities were also evaluated for the SSTO concept, such that the viability for further evaluation could be established. 


\subsection{Analysis Tools and Methodology}

\subsection{OTIS}

Optimal Trajectories by Implicit Simulation program (OTIS) is a general-purpose simulation and optimization program, which can be used to perform trajectory performance studies (otis.grc.nasa.gov) (Ref. 8). A user can simulate and optimize a wide variety of vehicles such as aircraft, missiles, reentry vehicles, ascent vehicles, satellites, and interplanetary vehicles. The vehicle models used in OTIS are defined by user inputs; there are no embedded, vehicle specific aerodynamic or propulsion models. OTIS is primarily a point mass, three-degree of freedom (3DOF) program. It makes available to the user two well known and proven optimizer options: SNOPT and SLSQP. The program name is derived from the implicit methods used to solve differential equations, which were distinctive at the time of OTIS' origin. Although named after its implicit integration capabilities, OTIS is capable of generating flight paths using implicit, explicit or analytical integration. Trajectory analysis using OTIS can be performed with respect to any of the major bodies in the solar system.

\subsection{POST 3D}

Program to Optimize Simulated Trajectories (POST) 3D is a generalized point mass, discrete parameter targeting and optimization program (Ref. 9). POST provides the capability to target and optimize point mass trajectories for a powered or unpowered vehicle near an arbitrary rotating, oblate planet. POST has been used successfully to solve a wide variety of atmospheric ascent and reentry problems. The generality of the program is evidenced by its multiple phase simulation capability which features generalized planet and vehicle models. This flexible simulation capability is augmented by an efficient discrete parameter optimization capability that includes equality and inequality constraints.

\subsection{Analysis Methodology}

Vehicle sensitivities were established for the MAV through the minimization of the GLOM. In all cases, this results in the vehicle propellant load being varied to minimize the total vehicle mass. POST and OTIS used control angles, along with propellant weights, to find the optimal combination of parameters. In selected cases, thrust was also left open for optimization to also characterize the thrust level providing minimal vehicle mass. The majority of cases used static vehicle weights and engine parameters as described in Section 2.0.

The sensitivities presented here were initially run in both POST and OTIS such that both the baseline cases and sensitivity results could be compared. To do so, Python scripts were developed to independently run each desired vehicle sensitivity. The functionality of the scripts necessary to run each analysis program was quite different due to the differing methods in which POST and OTIS operate. Despite differences in operation, these run scripts provided three important functions: run each optimization case while ensuring an optimal result, vary the input parameters necessary to accomplish each parameter sweep and record desired output data for post processing.

To run each case, the scripts contained the ability to correctly read and interpret the optimization output from POST or OTIS. After each case was successfully optimized, the script would automatically increment the parameter, or parameters, of interest and rerun the program. This process was repeated until the entire parameter range was completed. For OTIS, no additional guess generation or guess tweaks were necessary, as the next case was easily converged from a previously converged case. In POST, the operation was a bit more complex as it was necessary to use a combination of a bi-section step algorithm and a genetic algorithm to automatically generate independent variable guesses for each new POST run that would allow successful problem completion. This allowed for less user interaction with each POST run and helped to minimize noise in the POST GLOM results. 


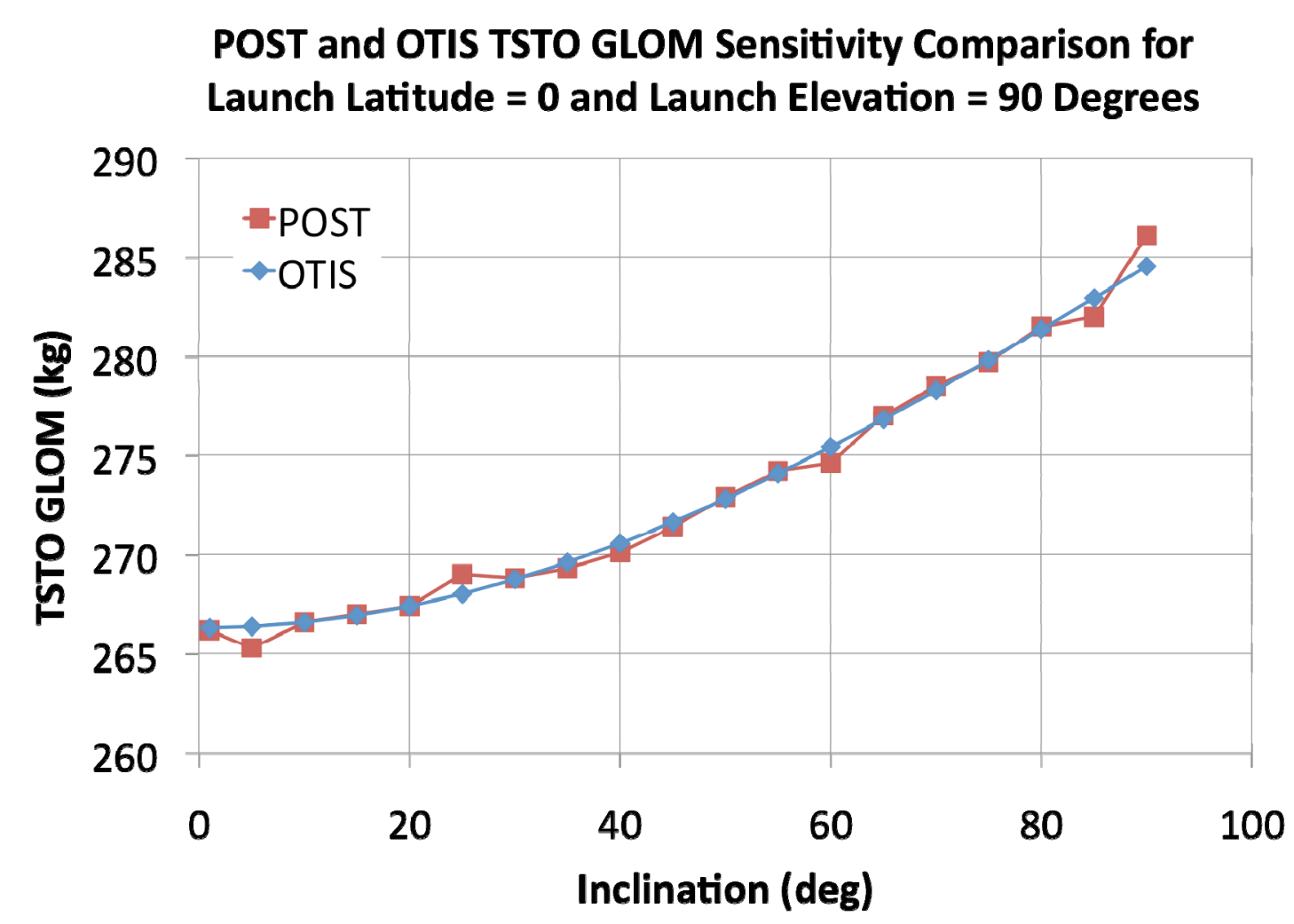

Figure 7.-Comparison of POST and OTIS MAV GLOM sensitivity data.

POST and OTIS comparisons show matching results for the baseline cases as well as matching trends for the various GLOM sensitivities completed. A detailed comparison of the POST and OTIS SSTO and TSTO baseline cases can be found in Section 5.0. A close match between these programs is not unexpected, as previous studies have shown a close correspondence between POST and OTIS results (Ref. 10). Although great care was taken to ensure that POST found the most optimal solution, a great deal of noise was observed in the POST GLOM sensitivity results. An in depth comparison between the POST and OTIS sensitivities is not included here, but matching trends were observed for all sensitivities analyzed. Due to the smoother resulting OTIS trends, all GLOM sensitivity data discussed in this document is derived from OTIS results. An example of the noise in the POST GLOM results, compared to OTIS results, is found in Figure 7.

\subsection{MAV Baseline Comparison}

\subsection{TSTO POST and OTIS Trajectory Comparison}

Using the payload, dry mass, thrust and Isp assumptions listed in Table 1 and Table 2 an OTIS TSTO model was developed at NASA's Glenn Research Center (GRC) along with a POST TSTO model by the team at NASA's Marshall Space Flight Center (MSFC). The existing TSTO baseline mission and launch site assumptions were also used as defined in Table 4. This includes the important assumption of a vertical launch orientation and the use of an optimal launch azimuth. As described above, the propellant loads for both the first and second stages were allowed to vary so that the minimum overall GLOM could be achieved. The orbital targets were defined using orbit radius, inertial velocity, inertial flight path angle and inclination with the values listed in Table 9. 
TABLE 9.-TRAJECTORY TARGET PARAMETERS

\begin{tabular}{|l|c|}
\hline \multicolumn{1}{|c|}{ Orbital target parameter } & Value \\
\hline Orbit radius $(\mathrm{km})$ & 3893.9 \\
\hline Inertial velocity $(\mathrm{km} / \mathrm{s})$ & 3.316 \\
\hline Inertial flight path angle (degrees) & 0.0 \\
\hline Orbital inclination (degrees) & 45.0 \\
\hline
\end{tabular}

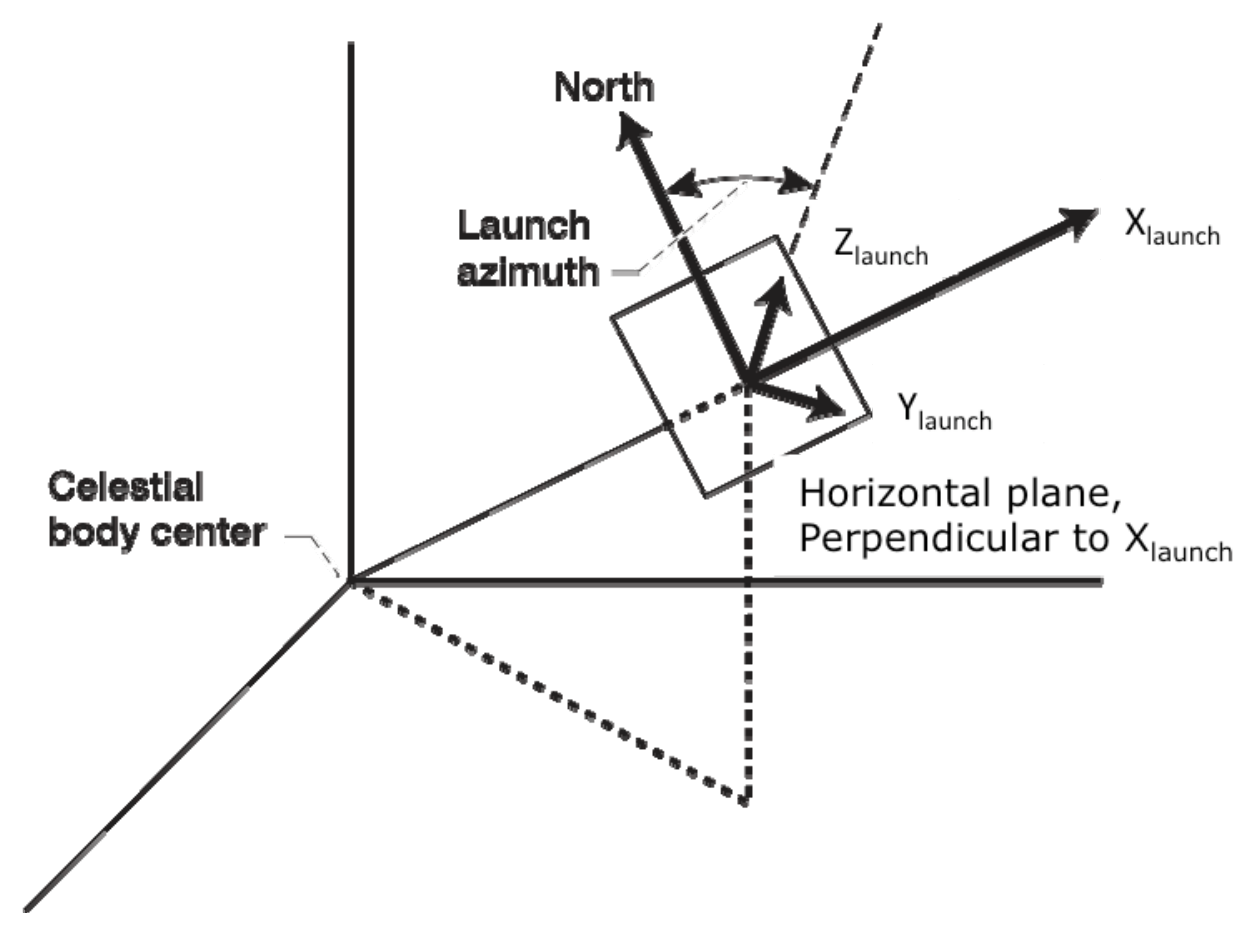

Figure 8.-Coordinate system used to define launch inertial Euler control angles.

Both programs used launch inertial Euler angles to control the vehicle orientation during the first and second burns. Figure 8 shows the basis for the launch inertial Euler control angles. This coordinate system is centered at the longitude and geodetic latitude of the launch site with a fundamental plane formed by the $\mathrm{y}$ and $\mathrm{z}$-axis, parallel to local horizontal. The $\mathrm{x}$-axis, $\mathrm{X}_{\text {launch }}$, is perpendicular to this plane and points up (i.e., lies along the positive radius vector). The $\mathrm{z}$-axis, $\mathrm{Z}_{\text {launch }}$, is the reference direction and points downrange along the launch site azimuth, as measured clockwise around $X_{\text {launch }}$, with the $y$-axis, $\mathrm{Y}_{\text {launch }}$, completing the right-handed system. The launch inertial Euler angles, are then calculated based on the coordinate system in Figure 8 using a 1-3-2 Euler angle rotation as shown in Figure 9. In this diagram, the first rotation is by the inertial Euler roll angle, $\phi$, around the vehicle's $\mathrm{x}$-axis, $\mathrm{X}_{\text {body }}$, which in initially concurrent with $X_{\text {launch. }}$ The second rotation of the inertial Euler yaw angle, $\psi$, is then completed around the vehicle $\mathrm{z}$-axis, $Z_{\text {body }}$. The third and final rotation is the inertial Euler pitch angle, $\theta$, around the vehicle $\mathrm{y}$-axis, $Y_{\text {body }}$. 


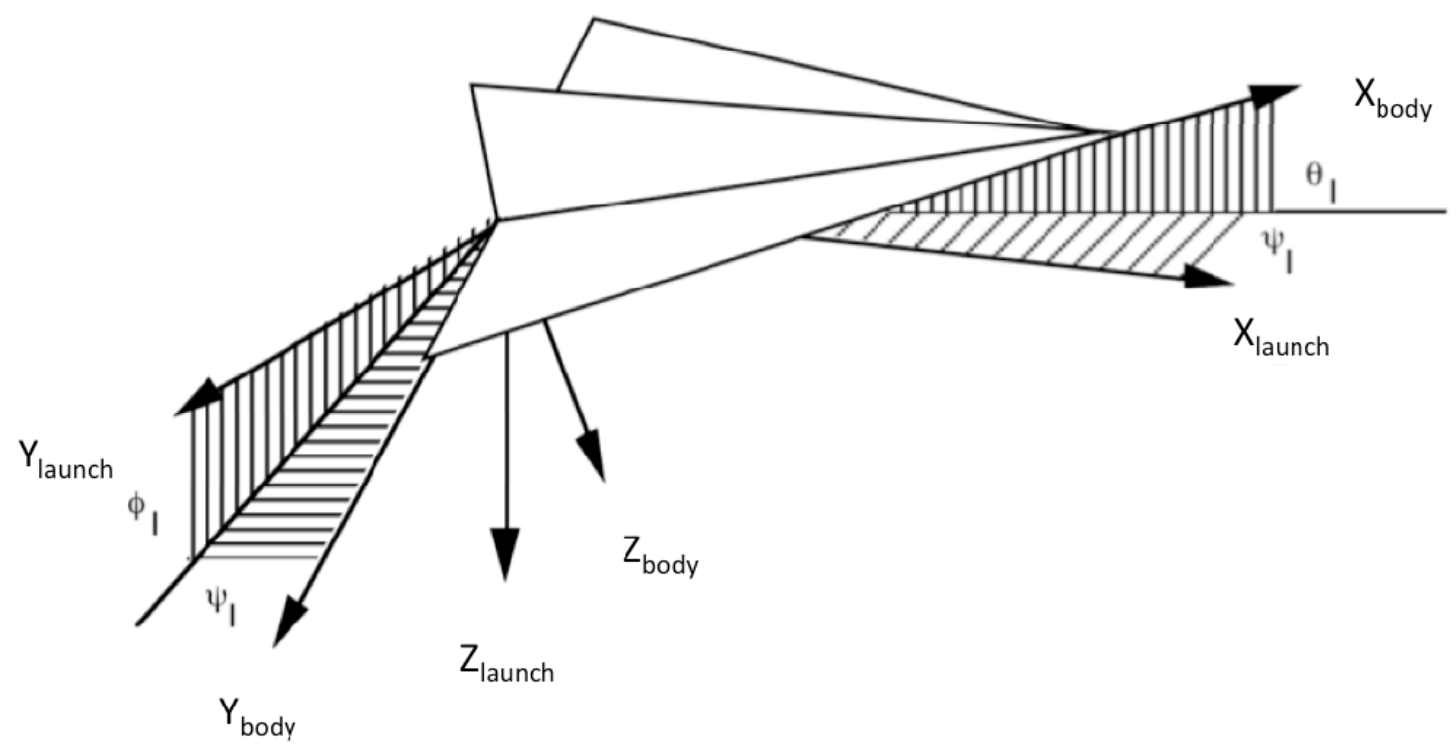

Figure 9.-Launch inertial Euler control angle rotation sequence.

TABLE 10.-COMPARISON OF OTIS AND POST BASELINE TSTO BASELINE TRAJECTORIES

\begin{tabular}{|l|r|r|c|}
\hline \multicolumn{1}{|c|}{ Comparison parameter } & \multicolumn{1}{c|}{ POST } & \multicolumn{1}{c|}{ OTIS } & \multicolumn{1}{c|}{ POST - OTIS } \\
\hline Gross lift-off mass $(\mathrm{kg})$ & 271.75 & 272.63 & $-0.88(0.32 \%)$ \\
\hline Launch azimuth $(\mathrm{deg})$ & 88.77 & 87.56 & $1.21(1.37 \%)$ \\
\hline First stage propellant load $(\mathrm{kg})$ & 149.31 & 153.85 & $-4.54(-3.04 \%)$ \\
\hline Second stage propellant load $(\mathrm{kg})$ & 48.24 & 44.67 & $3.58(7.41 \%)$ \\
\hline Mission time (s) & 656.67 & 659.09 & $-2.42(-0.37 \%)$ \\
\hline Maximum dynamic pressure (Pa) & 11956.65 & 12290.78 & $-334.13(-2.79 \%)$ \\
\hline Maximum dynamic pressure (psf) & 249.72 & 256.70 & $-6.98(-2.79 \%)$ \\
\hline
\end{tabular}

Both the POST and OTIS models use one linear segment to control the inertial Euler pitch angle during pitch over, with inertial roll and yaw angles set to zero. For this analysis, a linear control segment is defined as period of time where the control angle is varied at a constant (linear) rate. To reach a zero angle of attack (AOA) before first stage burnout, aerodynamic control angles (AOA, side slip, and bank angle) are then used with one linear control segment for each angle. After first stage burnout, aerodynamic control angles continue to be used to maintain a zero aerodynamic angle gravity turn. The second stage burn then uses one linear segment to control the inertial Euler pitch angle, with the inertial Euler roll and yaw angles held constant. For the TSTO vehicle model, the vehicle orientation is assumed to remain unchanged throughout the coast period up to the start of the final burn through use of the vehicle's reaction control system (RCS). The OTIS and POST baseline vehicle models, using the assumptions detailed above, are shown in Table 10. All comparisons in Table 10 are relative to POST, meaning the OTIS result is subtracted from POST and then compared to the POST result to determine the percentage difference.

The comparison results demonstrate a match of the MAV trajectory from each program with a GLOM difference between the POST and OTIS baselines of less than $1 \mathrm{~kg}$ or about 0.3 percent. Due to the control rate restriction imposed it can be seen that both the OTIS and POST GLOM are approximately $5 \mathrm{~kg}$ greater than the existing TSTO baseline of $267.5 \mathrm{~kg}$, which is consistent with the GLOM trend found in Figure 3. The percentage deltas in the propellant load of each stage appear to be large, but the total propellant burned by each simulation is similar, as evident by the small GLOM differences. The different solutions found by each program cause more propellant to be burned by OTIS in the first stage and less in the second. It is 
evident that these differences in each burn also result in slightly different burn times, again with little change to the overall trajectory. Finally the maximum dynamic pressure difference is a direct result of the slightly longer OTIS burn on the first stage. A dynamic pressure difference of $6.98 \mathrm{psf}$, out of $249.7 \mathrm{psf}$, is a small difference compared to loads experienced by many Earth based launch vehicles.

In conjunction with the small deltas in the parameters discussed, similar trends in other key trajectory parameters also demonstrate the close POST/OTIS model match. Important trajectory parameters compared for match purposes include all vehicle control angles, physical states and loading indicators. All parameter comparisons are not shown here for brevity. Figure 10 through Figure 13 show the geodetic altitude, inertial velocity, inertial pitch angle, angle of attack, and dynamic pressure plotted against mission elapsed time (MET). All plots show matching trends with only minor differences. The differences in the length of the first and second burn, as discussed above, can be seen more clearly in the plot of inertial velocity and geodetic altitude versus time, Figure 10. OTIS adds more velocity in the first burn; both programs then lose velocity through the coast to apoapsis and, after the second burn, end at the same inertial velocity target. The effects of the Mars GRAM wind model are evident in the plot of inertial pitch angle, Figure 11, between approximately 20 and $150 \mathrm{sec}$. The odd shape found from the control history of both programs results from holding zero angle of attack through the wind profile modeled. The assumption made is that the vehicle will always stay oriented with the velocity vector relative to the wind, which may not be the case in the real world. This simplifying assumption has very little impact in overall vehicle performance but does affect the shape of the controls and launch azimuth necessary to target the required inclination. Figure 14 and Figure 15 demonstrate how the control angle histories change when no wind profile is modeled. For the baseline case, when wind was not included, the GLOM increased by approximately $0.2 \mathrm{~kg}$, demonstrating dependence on the wind for additional vehicle performance is insignificant. Further impacts of wind modeling and the assumption of control continuity will be discussed in Section 6.0.

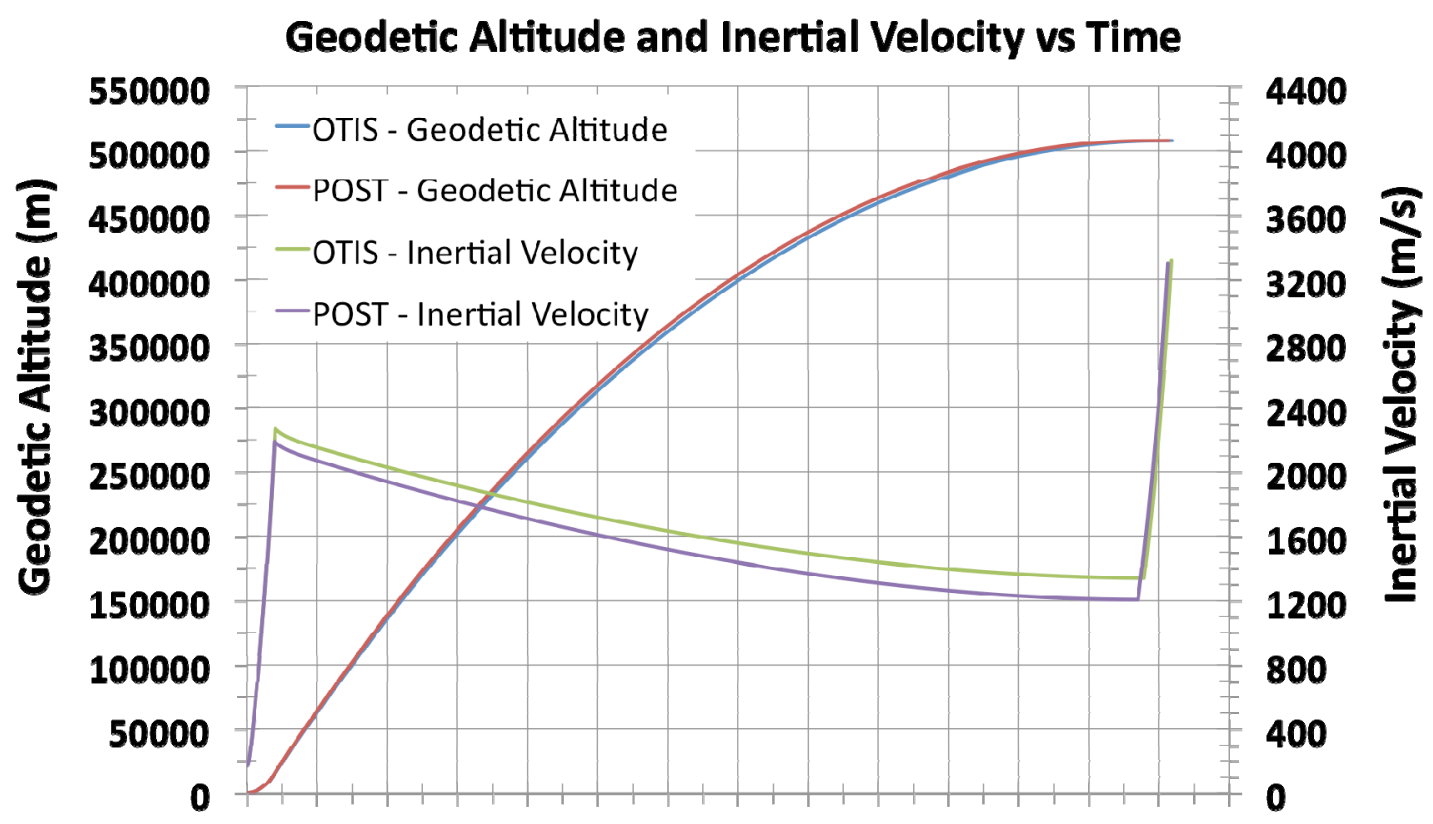

\section{O 50100150200250300350400450500550600650700 $\operatorname{MET}(\mathbf{s})$}

Figure 10.-Comparison geodetic altitude and inertial velocity histories for OTIS and POST TSTO baseline. 


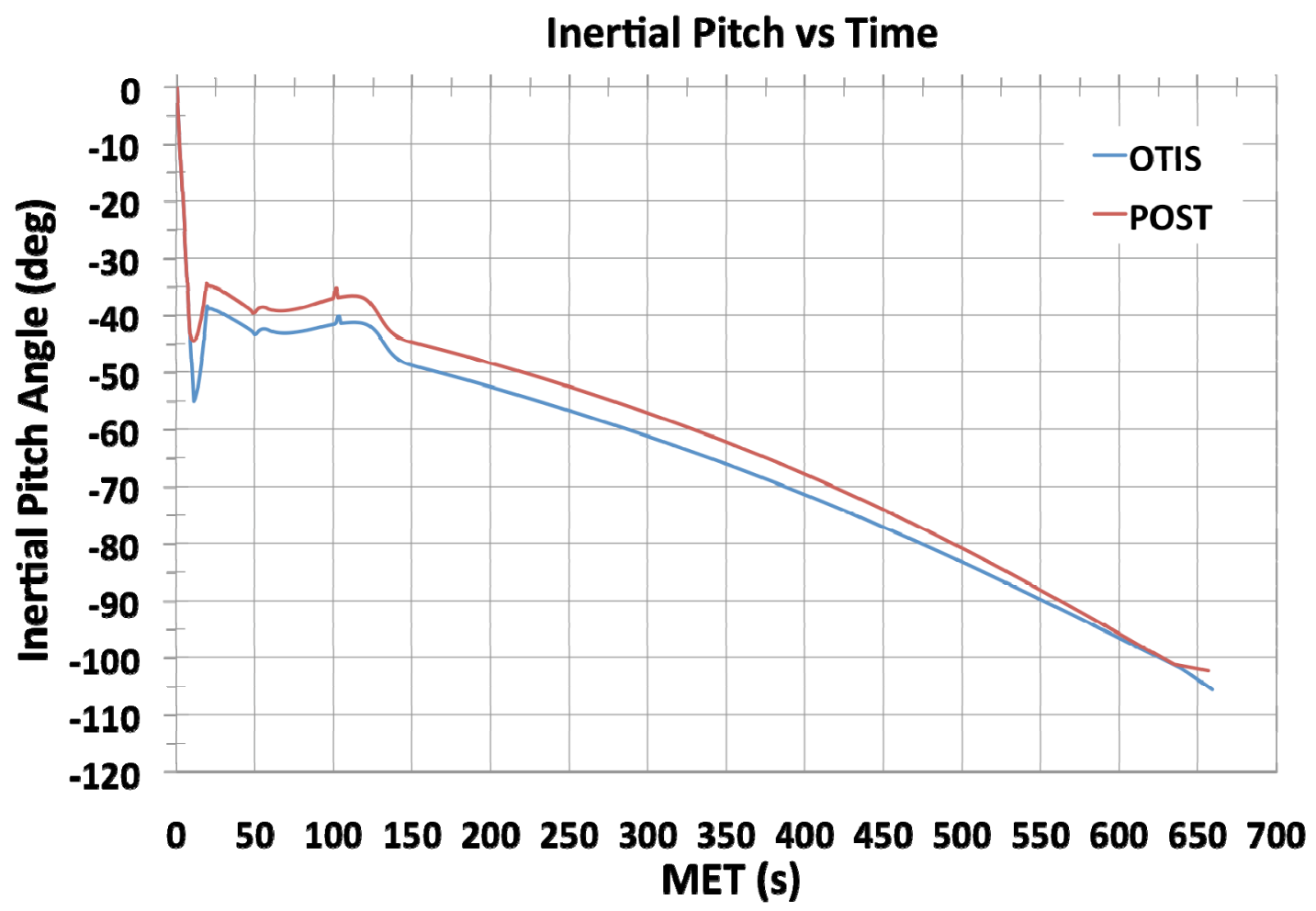

Figure 11.—Comparison of inertial Euler control angle history for OTIS and POST TSTO baseline.

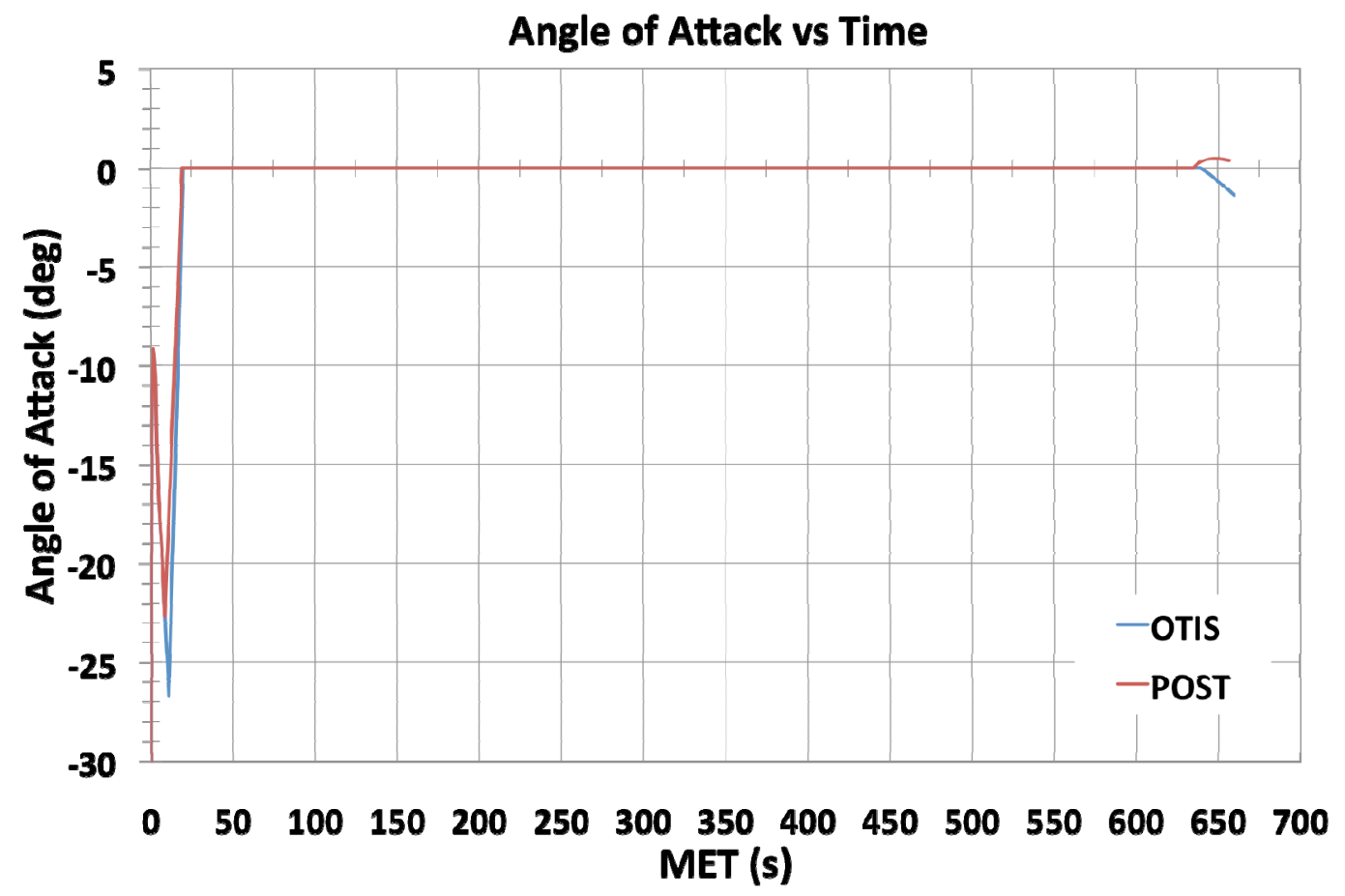

Figure 12.-Comparison of AOA history for OTIS and POST TSTO baseline. 


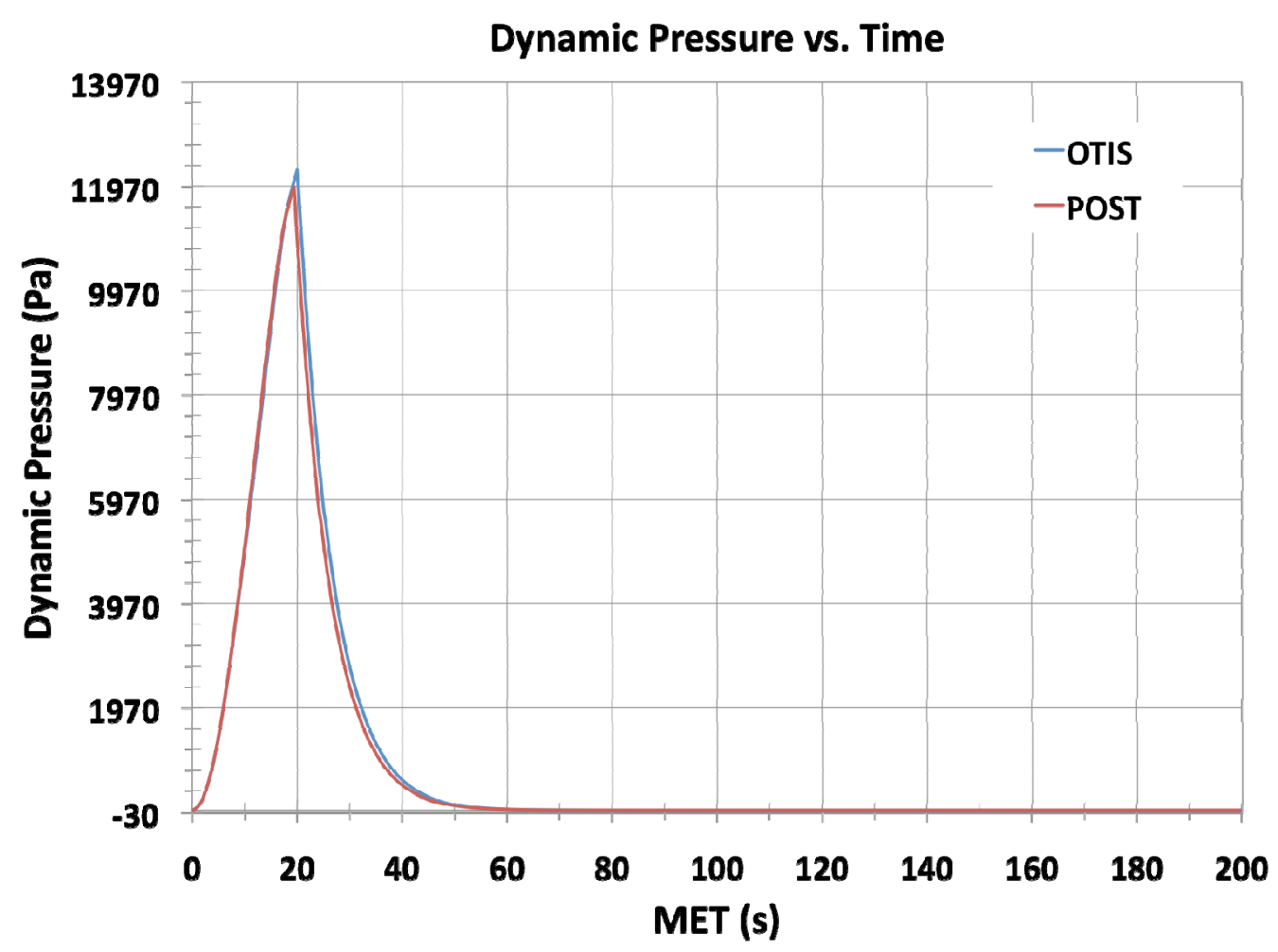

Figure 13.-Comparison of dynamic pressure history for OTIS and POST TSTO baseline.

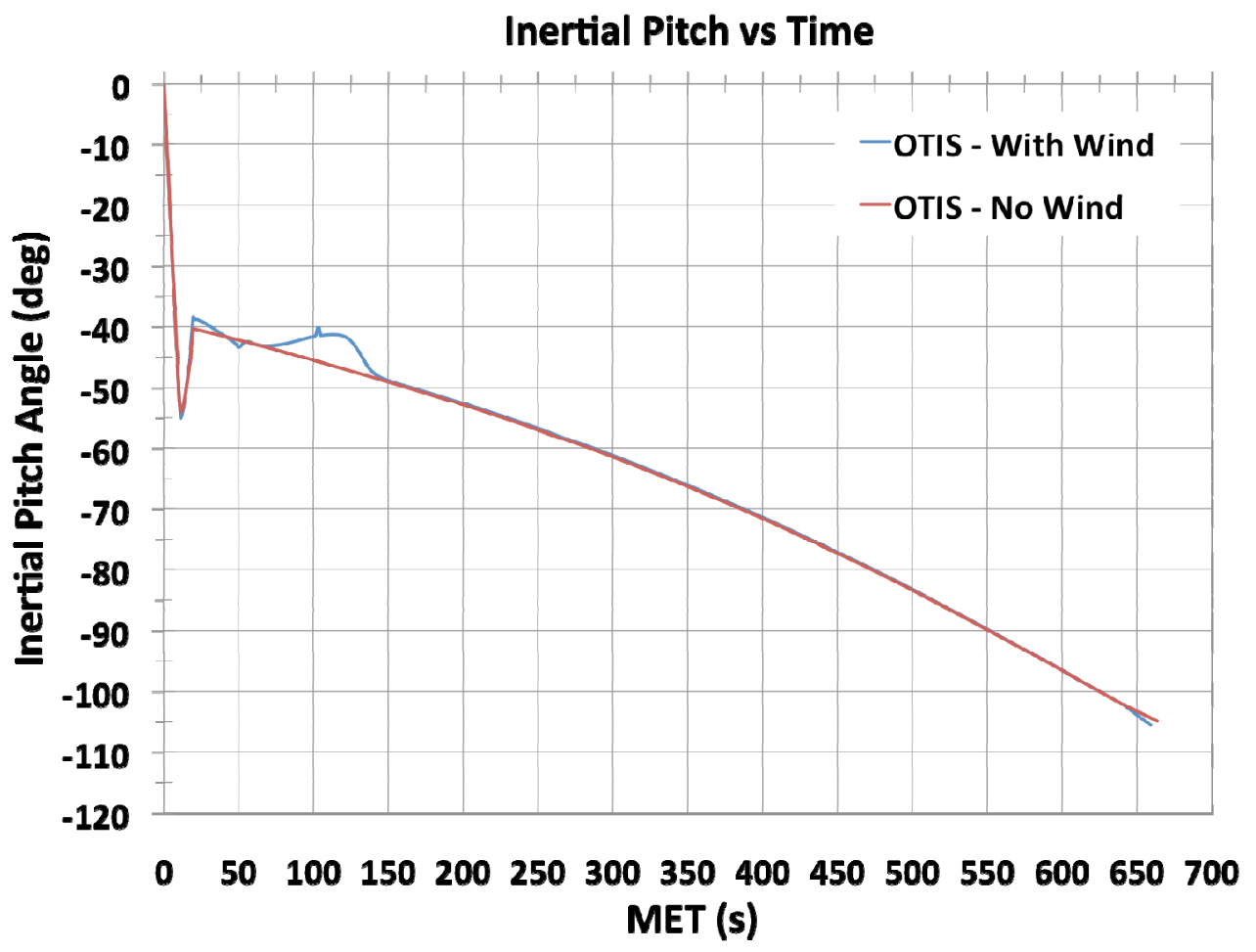

Figure 14.-OTIS inertial Euler pitch history comparison of wind modeling. 


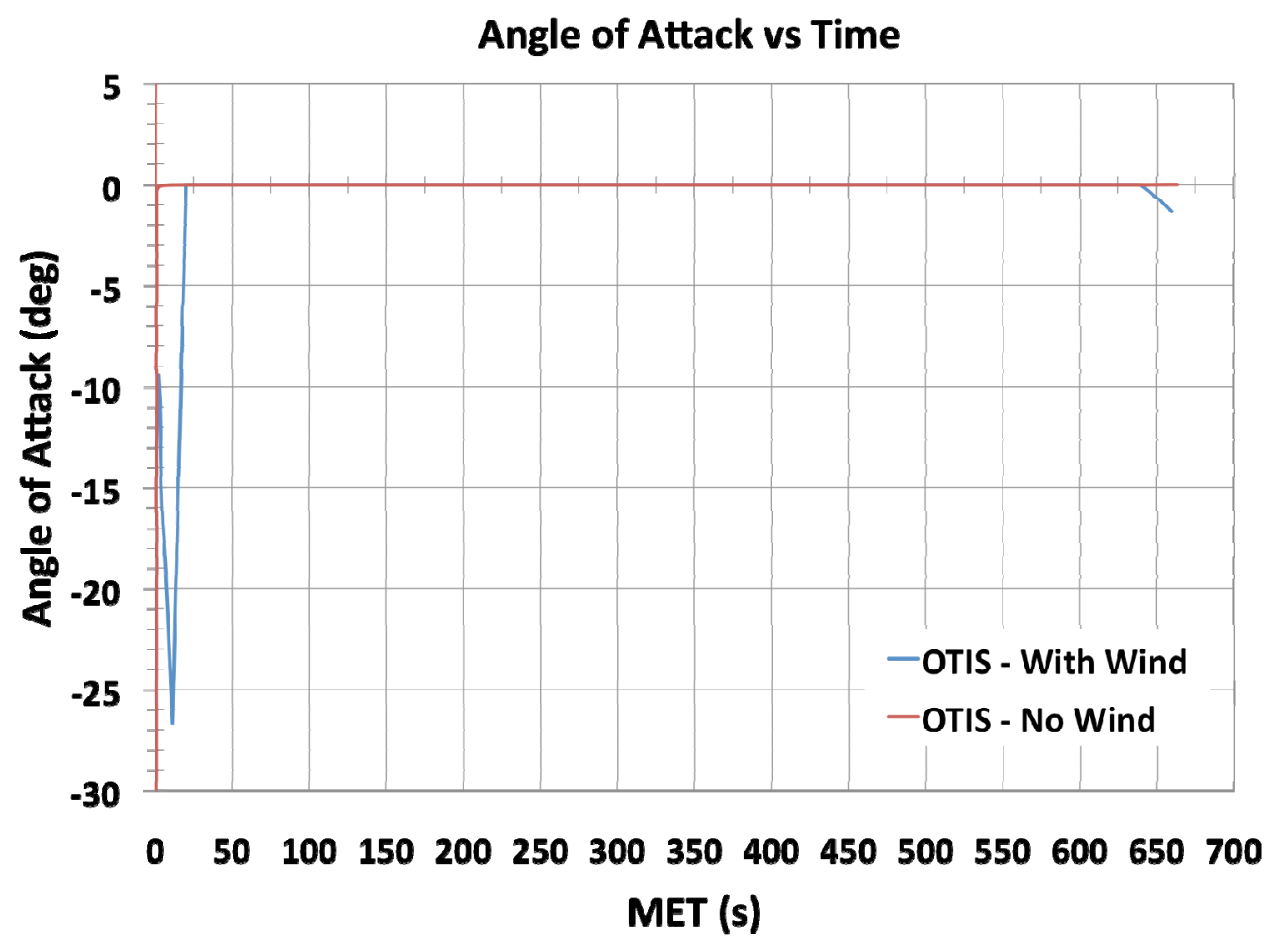

Figure 15.—OTIS AOA history comparison of wind modeling effects.

\subsection{SSTO POST and OTIS Trajectory Comparison}

Similar to the TSTO models, a GRC OTIS model and MSFC POST model were completed for the SSTO baseline vehicle. Comparison of the POST and OTIS SSTO models were complicated by the optimization of thrust. As comparisons between the POST and OTIS solutions were completed, using the assumptions in Table 5 through Table 7, two main points became evident: POST was locked onto a suboptimal solution which did not utilize all available pitch control rate and OTIS was leveraging the modeled wind profile to find a slightly lower GLOM solution. To mitigate the effect of wind on the design solution, the wind profile was removed from all SSTO cases to prevent it from driving the design of the vehicle. With POST locked onto a suboptimal solution, a decision was made to compare POST and OTIS with OTIS constrained to use the POST generated values of optimal thrust and control rate.

The SSTO baseline comparison also shows that allowing the vehicle orientation to vary at the start of the second burn results in both a smaller GLOM and smaller optimized thrust value. Similar to the TSTO vehicles, where it is assumed that the MAV RCS system is used to maintain a constant vehicle orientation, the SSTO RCS system would be used to orient the vehicle to a more optimal second stage burn orientation.

A minimum GLOM OTIS solution was established using the baseline assumption of a $5^{\circ}$ per second control rate with no lower limit on the optimized thrust value. As noted, matching the POST solution required additional constraints in OTIS, as listed in Table 11, to model the values used by POST. The parameters in Table 11 are the optimal values of the independent variables calculated by POST to minimize initial mass for the SSTO baseline. All three solutions for the SSTO vehicle can be found in Table 12, which compares the POST solution to the OTIS case that uses the restricted parameters in Table 11. Importantly, the last column in Table 12 is the minimum GLOM OTIS case that is considered the baseline solution to which all SSTO sensitivities should be compared. All comparisons in Table 12 are relative to POST, meaning the OTIS results is subtracted from POST and then compared to the POST results to determine the percentage difference. 
TABLE 11.-OTIS CONSTRAINTS NECESSARY

TO MATCH POST SSTO BASELINE

\begin{tabular}{|l|r|}
\hline \multicolumn{1}{|c|}{ Additional OTIS constraints } & Value \\
\hline POST thrust $(\mathrm{N})$ & 6082.0 \\
\hline POST control rate $($ degree/sec) & 3.1 \\
\hline
\end{tabular}

TABLE 12.-COMPARISON OF OTIS AND POST BASELINE SSTO BASELINE TRAJECTORIES

\begin{tabular}{|l|r|c|c|c|}
\hline \multicolumn{1}{|c|}{ Comparison parameter } & POST & $\begin{array}{c}\text { OTIS (POST Match } \\
\text { assumptions) }\end{array}$ & POST - OTIS & $\begin{array}{c}\text { OTIS (minimum GLOM } \\
\text { assumptions) }\end{array}$ \\
\hline Gross lift-off mass (kg) & 288.2 & 288.6 & $-0.4(-0.1 \%)$ & 285.6 \\
\hline Launch azimuth (deg) & 91.8 & 87.2 & $4.6(5.0 \%)$ & 87.3 \\
\hline Propellant load (kg) & 218.2 & 218.8 & $-0.6(-0.3 \%)$ & 215.7 \\
\hline Mission time (s) & 1039.8 & 1062.0 & $-22.1(-2.1 \%)$ & 1204.2 \\
\hline Maximum dynamic pressure (Pa) & 3363.3 & 3505.6 & $-142.3(4.2 \%)$ & 2996.0 \\
\hline Maximum dynamic pressure (psf) & 70.2 & 73.2 & $-3.0(-4.2 \%)$ & 62.6 \\
\hline Thrust (N) & 6082.0 & 6082.0 & 0.0 & 4425.7 \\
\hline Max control rate (deg/s) & 3.1 & 3.1 & 0.0 & 5.0 \\
\hline
\end{tabular}

Comparisons of POST to the OTIS cases using similar thrust and control rate assumptions, show that the OTIS GLOM matches POST within 0.1 percent or approximately $0.4 \mathrm{~kg}$. However, this close match in GLOM does come with a slight difference to the trajectories flown by both programs. The two major differences show up in total mission time, $22.1 \mathrm{sec}$, and initial launch azimuth, $4.6^{\circ}$. Differences in launch azimuth are primarily related to the control sets used for both solutions. Similar to the TSTO solution, the OTIS model uses the launch inertial Euler control set, Figure 9, for both vehicle burns. The POST model used the launch inertial Euler control set for the first burn, but due to convergence issues used the inertial aerodynamic control set for the second burn. Differing control sets necessitated the use of different launch azimuths to target the same inclination. The total mission time difference is closely correlated with the remaining large difference observed in dynamic pressure of $2.9 \mathrm{psf}$. This difference is smaller than that found in the TSTO comparisons, but a larger percentage due to the smaller over all SSTO maximum dynamic pressure. Compared to the TSTO baseline, the SSTO trajectories all fly a much slower, more depressed trajectory, due to the much smaller thrust used on the SSTO vehicle. When comparing the SSTO trajectories, the POST case flies a slightly more lofted trajectory, hence the lower dynamic pressure of $70.2 \mathrm{psf}$. This causes POST to reach apoapsis slightly before the OTIS trajectory resulting in a smaller overall mission time.

The minimum GLOM OTIS case, by using a lower thrust and body control rates of up to $5^{\circ}$ per second, is able to reduce GLOM by an additional $3 \mathrm{~kg}$ compared to POST. This comes with a dynamic pressure $7.7 \mathrm{psf}$ lower than the POST case and a significantly longer total mission time. The lower thrust, coupled with a higher control rate, allows OTIS to gain velocity over a longer period of time resulting in longer first burn. This effect results in the lower dynamic pressure observed for this trajectory. The differences and similarities between all three trajectories are more easily observed in plots of geodetic altitude, inertial velocity, inertial Euler pitch angle, inertial Euler yaw angle, and dynamic pressure plotted against mission elapsed time (MET) found in Figure 16 through Figure 19.

In looking at these comparison plots, key characteristics are noted. First is the difference in burn lengths that is evident in Figure 16, which shows inertial velocity and geodetic altitude. The Minimum OTIS GLOM case can be observed to burn substantially longer than the other two cases and adds more velocity during the first burn. However it is interesting to note, that this larger velocity is coupled with a less lofted trajectory, resulting in the much longer burn time. Also of note is the absence of wind effects in the inertial control angles, due to the removal of the wind model for the SSTO vehicle analysis. Finally, both the inertial pitch and yaw plots, Figure 17 and Figure 18, clearly show the discontinuous control angles at the beginning of the second burn in both the POST and OTIS simulations. 


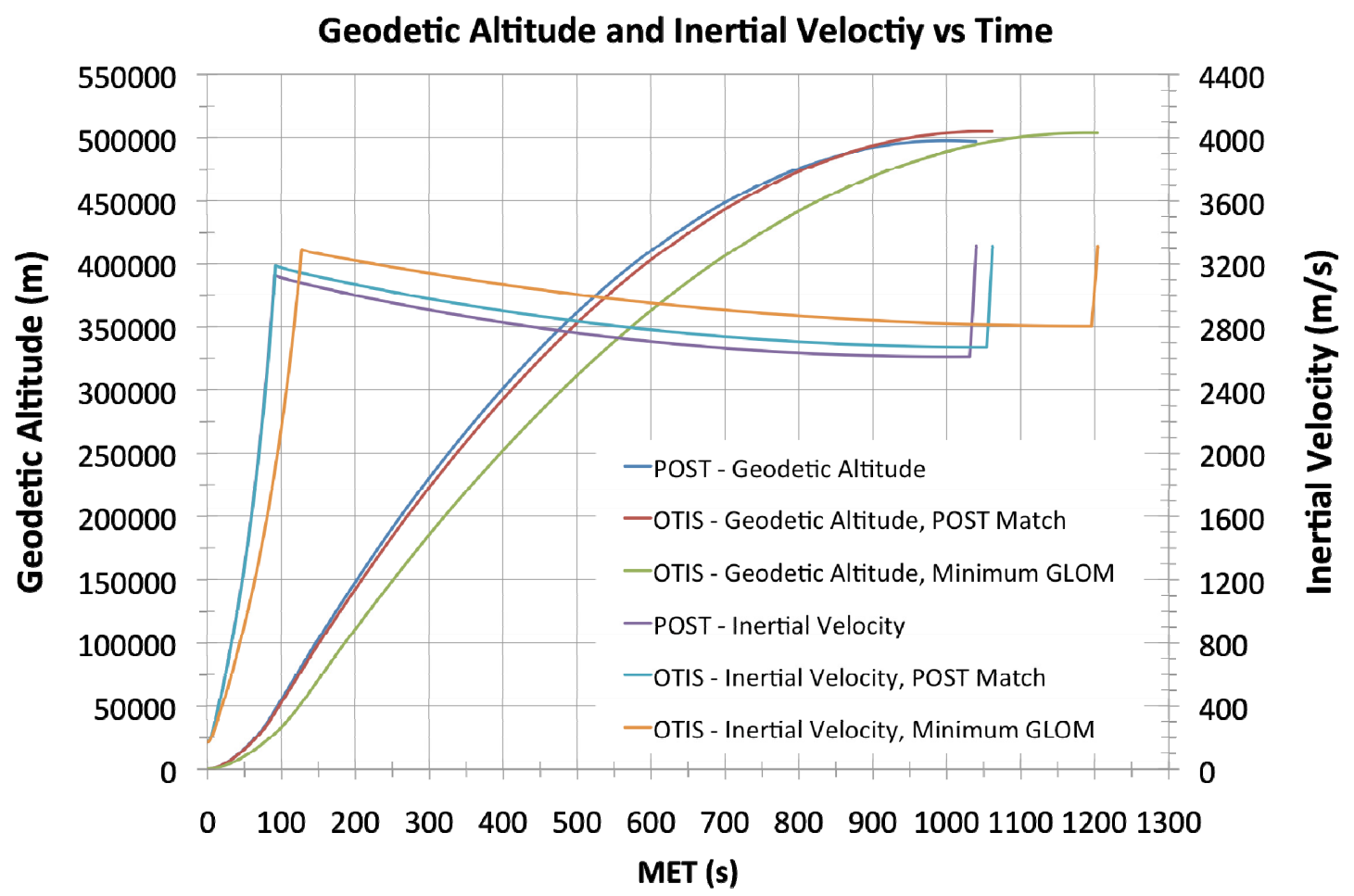

Figure 16.-Comparison of geodetic altitude and inertial velocity histories for POST and OTIS SSTO baselines.

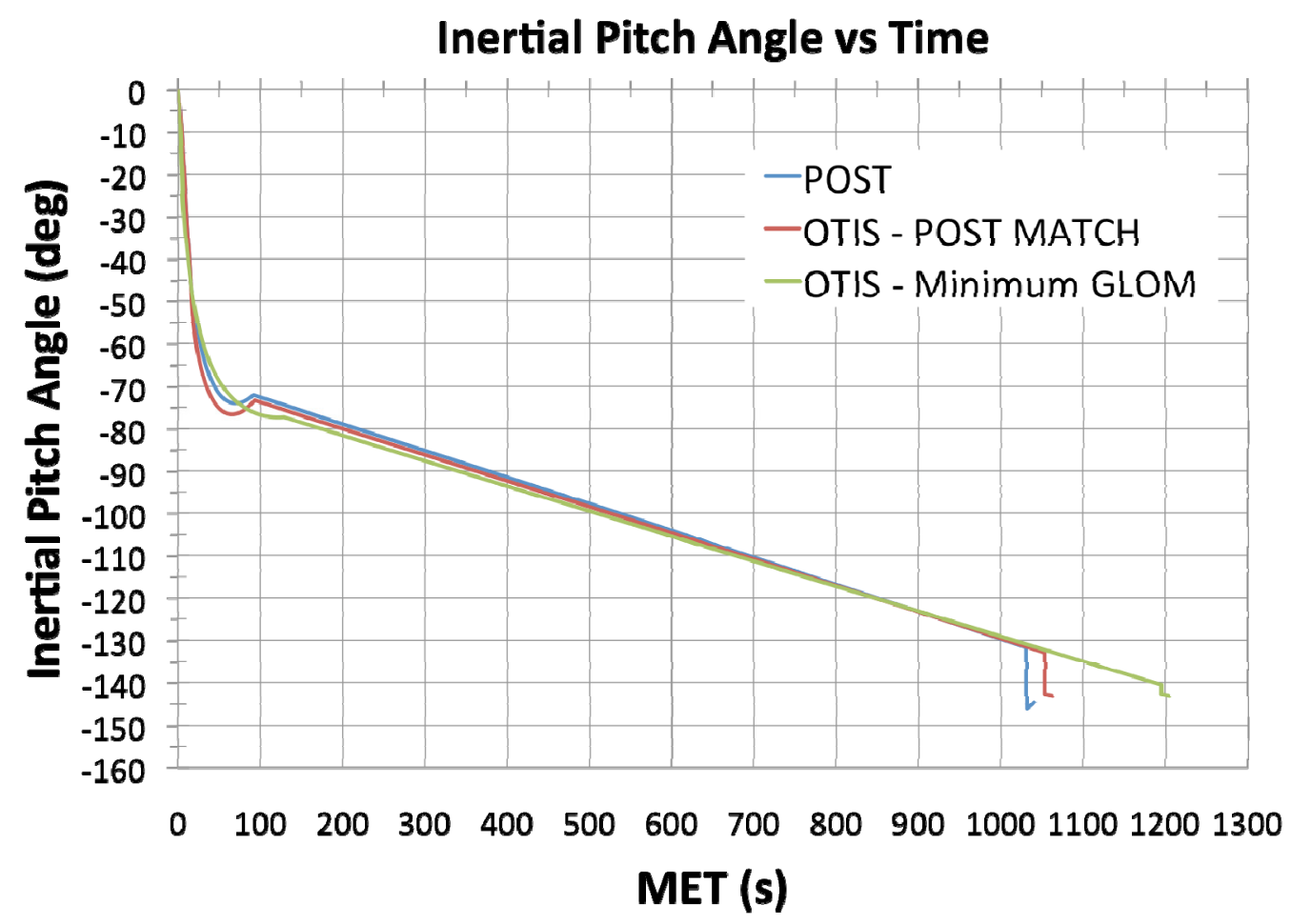

Figure 17.-Comparison of inertial Euler pitch control history for POST and OTIS SSTO baselines. 


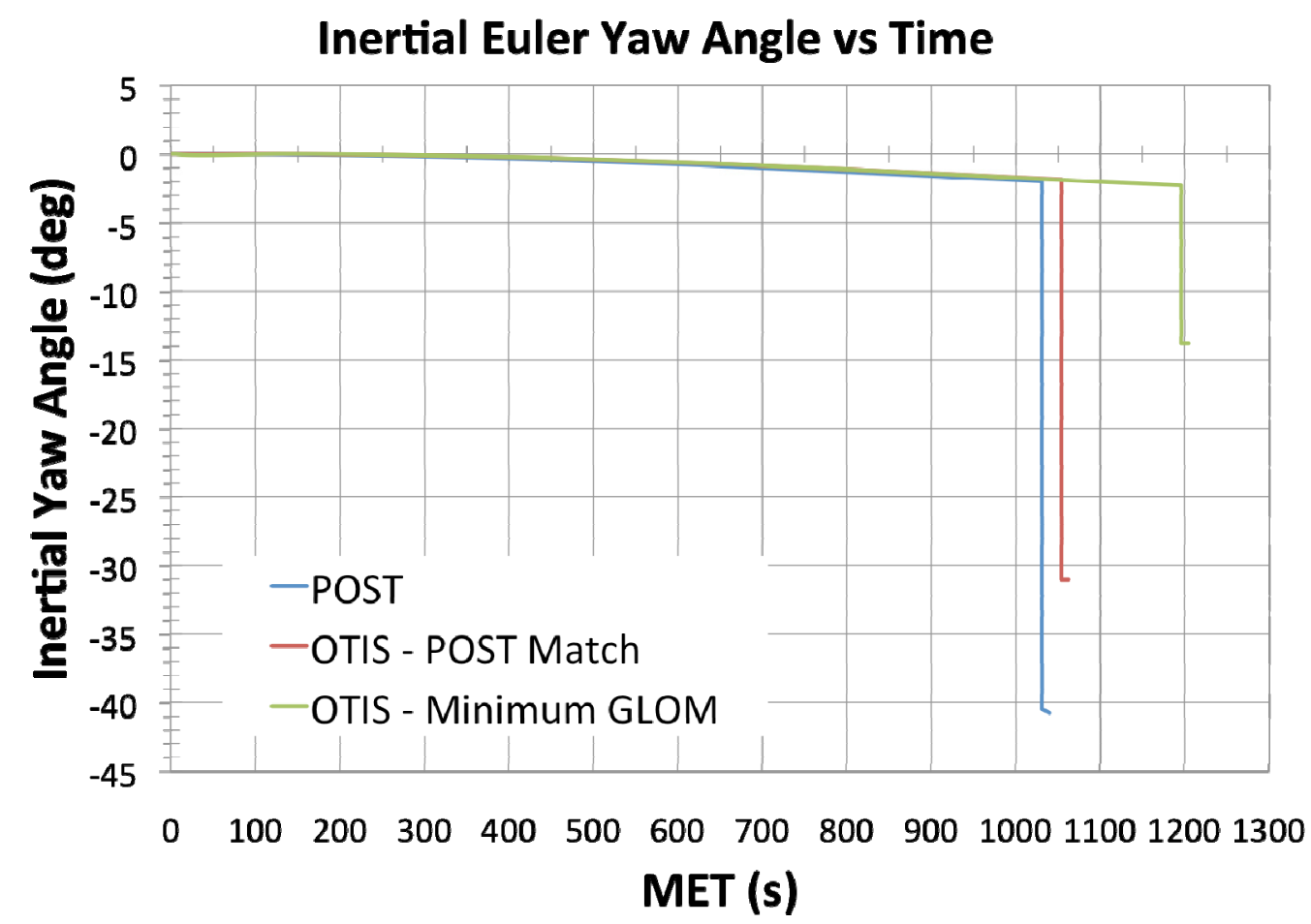

Figure 18.-Comparison of inertial Euler yaw control history for POST and OTIS SSTO baselines.

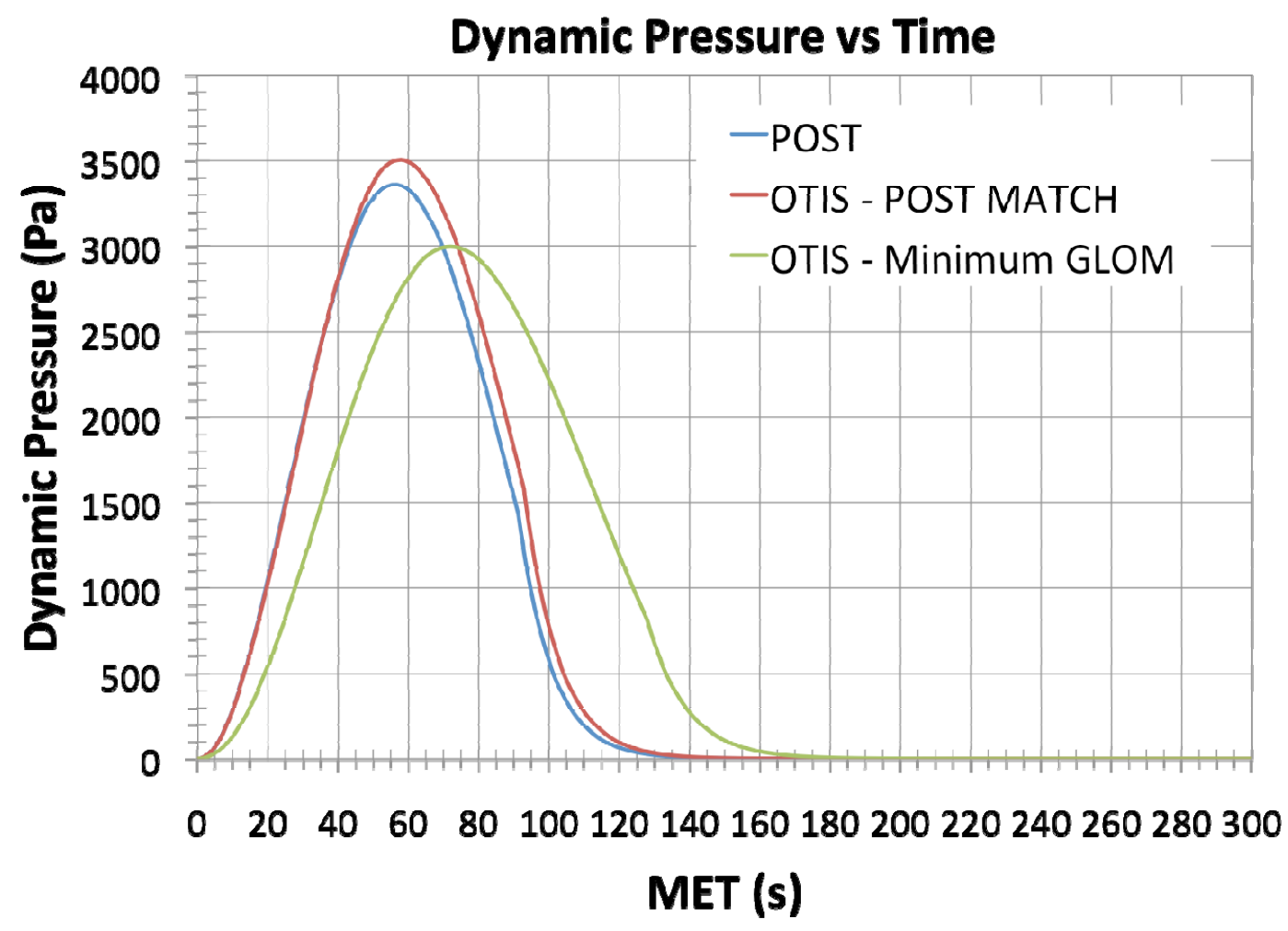

Figure 19.-Comparison of dynamic pressure history for POST and OTIS SSTO baselines. 
The SSTO match results again demonstrate that with consistent assumptions, POST and OTIS produce similar trajectory results. Comparisons between these trajectories show that both programs are modeling the SSTO vehicle in a similar manner indicating matching simulations. This is demonstrated both in the performance match and through comparison of the trajectory parameter trends. In this case, OTIS was able to fully utilize the baseline mission constraints to find a more optimal solution. Additional discussion of the use of a wind model and its effects on the SSTO GLOM sensitivities is included in Section 7.0.

\subsection{TSTO GLOM Sensitivities}

\subsection{GLOM Sensitivity to Target Inclination, Launch Latitude, and Launch Elevation}

Before, and to a lesser degree after, a landing site is selected there is the potential for variability in the location and type of terrain on which the MAV launch platform may come to rest. Although the MAV lander is targeted to land with $\pm 30^{\circ}$ latitude of the equator, a broader latitude range of $0^{\circ}$ to $90^{\circ}$ was analyzed to establish complete GLOM growth trends. The launch elevation angle, as shown in Figure 6, is defined as the launch angle of the MAV measured from local horizontal. This results in a $90^{\circ}$ elevation angle when the MAV is launched vertically as modeled for the TSTO and SSTO baseline cases. Launch latitudes between $0^{\circ}$ and $90^{\circ}$ were analyzed at launch elevations from $30^{\circ}$ to $90^{\circ}$. Also shown in Figure 6 is the orientation of the MAV launch azimuth relative to the optimal launch azimuth. For all latitude/ inclination/elevation sensitivities shown, the vehicle is always launched along the optimal launch azimuth, which corresponds to an off optimal azimuth angle of zero as defined in Figure 6. Section 6.2 will discuss the nonoptimal launch azimuth geometry in further detail and present GLOM sensitivities at varying off optimal launch azimuth and elevation combinations.

For each latitude and elevation combination, a range of target inclinations up to $90^{\circ}$ was also analyzed. From spherical geometry, only inclinations greater than or equal to the current latitude can be reached during ascent, as shown in Figure 5. To reach an inclination lower than the current latitude, an additional burn would be necessary after reaching orbit. The GLOM penalty for doing an additional burn is quite high as demonstrated in Figure 20, which shows the total GLOM increase from the OTIS TSTO baseline, $272.6 \mathrm{~kg}$, plotted against on-orbit inclination change capability. The GLOM increase observed consists of the propellant necessary to perform the on-orbit inclination change maneuver as well as the additional MAV GLOM needed to lift that propellant to orbit. If the MAV were to launch from a $30^{\circ}$ inclination and needed to end up in an equatorial ( $0^{\circ}$ inclination) orbit, a $30^{\circ}$ on-orbit inclination change would be necessary with an associated GLOM increase of approximately $168 \mathrm{~kg}$.

For a launch latitude of $0^{\circ}$ (equatorial) the resulting GLOM growth for varying both launch elevation and target orbit inclination are shown in Figure 21. It is noted that for optimal azimuth launches at a launch latitude and target inclination of zero, any elevation angle less than $90^{\circ}$ results in a GLOM less that the TSTO baseline of $272.6 \mathrm{~kg}$. The minimum total GLOM was found at a launch elevation angle near $45^{\circ}$. This can be more clearly seen in Figure 22, which shows only the $90^{\circ}, 45^{\circ}$, and $30^{\circ}$ launch elevation angles. A direct relationship between GLOM and inclination was hard to develop due to the nonlinear nature of the results. Figure 23 plots the slope of the curves shown in Figure 22 and demonstrates this nonlinear behavior. It can be observed that as the targeted inclination reaches $90^{\circ}$, the change in GLOM per degree inclination approaches a constant value of $0.33 \mathrm{~kg}$ GLOM per degree in inclination. This translates into a maximum GLOM necessary to cover launches to inclinations up to $90^{\circ}$ of approximately $286 \mathrm{~kg}$, an increase of about $13 \mathrm{~kg}$ over the TSTO baseline. Further, by limiting launches to inclinations less than or equal to $45^{\circ}$, the baseline GLOM can be maintained for any launch elevation angle. For brevity, only the equatorial latitude results are shown here. The remaining elevation and inclination combinations for all launch latitudes are shown in Appendix A. 


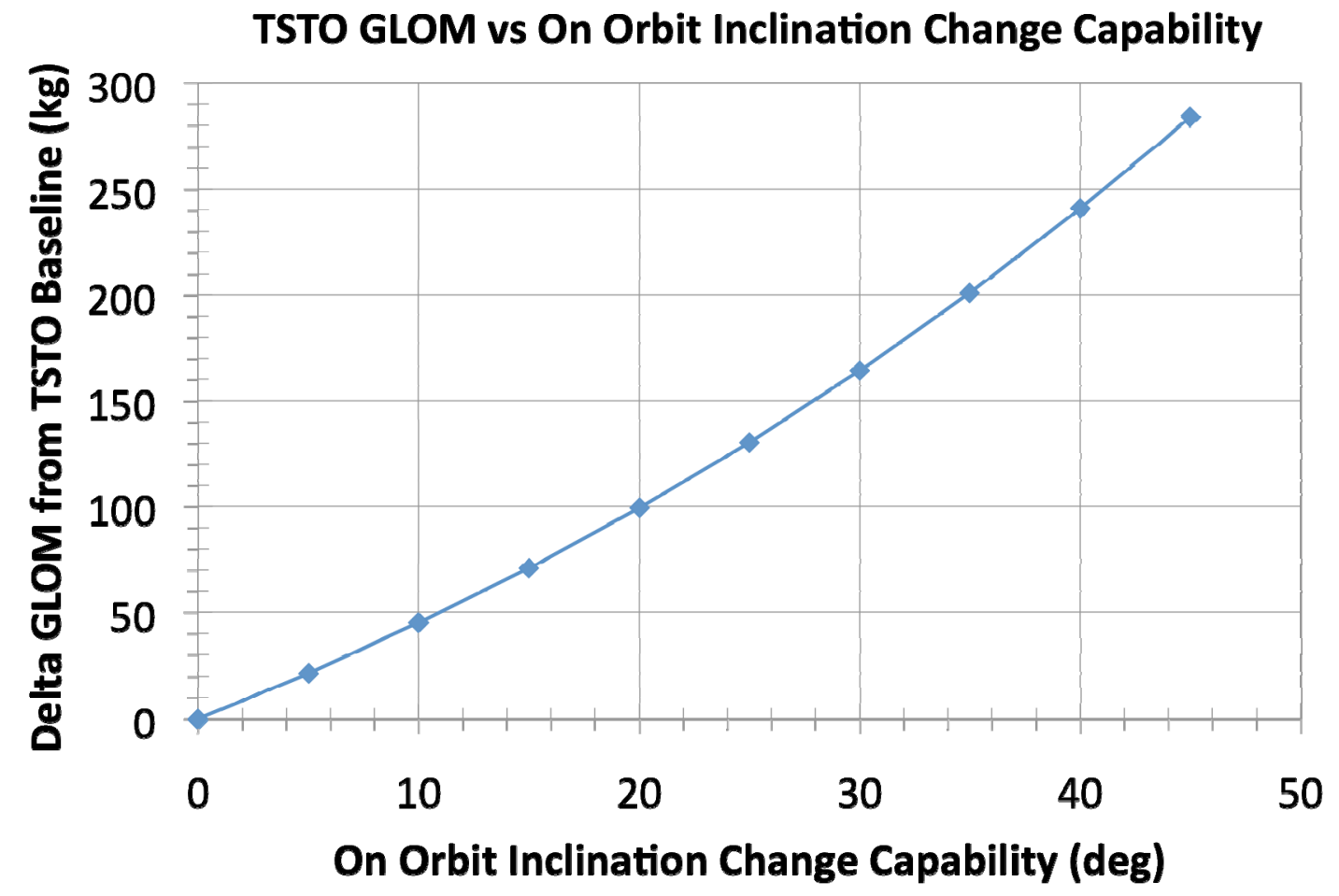

Figure 20.-GLOM growth for an on-orbit inclination change necessary to reach inclinations lower than the launch latitude.

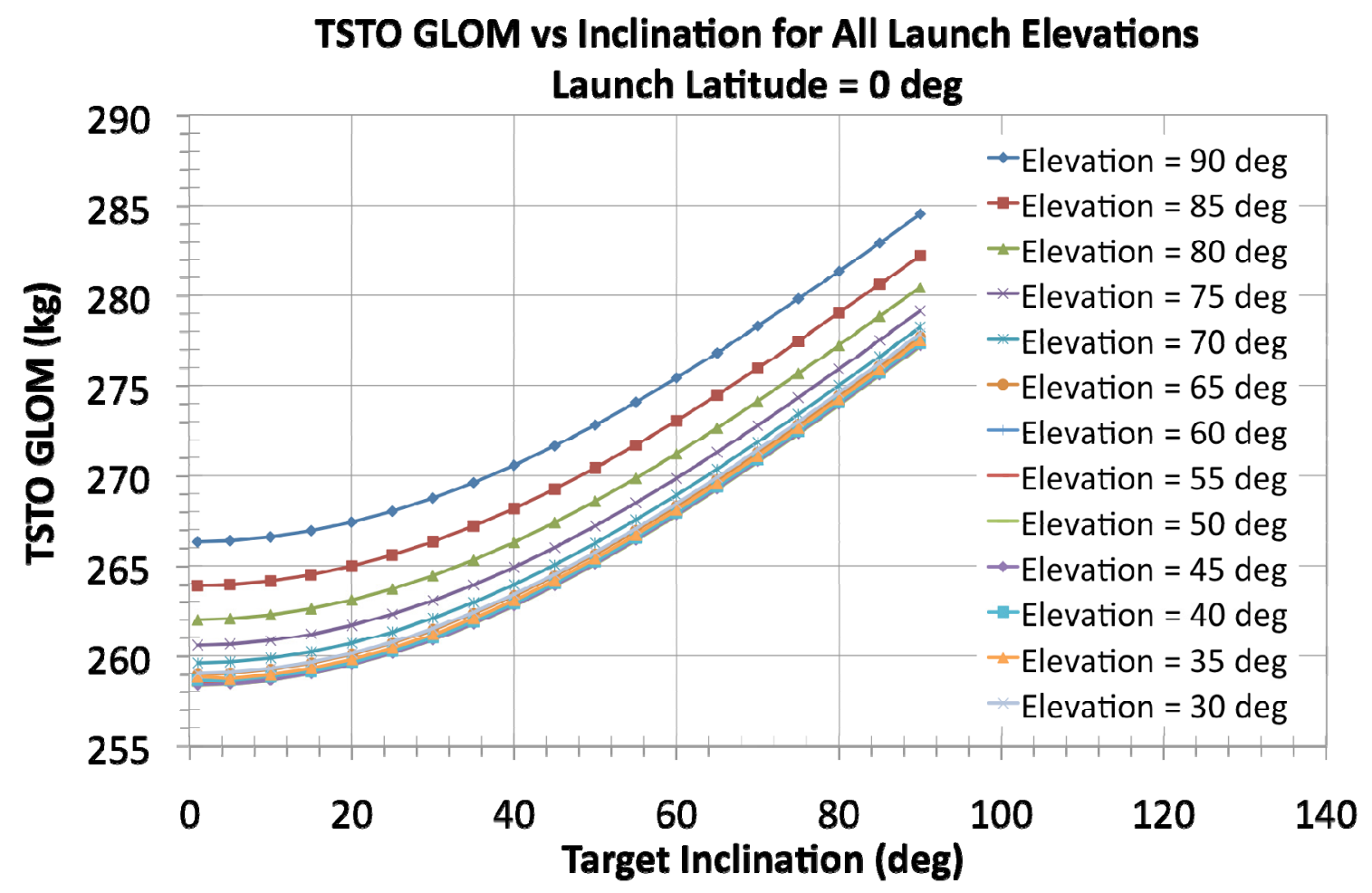

Figure 21.-GLOM sensitivity for all launch elevations and target orbit inclinations at a launch latitude of $0^{\circ}$. 
TSTO GLOM vs Inclination for Selected Launch Elevations

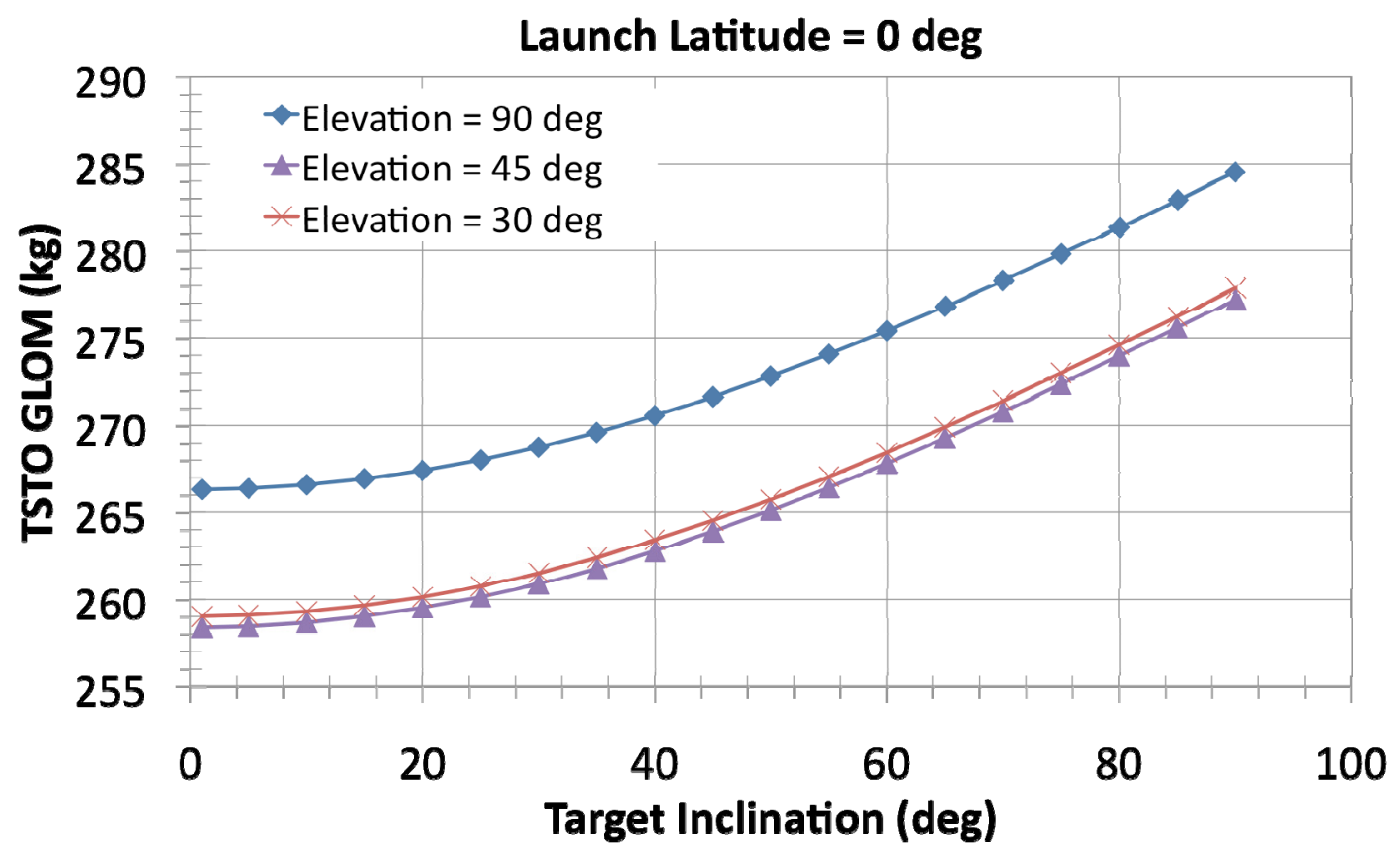

Figure 22.-GLOM sensitivity for selected elevations and target orbit inclinations at a launch latitude of $0^{\circ}$.

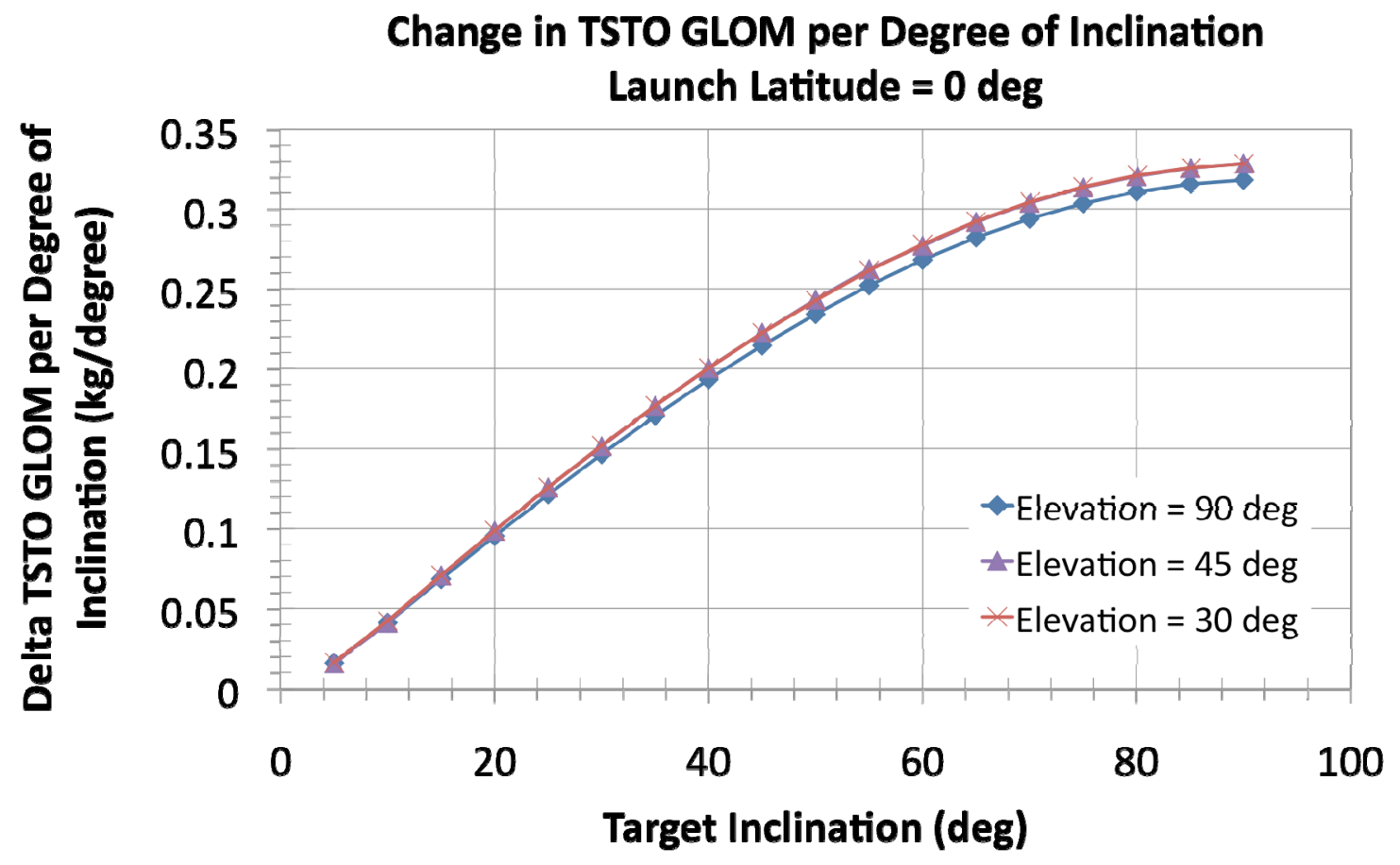

Figure 23.- Slope of GLOM change per degree of inclination for a launch latitude of $0^{\circ}$ at selected launch elevations. 
Interesting insight results from looking at the same GLOM sensitivities at a constant launch elevation angle for combinations of launch latitude and target inclination, found in Figure 24 for a $90^{\circ}$ launch elevation and Figure 25 for a $45^{\circ}$ launch elevation. Both of these figures demonstrate that for any target inclination, GLOM grows by about $0.23 \mathrm{~kg}$ per $10^{\circ}$ of launch latitude. The data run for all other combinations of launch parameters, not shown here, demonstrates that GLOM growth of this magnitude can be expected for all launch elevations. This means that if targeting a $90^{\circ}$ inclination orbit, the GLOM difference between launching from a pole, instead of the equator, is only about $2 \mathrm{~kg}$. This is a significant finding as this indicates that launch latitude makes very little difference in the size of the MAV, as long as that latitude is less than or equal to the target inclination.

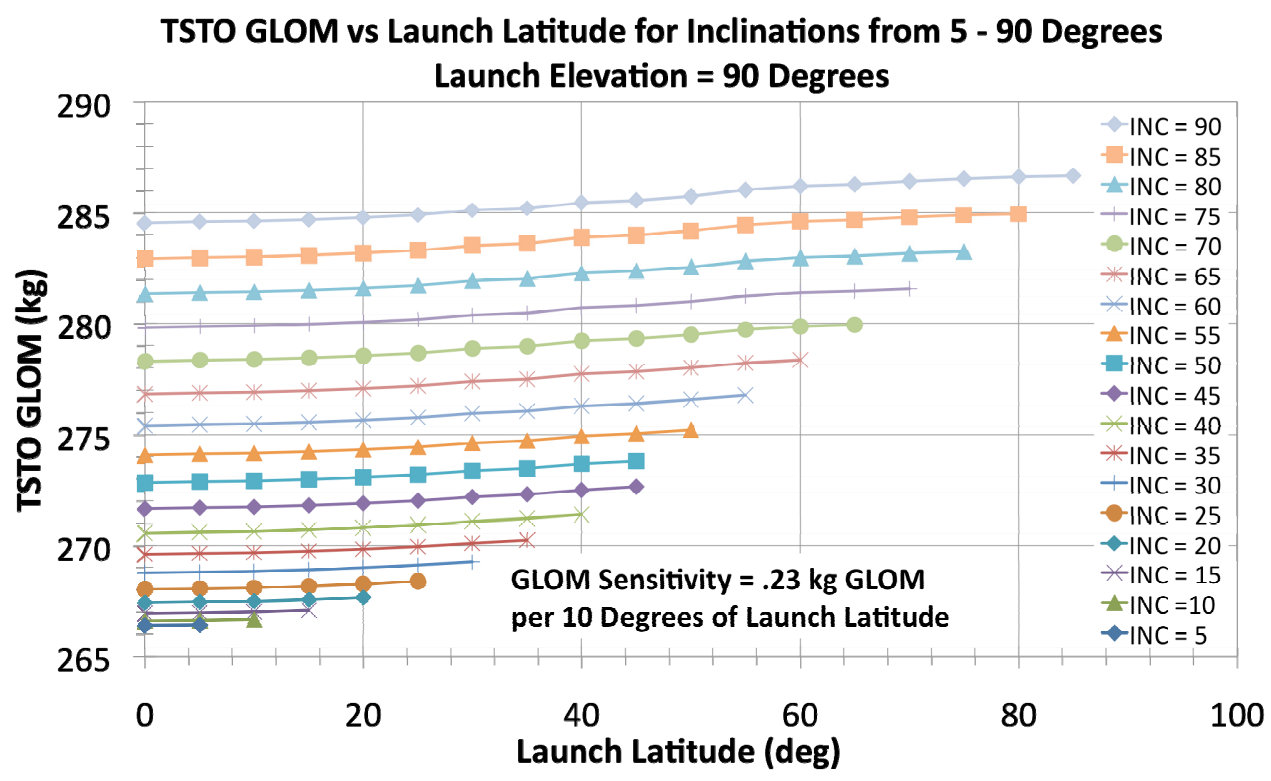

Figure 24.-GLOM sensitivity for all launch latitudes to target orbit inclinations greater than the launch latitude, at a launch elevation of $90^{\circ}$.

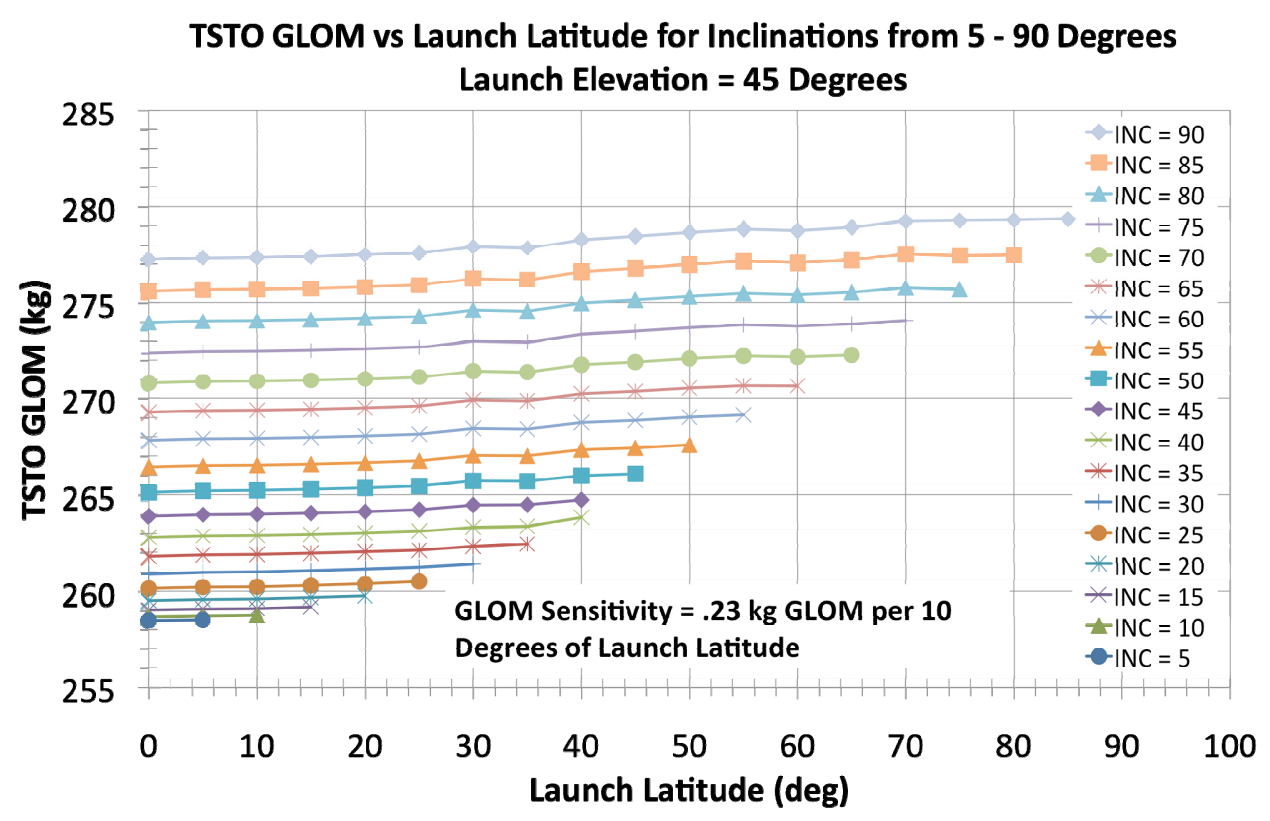

Figure 25.-GLOM sensitivity for all launch latitudes to target orbit inclinations greater than the launch Latitude, at a launch elevation of $45^{\circ}$. 
For a launch latitude of $45^{\circ}$ and a vertical launch elevation, a number of inclination sweeps were run to estimate the effects of control rate, control continuity and wind modeling on the GLOM sensitivities presented in this section. It is expected that the trends shown here are representative of the remaining launch elevations and launch latitudes. As Figure 26 and Figure 27 show, control continuity and the use of a wind model have less that $0.25 \mathrm{~kg}$ effect on the GLOM trends generated. Although not shown here, the effects of these modeling assumptions remain similar when combined. The use of varying pitch body control rates for these sweeps was also analyzed, with the results found in Figure 28. GLOM is predictably lower with the use of higher body control rate limits and matches closely with the GLOM trend presented in Figure 3.

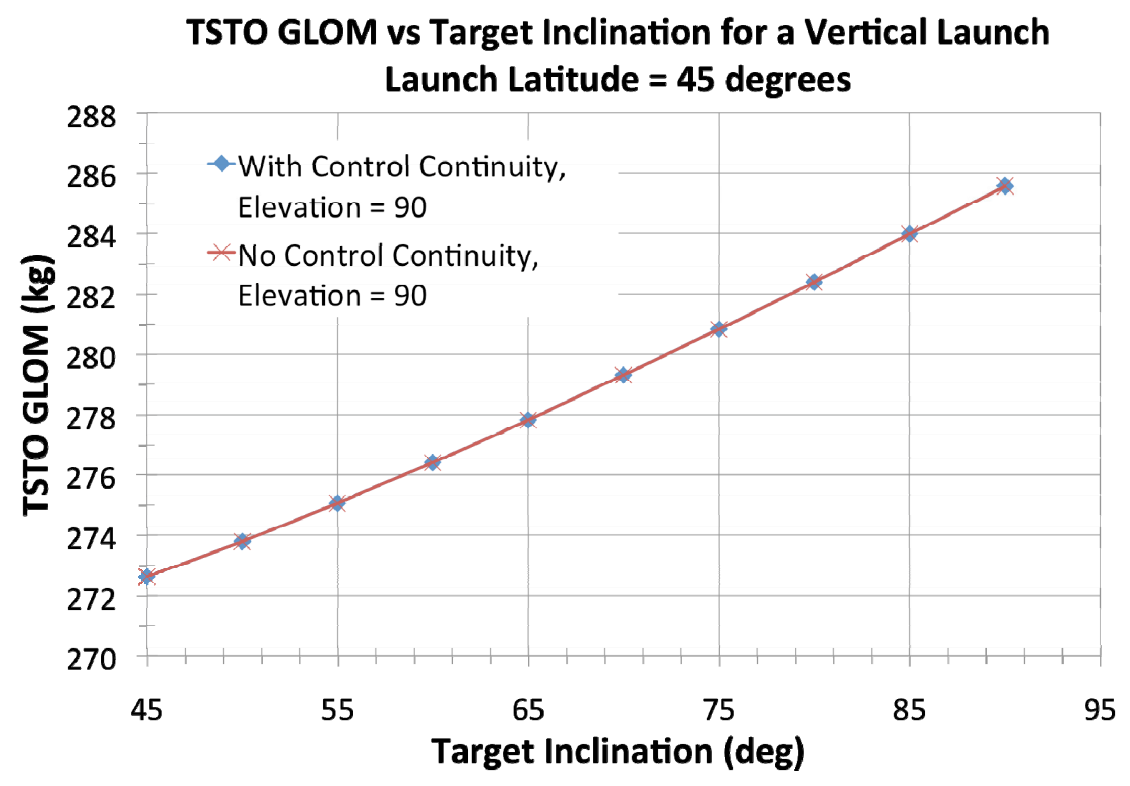

Figure 26.-Impact of control continuity on TSTO GLOM sensitivity of a vertical launch elevation to an inclination greater than the launch latitude of $45^{\circ}$.

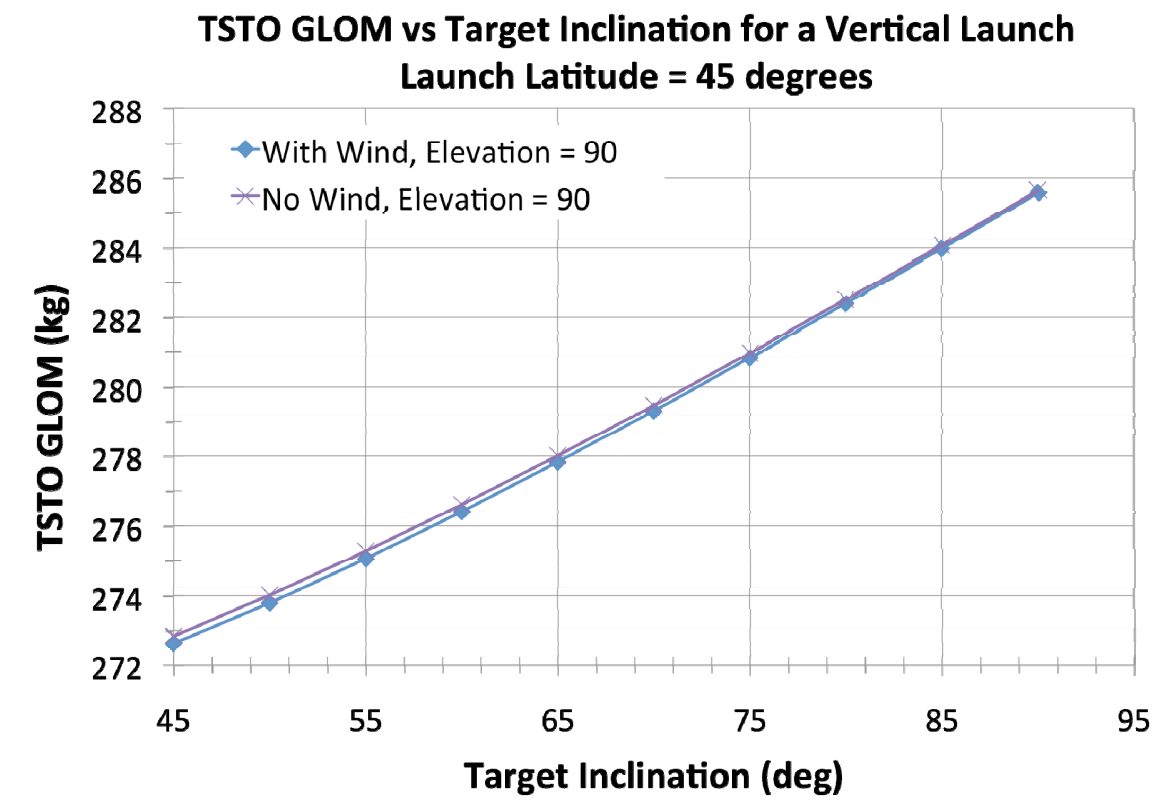

Figure 27.-Impact of wind modeling on TSTO GLOM sensitivity of a vertical launch elevation to an inclination greater than the launch latitude of $45^{\circ}$. 


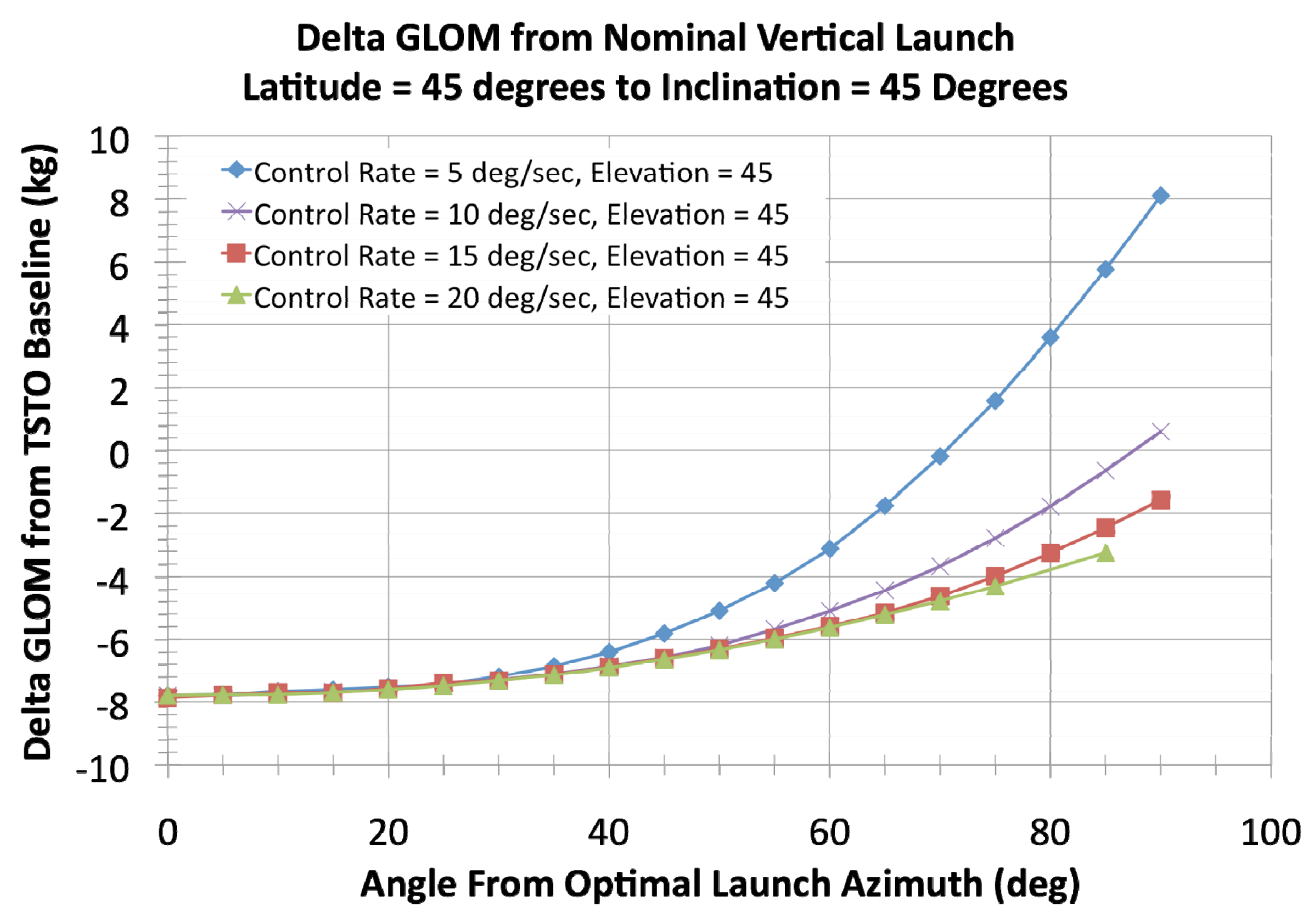

Figure 28.-Impact of control rate limit on TSTO GLOM sensitivity of a vertical launch elevation to an inclination greater than the launch latitude of $45^{\circ}$.

\subsection{Sensitivity to Launch Azimuth and Launch Elevation}

The GLOM sensitivities discussed for latitude, inclination and launch elevation, all assume that the MAV is able to lift off and pitch over directly into the optimal launch azimuth. This provides the minimal GLOM for each set of launch conditions. The optimal launch azimuth varies greatly as the launch latitude and target inclination change. However, the entry, descent and landing system may not be able to guarantee that the MAV launch platform will land in an orientation that allows a direct launch into the optimal launch azimuth. This necessitates that GLOM sensitivities be established for launches to azimuths not aligned with the optimal launch azimuth. As depicted in Figure 6, the distance from the optimal launch azimuth for each case considered is quantified as the angle from the optimal launch azimuth. An angle from optimal azimuth of zero results in a vehicle launch aligned with optimal, while an angle $180^{\circ}$ represents a launch in exactly the opposite direction from the optimal azimuth.

GLOM sensitivities were established from the baseline launch assumptions, with a launch from a latitude of $45^{\circ}$ and an inclination target of $45^{\circ}$. Each nonoptimal launch azimuth case was analyzed using the full set of control angles, allowing for the vehicle's pitch, yaw and roll angles to be varied. This is necessary since it is not possible to launch from varying launch azimuths to the same inclination target without the use of out of pitch plane control. Similar to the TSTO baseline, all out of pitch plane controls are calculated using one linear control segment during the first stage burn with a second linear segment used to ramp aerodynamic angles to zero. Each angle is also controlled using one linear segment during the second stage burn.

Launch elevation angle is a key driver in the sensitivity of GLOM to launch azimuth variation. If the vehicle is assumed to always launch at a $90^{\circ}$ launch elevation angle, as shown in Figure 6, the optimal azimuth can be reached with very little effect to GLOM. As launch elevation angle is decreased, the effect on GLOM to launch at varying azimuths increases dramatically. This assessment considers the impact to GLOM if launch elevation can be guaranteed within $30^{\circ}$ of the targeted launch elevation. Therefore, GLOM comparisons were made for elevation angles from $60^{\circ}$ to $90^{\circ}$, to establish sensitivities for a 
mission designed to launch vertically. GLOM comparisons were also made for a mission designed to launch at a $45^{\circ}$ elevation, for elevation angles from $30^{\circ}$ to $75^{\circ}$. The results for off optimal azimuth angles from $0^{\circ}$ to $180^{\circ}$ are shown for the vertical launch in Figure 29 with deltas based on the baseline GLOM of $272.6 \mathrm{~kg}$. Figure 30 shows the $45^{\circ}$ launch elevation sensitivities, compared to a baseline GLOM of $265.8 \mathrm{~kg}$. It is assumed that GLOM sensitivities to launch azimuth are symmetric, with the GLOM growth for off azimuth angles from $0^{\circ}$ to $-180^{\circ}$ being similar to the results for off azimuth angles from $0^{\circ}$ to $180^{\circ}$ shown here.

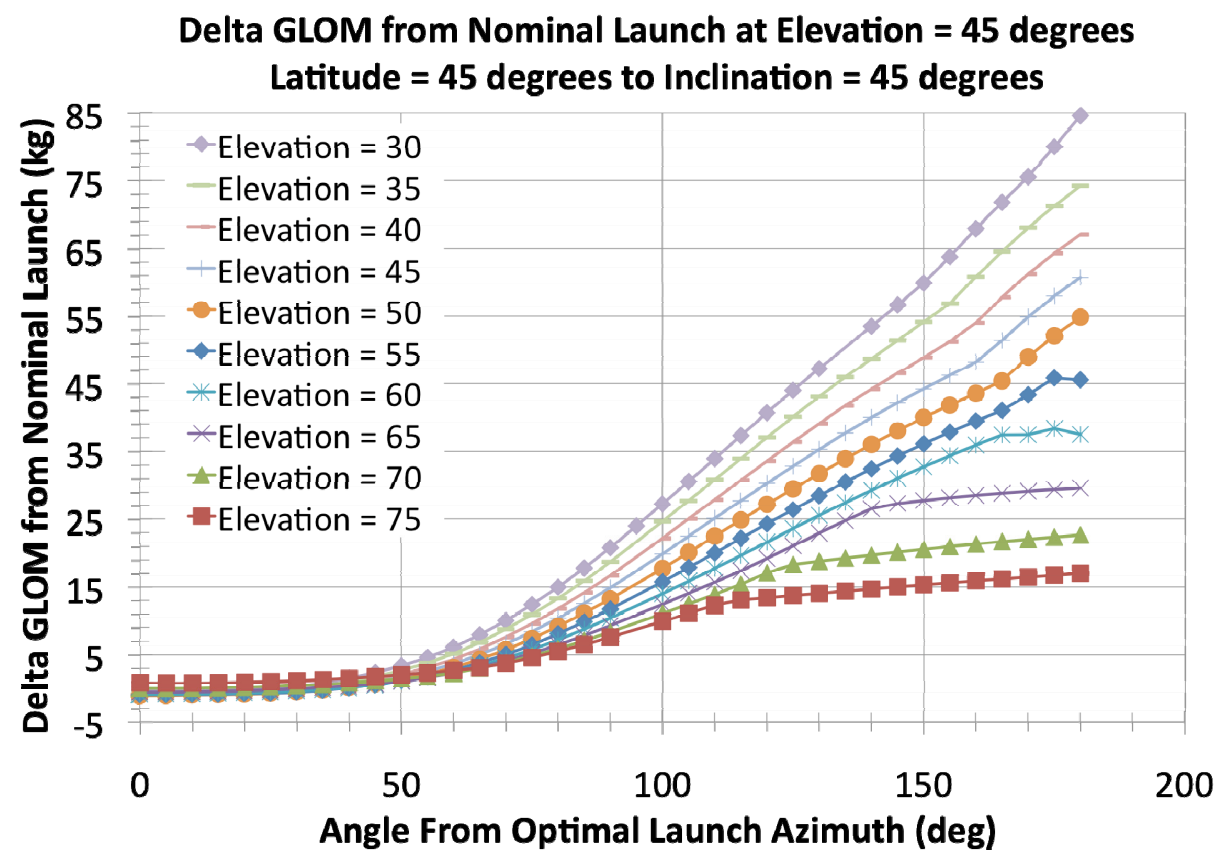

Figure 29.-GLOM delta for off optimal launch azimuths based on vertical launch with GLOM of $272.6 \mathrm{~kg}$.

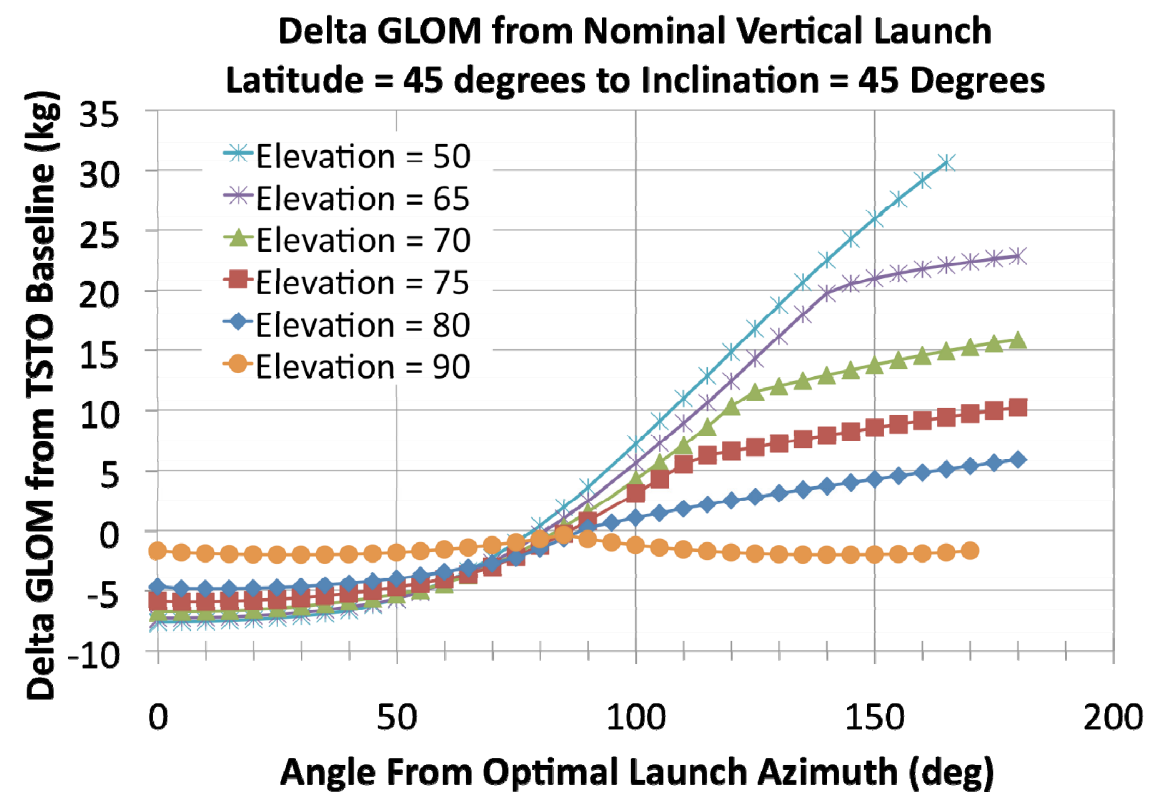

Figure 30.-GLOM delta for off optimal launch azimuths based on $45^{\circ}$ elevation launch with GLOM of $265.8 \mathrm{~kg}$. 
The off optimal launch azimuth cases analyzed demonstrate that for a nonvertical launch, maintaining the launch azimuth within approximately $80^{\circ}$ of optimal, keeps the total GLOM under the documented TSTO baseline of $272.6 \mathrm{~kg}$. For a targeted $45^{\circ}$ launch, if the launch azimuth can be guaranteed with approximately $70^{\circ}$ of optimal, the TSTO baseline GLOM can be maintained. Additionally a launch azimuth restriction of approximately $40^{\circ}$ from optimal would allow for GLOM to be reduced by about $6 \mathrm{~kg}$ from the TSTO baseline vertical launch GLOM. If the launch azimuth cannot be guaranteed within these ranges, it is apparent that launching close to vertical provides the smallest GLOM growth for large off azimuth angles. The performance sensitivities shown are only valid for launch inclinations and latitudes between $0^{\circ}$ and $45^{\circ}$. Launches to inclinations greater than $45^{\circ}$ will result in higher GLOM increases for off azimuth launches, caused by the larger GLOM necessary for an optimal azimuth launch to high inclinations.

Similar to the previous set of sensitivities, additional GLOM sweeps were completed to identify the effects of varying control rates as well as not enforcing control continuity for the start of the second burn. These cases were run for only a launch elevation of $45^{\circ}$ while targeting an orbital inclination of $45^{\circ}$. The angle from optimal azimuth was varied between $0^{\circ}$ and $90^{\circ}$, with GLOM comparisons made back to the baseline TSTO GLOM of $272.6 \mathrm{~kg}$. Figure 31 shows the effect on the presented GLOM sensitivities, when the maximum body control rate was varied. In these cases all angles were controlled and therefore limited to this maximum rate. These cases are driven primarily by the speed at which they can roll and yaw into the optimal azimuth so it is not surprising that increasing controls rates reduce the GLOM at $90^{\circ}$ off azimuth by $10 \mathrm{~kg}$. The use of control continuity was also examined, while maintaining the baseline body control rate of $5^{\circ}$ per second with results shown in Figure 32. It is quickly observed that control continuity has very little effect the GLOM trend observed, with GLOM being reduced by less than $0.25 \mathrm{~kg}$.

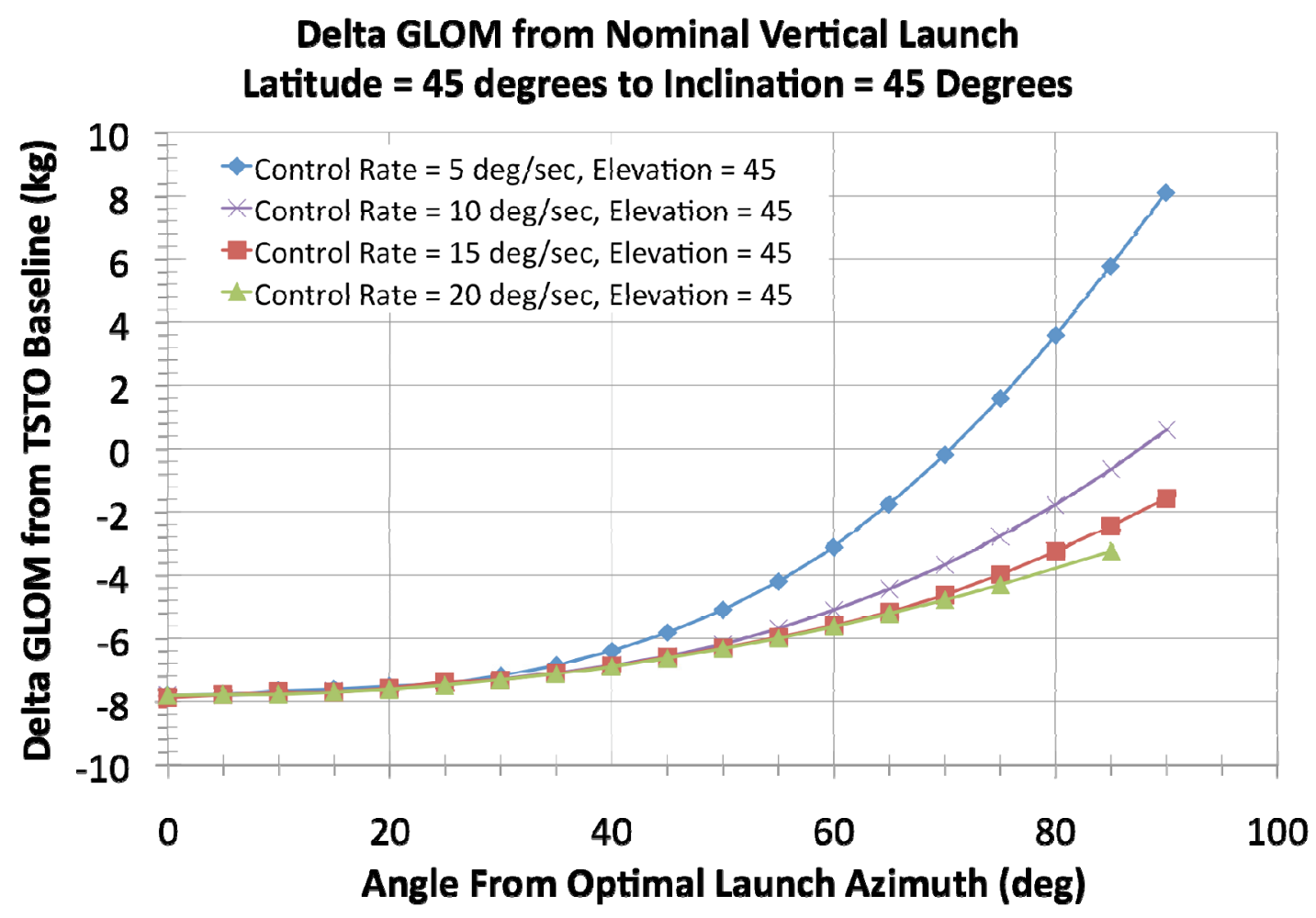

Figure 31.-GLOM delta for off optimal launch azimuths using varying control rate limits, based on a GLOM of $272.6 \mathrm{~kg}$. 


\section{Delta GLOM from Nominal Vertical Launch Latitude $=\mathbf{4 5}$ degrees to Inclination $=45$ Degrees}

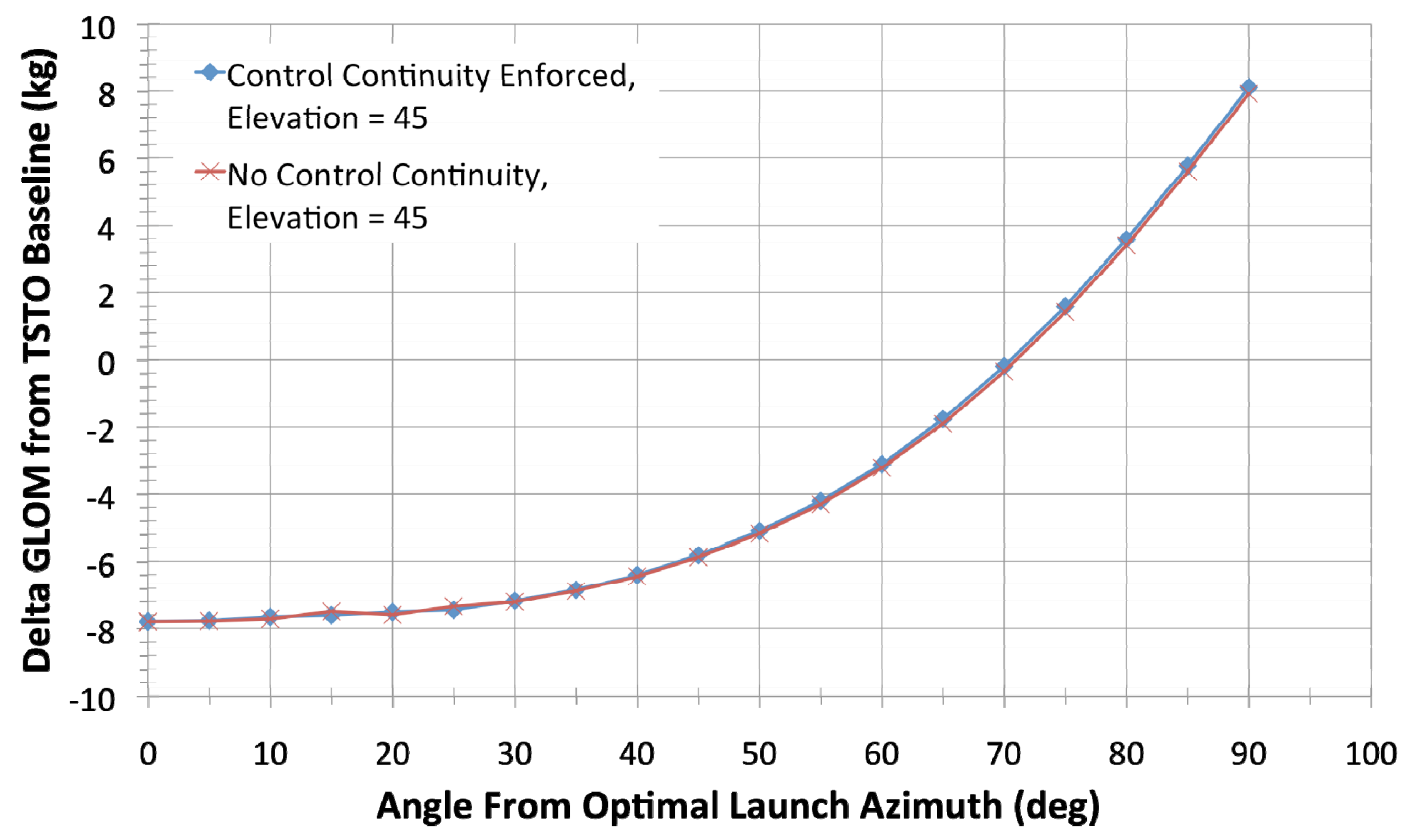

Figure 32.-GLOM delta for off optimal launch azimuths without second stage control continuity, based on a GLOM of $272.6 \mathrm{~kg}$.

\subsection{Circular Orbit Altitude Sensitivity}

With the sensitivity to insertion orbit inclination well characterized, it was also necessary to determine sensitivity to the targeted circular orbit altitude. As Figure 33 shows, the delta in GLOM for variations in targeted altitude are small. A weight change of approximately $5.1 \mathrm{~kg}$ of GLOM per $50 \mathrm{~km}$ of altitude was observed, with GLOM growing as circular orbit altitude increases. This partial was much lower than expected and results in minimal impact to the vehicle for changes in final orbit altitude.

\subsection{Vehicle Mass and Engine Parameter Sensitivities}

\subsubsection{Stage Mass}

All sensitivities presented to this point assumed vehicle mass and engine parameters consistent with the TSTO baseline. To analyze the effect of changes to the inert mass of both TSTO stages, a matrix of different first and second stage mass combinations were run. The range studied represents a total inert mass range of 30 to $70 \mathrm{~kg}$, with the mass shifted between each stage to cover all combinations of first and second stage masses. After running the entire matrix of cases developed, two different plots were generated. The first, Figure 34, shows the GLOM growth along lines of constant first stage mass, for varying second stage masses. The second,

Figure 35, show the opposite, with lines of constant second stage mass for varying first stage weights. 


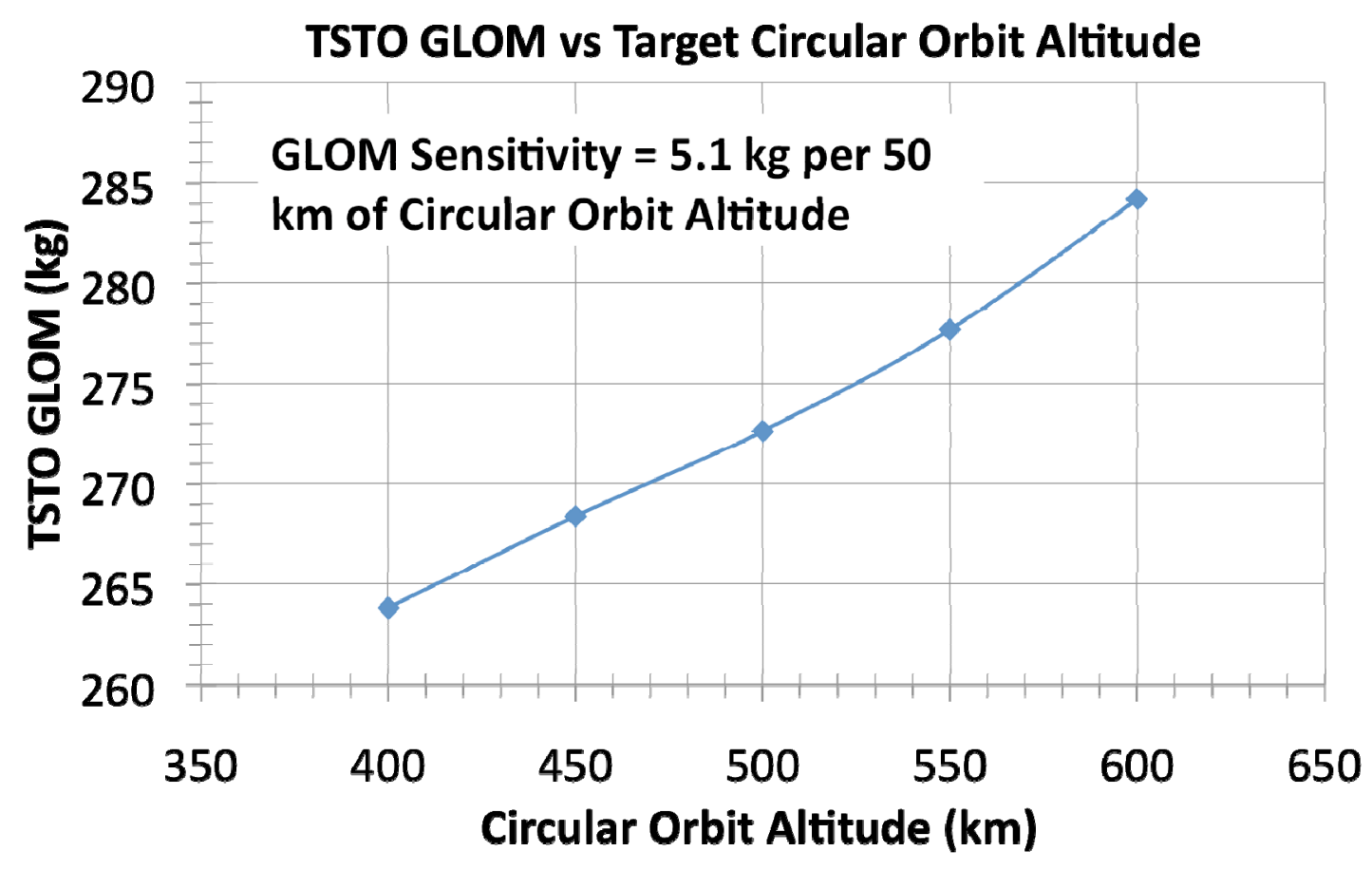

Figure 33.-TSTO GLOM sensitivity to circular orbit altitude.

From Figure 34 and Figure 35, partials were identified for GLOM growth with respect to mass changes in each stage. These show that for every kilogram of first stage growth, a GLOM increase of $1.9 \mathrm{~kg}$ can be expected. For the same $1 \mathrm{~kg}$ growth on the second stage, a $4.6 \mathrm{~kg}$ growth in GLOM can be expected. A third partial falls out from the first two; in that vehicle GLOM can be decreased by $2.7 \mathrm{~kg}$ for every kilogram of mass that can be shifted from second stage to the first. Since the first stage can stay with the vehicle until just before second stage ignition, this could present the opportunity to reduce GLOM by shifting functionality, and mass, to the first stage. These partials demonstrate the well-known benefit of staging, showing that mass added to the first stage comes at a cheaper cost to performance than mass added to the second stage.

For a constant Isp, the partials identified apply to any combination of inert masses, and do not change as total vehicle mass increases. As other vehicle parameters changed, the calculated mass partials also change. This is evident in Figure 36 and Figure 37, which show the change in dry mass partial as Isp is changed for both the first and second stage. Although the partial does not change drastically over the Isp range analyzed, it does show that increases in Isp allow mass to be added to the vehicle at a lower rate. However, the reverse also applies that the GLOM savings are mitigated at higher Isp values for decreases in stage mass. These are important partials for vehicle designers to keep in mind as investments are considered in stage mass reductions and Isp improvement. 


\section{TSTO GLOM vs. Second Stage Dry Mass Variation}

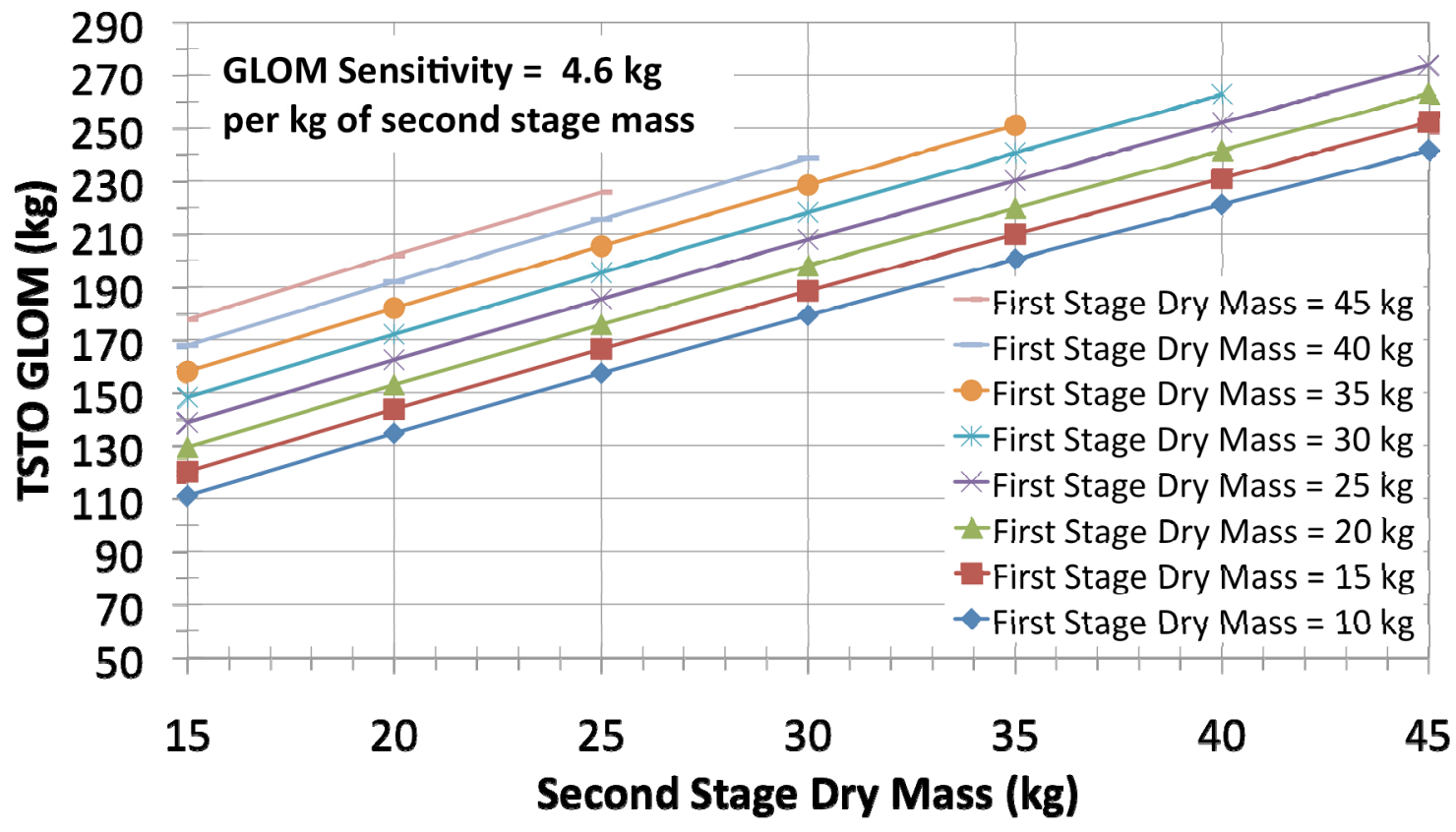

Figure 34.-TSTO GLOM sensitivity to second stage mass variation for a fixed first stage mass.

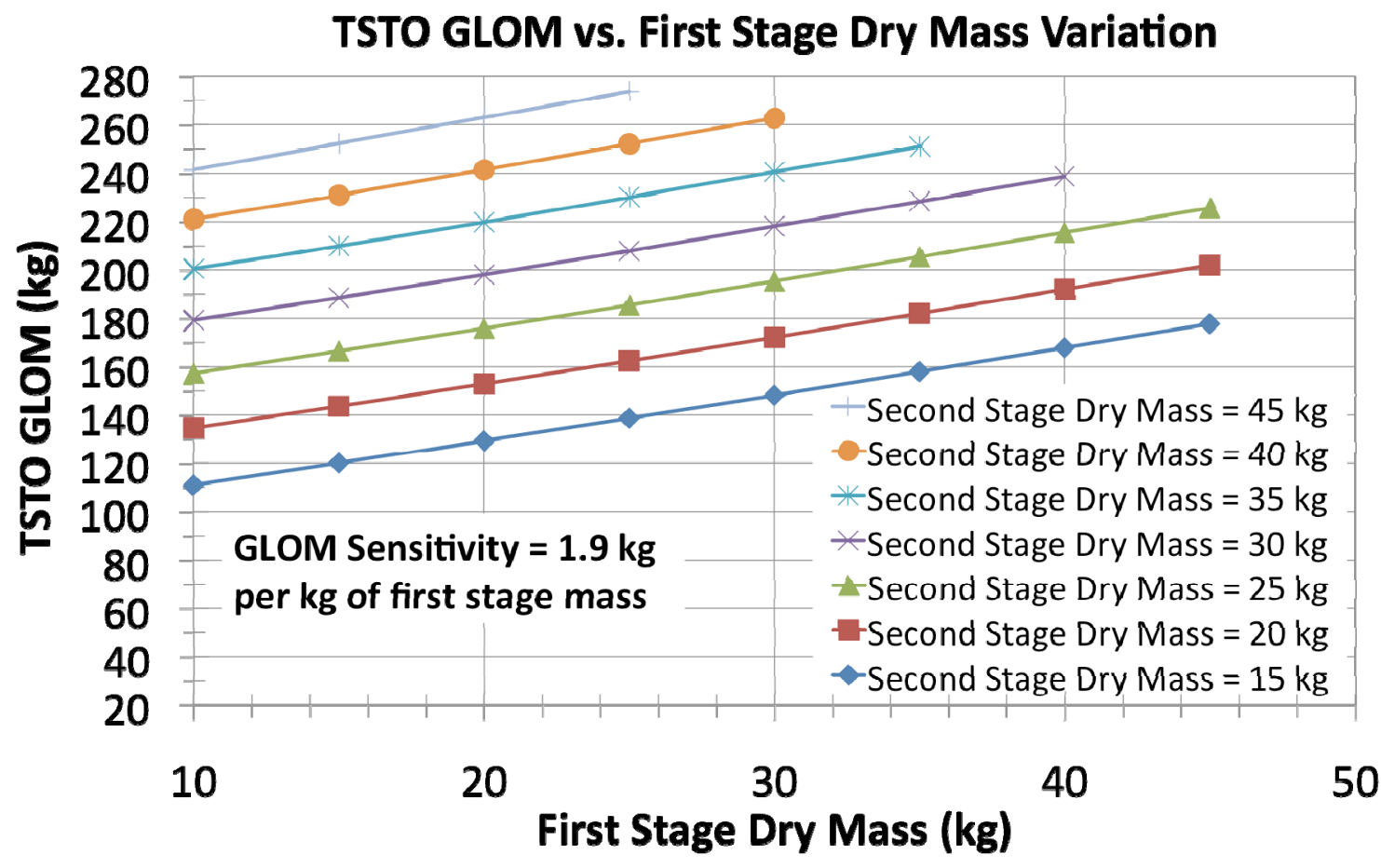

Figure 35.-TSTO GLOM sensitivity to first stage mass variation for a fixed second stage mass. 


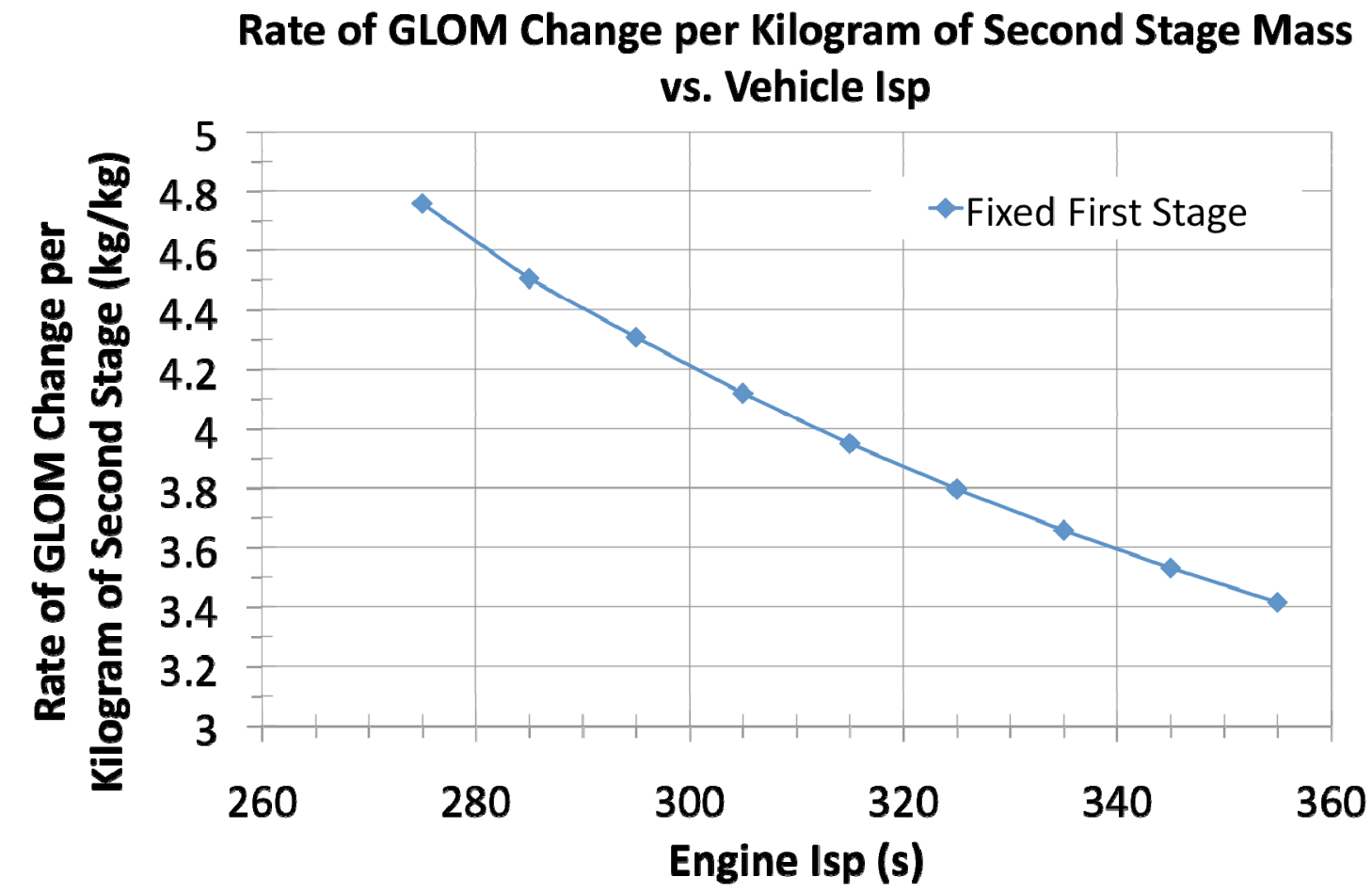

Figure 36.-Second stage dry mass sensitivity at varying values of Isp.

Rate of GLOM Change per Kilogram of First Stage Mass vs. Vehicle Isp

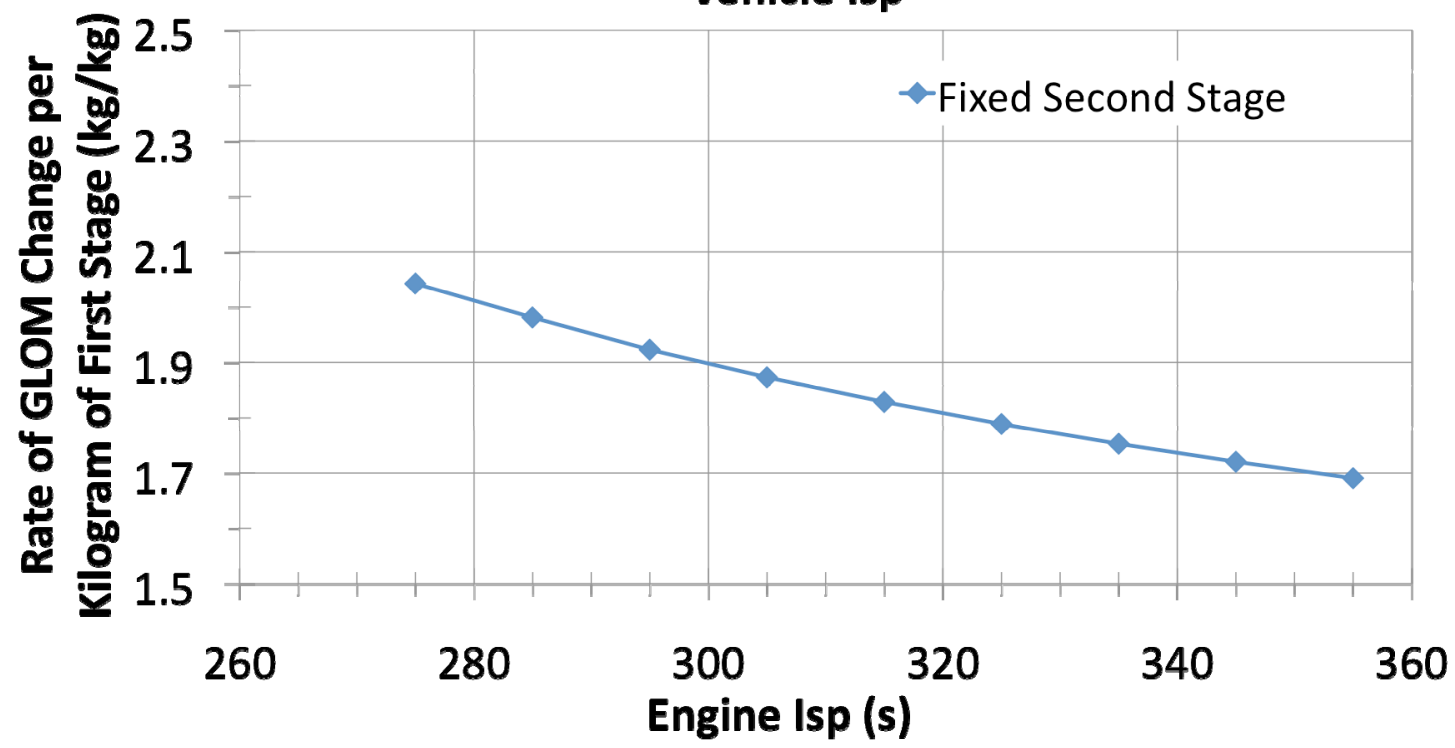

Figure 37.-First stage mass sensitivity at varying values of Isp. 


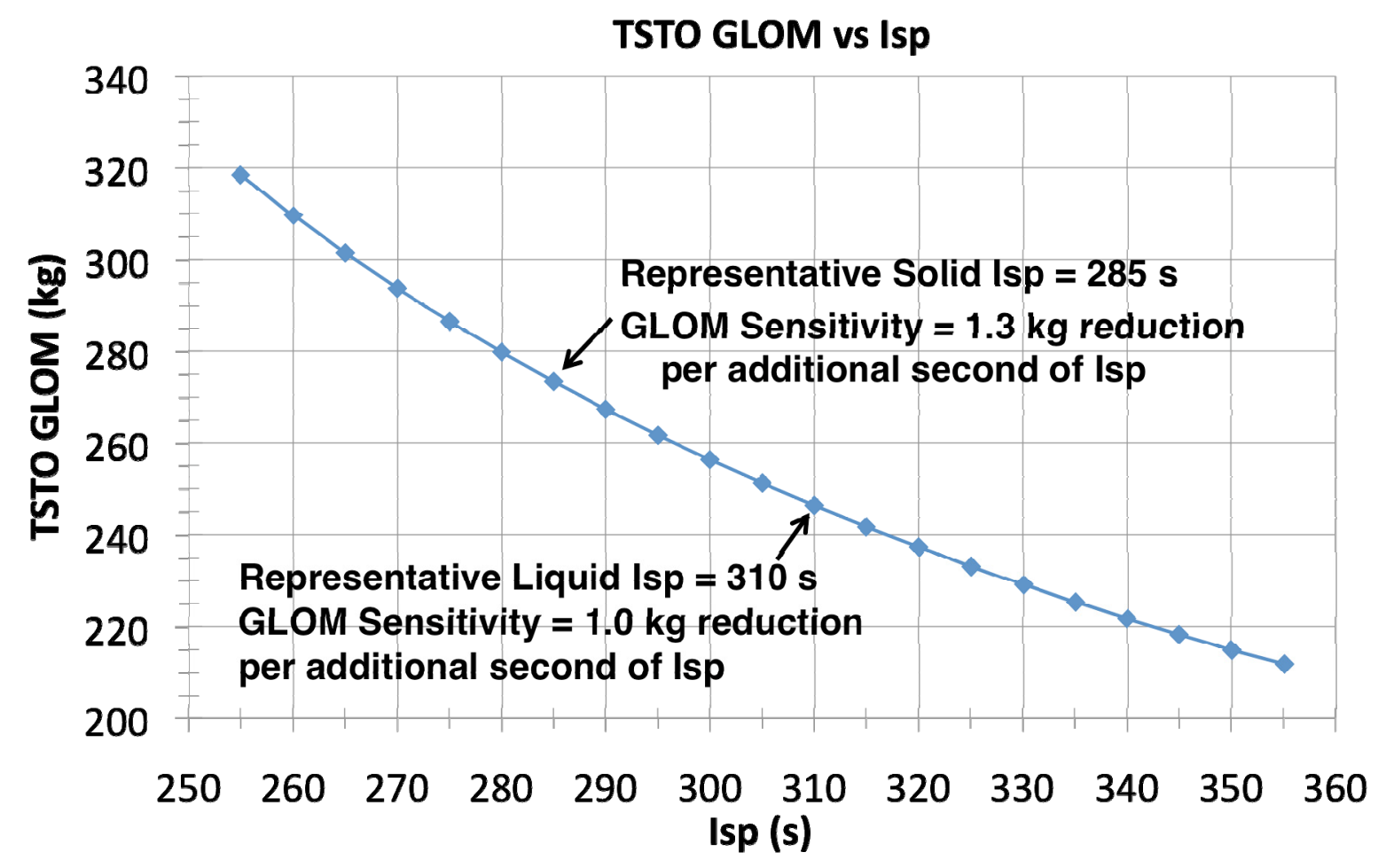

Figure 38.-TSTO GLOM sensitivity to Isp, constant for both stages.

\subsubsection{Engine Isp and Thrust}

Engine parameter GLOM sensitivities are also very important to consider for the MAV design. As done for other sensitivities, vehicle masses and mission parameters are held constant to the baseline assumptions. For thrust variations, Isp is held constant to baseline values while the thrust is held constant for the Isp partial. It is recognized the Isp and thrust are typically linked, along with potential mass increases. But as with other sensitivities discussed, this is intended to demonstrate the singular effect of each parameter. The effect to GLOM of varying the Isp is shown in Figure 38. The assumption was made that the Isp of both stages is the same, leading to the Isp listed in Figure 38 being used for both the first and second stages.

It is noted the resulting trend follows what would be expected due to the exponential nature of the rocket equation. An Isp range of 255 to $355 \mathrm{sec}$ was analyzed assuming a representative solid propellant Isp similar to the baseline of $285 \mathrm{sec}$ with a representative liquid system Isp of $310 \mathrm{sec}$. Due to the nonlinear nature of the Isp GLOM trend, linear relationships around each representative system Isp were established, and are valid for approximately $10 \mathrm{sec}$ of Isp around each design point. For a solid system, every additional second of Isp, a GLOM reduction of approximately $1.3 \mathrm{~kg}$ can be expected. A liquid system showed similar results with each additional second of Isp resulting in a GLOM reduction of approximately $1 \mathrm{~kg}$.

Unlike Isp, the thrust of each stage was considered separately. For each stage the sensitivity was analyzed around the baseline thrust value. The GLOM sensitivity for variations in second stage thrust, Figure 39, shows that MAV GLOM is insensitive to second stage thrust, which is not unexpected. The very low vehicle gross mass of the second stage (payload, propellant, and dry mass) results in a very high thrust to weight ratio for the range analyzed, allowing little change in the propellant mass needed for a short circularization burn. The first stage thrust GLOM sensitivity, Figure 40, shows a reduction of GLOM is possible by reducing first stage thrust. The minimum GLOM solution was found at a thrust value of 8930 newtons, which is less than half the baseline first stage thrust value. Reducing thrust to this value results in a GLOM reduction of only $4.4 \mathrm{~kg}$. 


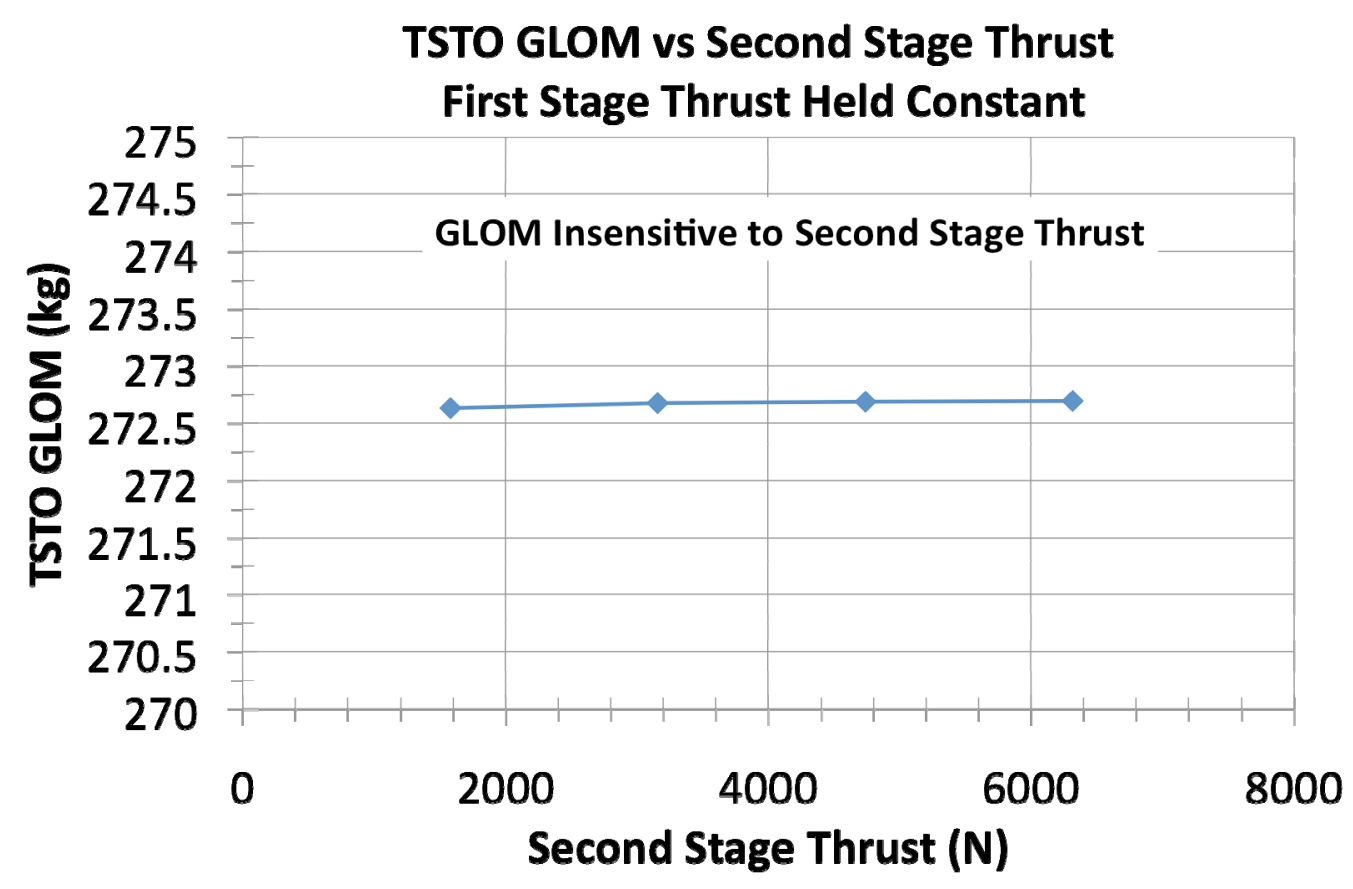

Figure 39._-TSTO GLOM sensitivity to second sage thrust, first stage thrust held constant.

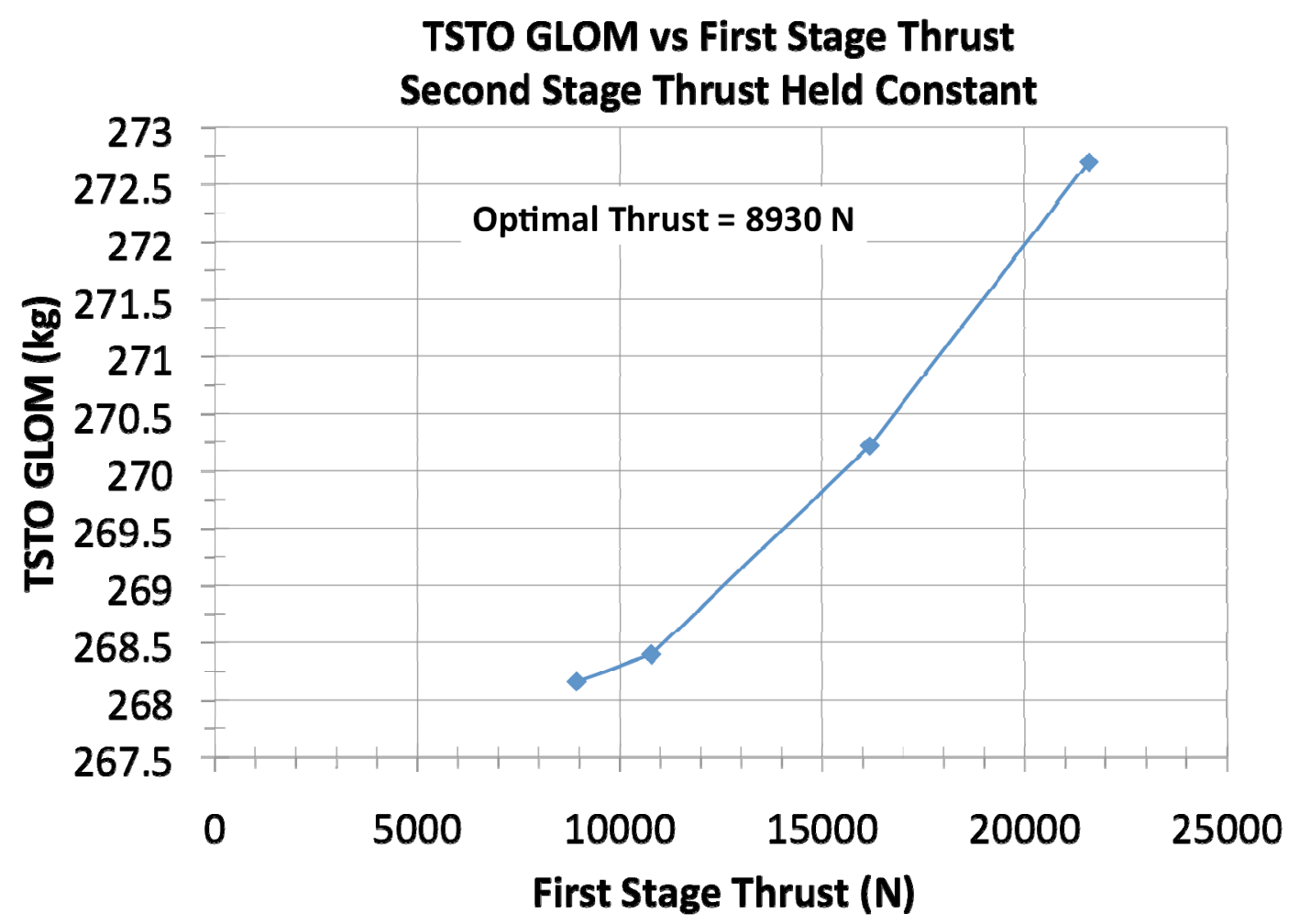

Figure 40.-TSTO GLOM sensitivity to first stage thrust, second stage thrust held constant. 


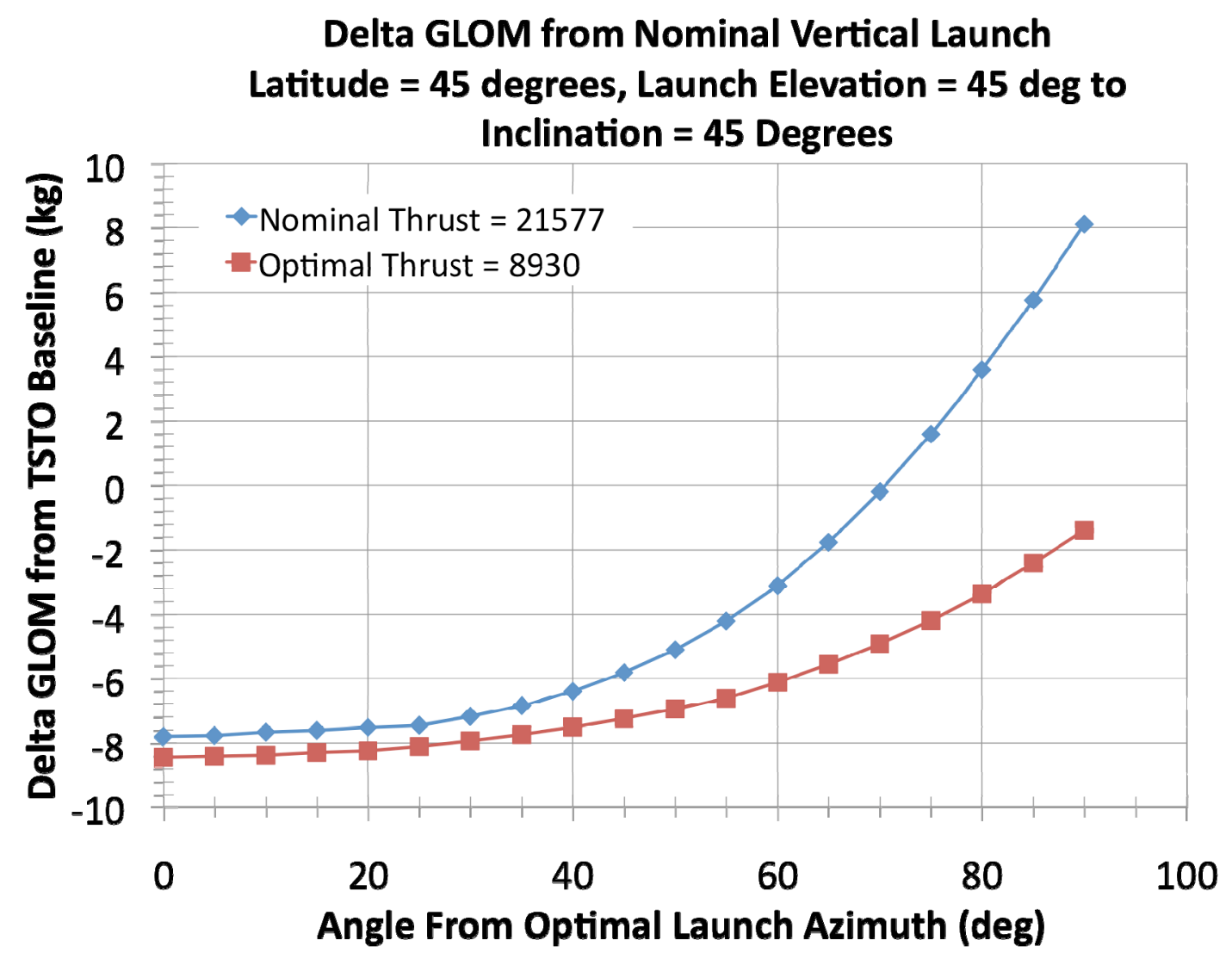

Figure 41.-TSTO delta GLOM difference for off azimuth launches using optimal thrust, based on a GLOM of $272.6 \mathrm{~kg}$.

Although the effects of using an optimized thrust are small for the baseline launch assumptions used for Figure 40 and Figure 41 shows that the effect of thrust on GLOM begins to increase when incorporated in with other vehicle sensitivities. At angles far from the optimal azimuth, the GLOM savings from the longer burn resulting from a lower, optimal, thrust grow considerably.

Figure 42 demonstrates that the GLOM reduction from Isp improvements is maintained for off azimuth launches at an almost constant reduction in GLOM. Both curves in Figure 42 were run using the same thrust value of 21,577 N further indicating that GLOM savings result from increases in Isp only. These results indicate that further study is necessary of the secondary effects on other vehicle sensitivities caused by engine parameter changes, as large additional GLOM benefits may be possible. 


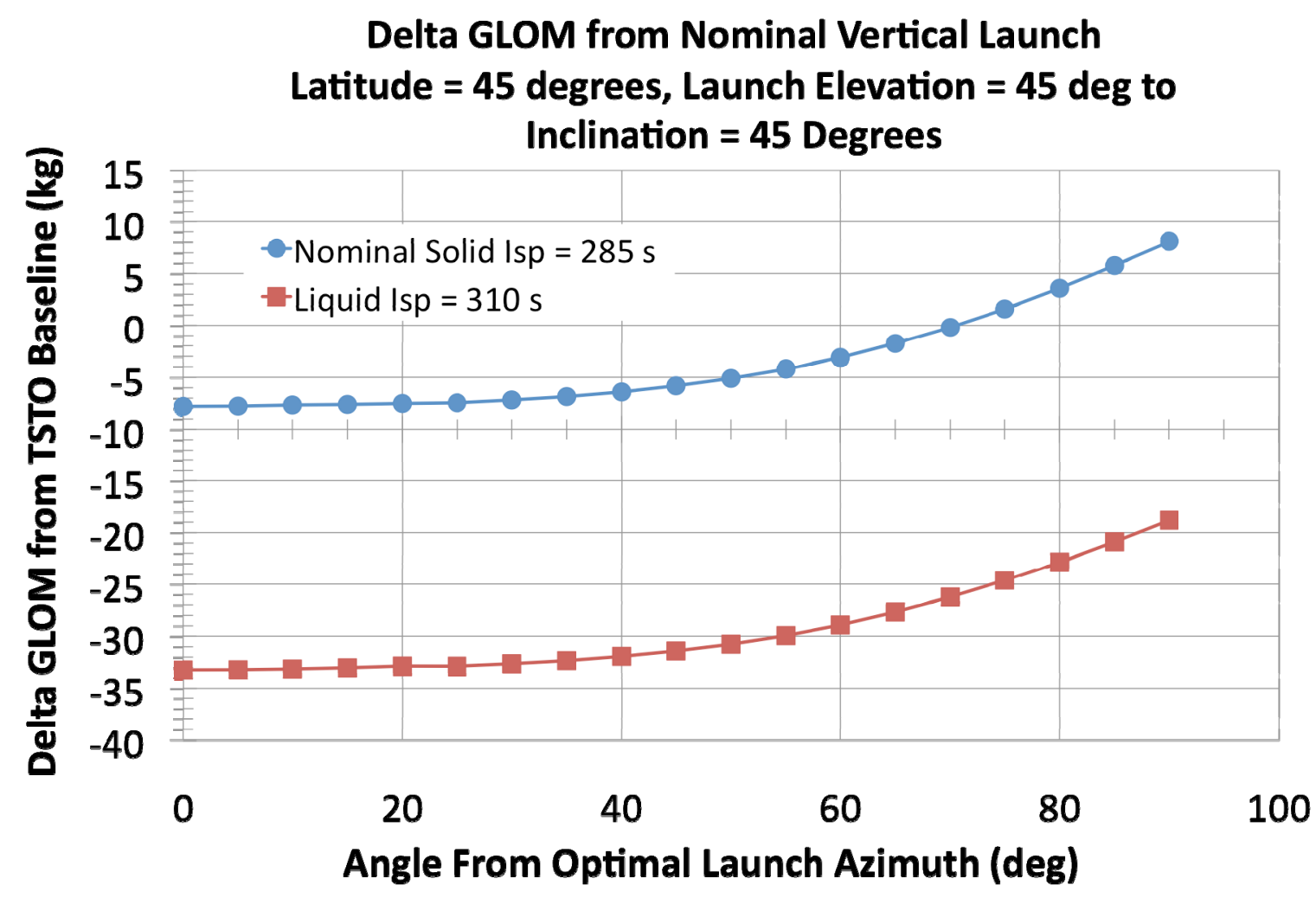

Figure 42.-TSTO delta GLOM difference for off azimuth launches using a representative liquid Isp, based on a GLOM of $272.6 \mathrm{~kg}$.

\subsection{Verification of Combined TSTO Sensitivities}

The TSTO sensitivities, as presented, all considered changes in only a maximum of three parameters at a time. Additionally sensitivities to off optimal azimuth were run only for nominal mission assumptions. The data presented in this paper is most useful if the multiple sensitivities can be combined to quickly determine GLOM predictions for numerous vehicle and mission configurations. To show the effect of doing this, cases were selected that combined various sensitivities. In some cases this included changing launch site, mission and vehicle parameters concurrently.

To complete these comparisons, the plots of GLOM sensitivity for elevation and inclination as well as those of elevation and off optimal azimuth angle were used in combination with the numerous vehicle partials identified. For each case, a set of parameters was selected to vary from their nominal values. The GLOM increase, or decrease, from TSTO baseline is then estimated using the presented vehicle sensitivities. OTIS cases were then run using the same sets of parameters to verify the GLOM predictions. Cases were not chosen at random but instead use combinations of parameters that are expected to be of some interest for the current MAV design and are intended to show the potential effects of using the sensitivities presented outside the ranges analyzed. The vehicle cases verified are shown in Table 13, with the vehicle parameters, mission parameters, predicted GLOM and the actual GLOM from OTIS. The GLOM comparisons are calculated as the actual GLOM subtracted from the predicted GLOM and then compared back to the actual GLOM as a percentage. All parameters from the baseline TSTO case are also included in Table 13 to allow comparisons of the changes made for each verification case. 


\begin{tabular}{|c|c|c|c|c|c|c|c|c|c|c|c|c|}
\hline & 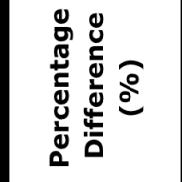 & $\because$ & $\stackrel{9}{-}$ & $\begin{array}{l}0 \\
\dot{p} \\
\dot{p}\end{array}$ & $\begin{array}{l}n \\
\text { on } \\
0\end{array}$ & 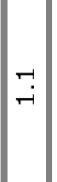 & ד. & $\begin{array}{l}\text { o. } \\
\text { in }\end{array}$ & $\begin{array}{l}\overrightarrow{1} \\
0 \\
\end{array}$ & $\begin{array}{c}\sigma \\
\infty \\
1 \\
1\end{array}$ & $\begin{array}{l}\infty \\
\sim \\
\sim\end{array}$ & $\stackrel{\imath}{0}$ \\
\hline$\frac{y}{3}$ & 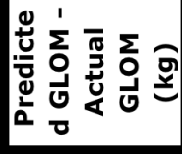 & $\stackrel{\circ}{\circ}$ & $\begin{array}{l}n \\
0 \\
0\end{array}$ & $\begin{array}{l}0 \\
0 \\
0 \\
\\
1\end{array}$ & $\stackrel{\infty}{\substack{1 \\
i}}$ & $\stackrel{q}{i}$ & $\begin{array}{c}\infty \\
\dot{p} \\
\dot{\gamma}\end{array}$ & $\begin{array}{l}\stackrel{O}{\sim} \\
\stackrel{T}{T}\end{array}$ & $\begin{array}{l}\stackrel{q}{\mathrm{j}} \\
\stackrel{p}{1}\end{array}$ & 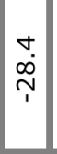 & $\stackrel{0}{\wedge}$ & $\stackrel{\infty}{\dot{N}}$ \\
\hline & 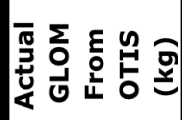 & 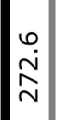 & $\begin{array}{l}\dot{t} \\
\dot{m} \\
\dot{m}\end{array}$ & r. & $\begin{array}{l}\infty \\
\infty \\
\infty \\
\dot{m}\end{array}$ & 官 & $\begin{array}{l}0 \\
\dot{\sigma} \\
\dot{m} \\
m\end{array}$ & $\begin{array}{l}\stackrel{9}{0} \\
\stackrel{n}{n}\end{array}$ & ヘิ & $\begin{array}{l}\hat{o} \\
\tilde{m}\end{array}$ & $\begin{array}{l}\stackrel{L}{N} \\
\stackrel{N}{N}\end{array}$ & $\begin{array}{l}\stackrel{\circ}{\stackrel{\leftrightarrow}{n}} \\
\stackrel{m}{m}\end{array}$ \\
\hline & 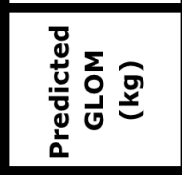 & 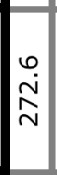 & $\begin{array}{l}\sigma \\
\dot{\sigma} \\
\dot{p} \\
m\end{array}$ & $\begin{array}{l}9 \\
\grave{D} \\
\curvearrowright\end{array}$ & $\stackrel{\stackrel{\circ}{\tilde{f}}}{\mathrm{~m}}$ & $\begin{array}{l}0 \\
\infty \\
\stackrel{\infty}{N}\end{array}$ & $\begin{array}{ll}-1 & \\
0 & 0 \\
0 & 0\end{array}$ & $\begin{array}{l}\dot{0} \\
\dot{n} \\
\end{array}$ & $\begin{array}{l}\infty \\
\stackrel{\text { N }}{\text { N }}\end{array}$ & $\begin{array}{l}m \\
\stackrel{i}{N} \\
\text { Na }\end{array}$ & & $\begin{array}{l}\infty \\
0 \\
\dot{f} \\
m\end{array}$ \\
\hline & 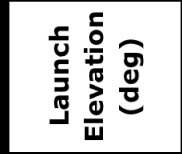 & পু & $\stackrel{m}{m}$ & $\stackrel{\mathrm{m}}{ }$ & $\stackrel{\text { p }}{ }$ & 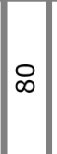 & 98 & ৪ & 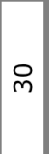 & 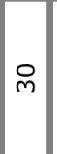 & ০ & $\stackrel{\circ}{m}$ \\
\hline 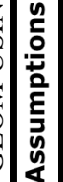 & 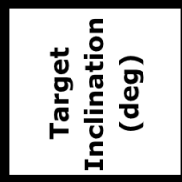 & 次 & 垨 & レ & $\stackrel{\text { p }}{ }$ & $\stackrel{\ln }{q}$ & ๒ & $\stackrel{\ln }{+}$ & $\stackrel{\text { L }}{\gamma}$ & ᄂn & $\stackrel{\circ}{m}$ & ᄂ \\
\hline$\frac{\bar{\sigma}}{\bar{y}}$ & 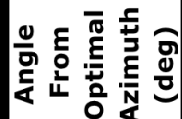 & 0 & 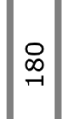 & ৪ & 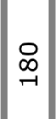 & $\underset{\infty}{\stackrel{\infty}{\infty}}$ & 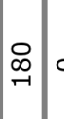 & 0 & $\begin{array}{l}\infty \\
\stackrel{\sim}{-}\end{array}$ & 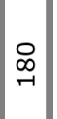 & 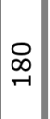 & $\stackrel{\infty}{\infty}$ \\
\hline & 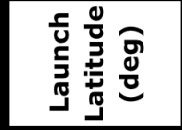 & 阜 & $\stackrel{\circ}{m}$ & $\stackrel{p}{\circ}$ & $\stackrel{\text { m }}{ }$ & 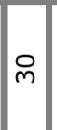 & เด ᄂ & $\stackrel{\ln }{+}$ & $\stackrel{\llcorner}{\sigma}$ & 户े & p & $\stackrel{\text { In }}{\rightarrow}$ \\
\hline & 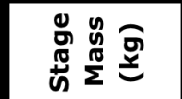 & $\begin{array}{l}\dot{v} \\
\dot{q} \\
\dot{q}\end{array}$ & $\begin{array}{l}\dot{v} \\
\dot{v} \\
\gamma\end{array}$ & $\stackrel{\dot{p}}{\dot{p}}$ & $\stackrel{\dot{v}}{\tilde{r}}$ & $\begin{array}{l}\dot{p} \\
\dot{m} \\
\dot{v}\end{array}$ & $\stackrel{\dot{v}}{\dot{g}}$ & i & 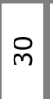 & ঃ & $\stackrel{\vec{p}}{\dot{v}}$ & $\stackrel{\vec{p}}{\dot{q}}$ \\
\hline 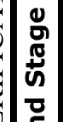 & $\begin{array}{l}0 \\
0 \\
0 \\
0\end{array}$ & 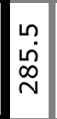 & 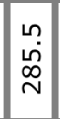 & 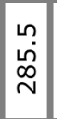 & 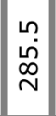 & $\begin{array}{l}n \\
\substack{n \\
\infty \\
\infty}\end{array}$ & 일 & 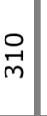 & 일 & 웅 & 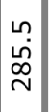 & in \\
\hline & 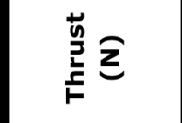 & $\begin{array}{l}0 \\
\infty \\
\infty \\
01 \\
0 \\
0\end{array}$ & $\begin{array}{l}0 \\
\infty \\
\infty \\
0 \\
0\end{array}$ & $\begin{array}{l}0 \\
\infty \\
0 \\
0 \\
0\end{array}$ & $\begin{array}{l}0 \\
\infty \\
\infty \\
01 \\
0\end{array}$ & $\begin{array}{l}\sigma \\
\infty \\
\bar{\beta} \\
\dot{c}\end{array}$ & \begin{tabular}{l|l}
0 & 0 \\
$\infty$ & 0 \\
-3 & 0 \\
0 & 0
\end{tabular} & $\begin{array}{l}0 \\
\infty \\
\\
\hat{c}\end{array}$ & $\begin{array}{l}\sigma \\
\infty \\
\overrightarrow{3} \\
0\end{array}$ & $\begin{array}{l}\sigma \\
\infty \\
0 \\
\hat{0} \\
0\end{array}$ & $\begin{array}{l}\sigma \\
\infty \\
\vec{m} \\
0\end{array}$ & $\begin{array}{l}\sigma \\
\infty \\
0 \\
0 \\
0\end{array}$ \\
\hline & 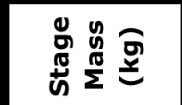 & 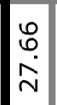 & 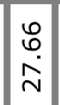 & $\begin{array}{l}8 \\
\stackrel{0}{N} \\
\grave{N}\end{array}$ & $\begin{array}{l}8 \\
\stackrel{N}{N}\end{array}$ & 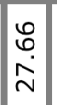 & $\begin{array}{l}\stackrel{0}{0} \\
\stackrel{\sim}{N}\end{array}$ & 우 & ㅇ & 우 & 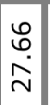 & $\begin{array}{l}8 \\
\dot{1} \\
\end{array}$ \\
\hline 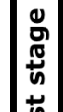 & $\begin{array}{l}0 \\
0 \\
0 \\
n \\
n\end{array}$ & $\begin{array}{l}\hat{N} \\
\infty \\
\infty \\
\sim\end{array}$ & $\begin{array}{l}\hat{N} \\
\infty \\
\infty \\
\sim\end{array}$ & $\begin{array}{l}\hat{\omega} \\
\infty \\
\sim \\
\sim\end{array}$ & 峁 & 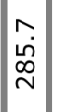 & $\stackrel{0}{m}$ & $\begin{array}{l}\text { 을 } \\
\text { m }\end{array}$ & $\begin{array}{l}\text { 음 } \\
\text { m }\end{array}$ & 을 & $\begin{array}{l}\hat{N} \\
\text { ஸे } \\
\stackrel{D}{N}\end{array}$ & $\begin{array}{l}\hat{N} \\
\infty \\
\infty \\
N\end{array}$ \\
\hline & 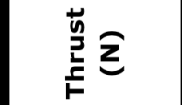 & $\stackrel{\hat{n}}{\hat{N}}$ & $\begin{array}{l}\hat{N} \\
\hat{n} \\
\end{array}$ & $\begin{array}{l}\hat{\imath} \\
\hat{n} \\
\vec{n}\end{array}$ & $\begin{array}{c}\hat{n} \\
\stackrel{n}{n}\end{array}$ & $\begin{array}{l}\hat{n} \\
\hat{n} \\
i\end{array}$ & 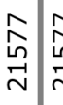 & مิ & $\begin{array}{l}\hat{N} \\
\stackrel{n}{N}\end{array}$ & $\begin{array}{c}\hat{N} \\
\hat{\omega} \\
\stackrel{N}{n}\end{array}$ & $\begin{array}{l}\hat{N} \\
\stackrel{n}{N}\end{array}$ & $\begin{array}{l}\text { ㅇ } \\
\text { m }\end{array}$ \\
\hline & 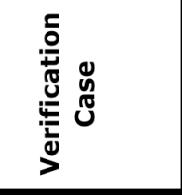 & 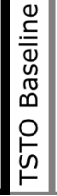 & $\begin{array}{l}-1 \\
\mathbb{u} \\
心 \\
心 \\
0\end{array}$ & 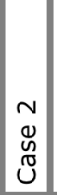 & $\begin{array}{l}m \\
0 \\
心 \\
心 \\
心\end{array}$ & 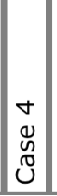 & 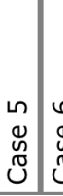 & $\begin{array}{l}0 \\
\mho\end{array}$ & $\ddot{u}$ & \begin{tabular}{l|l|}
$\infty$ \\
0 \\
0 \\
$心$ \\
0
\end{tabular} & $\begin{array}{l}a \\
0 \\
心 \\
心 \\
\tilde{J}\end{array}$ & 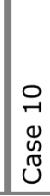 \\
\hline
\end{tabular}


When nominal thrust and Isp values are used, the results demonstrate that for launches under a latitude of $45^{\circ}$, off azimuth GLOM predictions using performance sensitivities match within approximately 5 percent of the actual GLOM. When thrust and Isp variations are combined with off optimal azimuth angles, predictions are off by larger amounts, but still match within approximately 10 percent of the actual GLOM. It is clear that additional study of off azimuth results at all possible launch latitudes is necessary to establish more accurate predictions. GLOM savings are observed for using lower Isp and thrust values for all launch conditions. As already discussed, the engine sensitivities established for the baseline TSTO case do not directly apply when baseline mission and launch conditions are changed as shown in Figure 41 and Figure 42. This is due to the changes in burn times that occur with changing engine parameters, which cannot be easily predicted. If engine improvements are considered, additional studies of off nominal launches need to be analyzed in further detail. Overall these results demonstrate that the off azimuth GLOM sensitivities, run at a $45^{\circ}$ latitude, provide a good preliminary estimate of off azimuth GLOM growth at lower latitudes. However, caution is advised for application of performance sensitivities at latitudes close to the equator and in cases that use large changes in thrust and Isp.

\subsection{Nominal Mission Availability for a MAV Designed for Off Nominal Launch Conditions}

To cover off nominal launches, the MAV will be designed with a GLOM large enough to cover a wide variety of launch and mission conditions. The possibility exists that a large GLOM MAV could still land in an optimal launch configuration, making it necessary for it to provide only enough performance for the baseline mission. To verify that a large GLOM MAV can fly a baseline mission, propellant masses from two verification cases, shown in Table 14, were run using the baseline mission and launch site assumptions as described in Table 4. The assumption was maintained that a solid rocket system was used, such that the burn could not be cut off early. Three-angle control was allowed and launch at the optimal launch azimuth was assumed. In all cases, a control scheme could be found in OTIS that allows the vehicle to waste the extra performance and achieve nominal mission targets with a mass equal to the payload and second stage dry mass. Figure 43 through Figure 45 show the selected cases compared to the TSTO baseline in geodetic altitude, inertial velocity, inertial Euler pitch and inertial Euler yaw control angles. All plots show large differences that are a result of OTIS bleeding off extra performance to accomplish a nominal mission. This analysis clearly demonstrates that the MAV can be designed for the worst possible launch conditions while maintaining the ability to launch at more optimal launch orientations.

TABLE 14.--LARGE GLOM VERIFICATION CASES

\begin{tabular}{|l|c|c|c|c|c|c|c|}
\hline $\begin{array}{c}\text { Verification } \\
\text { case }\end{array}$ & $\begin{array}{c}\text { Launch } \\
\text { latitude, } \\
\text { deg }\end{array}$ & $\begin{array}{c}\text { Angle from } \\
\text { optimal } \\
\text { azimuth, } \\
\text { deg }\end{array}$ & $\begin{array}{c}\text { Target } \\
\text { inclination, } \\
\text { deg }\end{array}$ & $\begin{array}{c}\text { Launch } \\
\text { elevation, } \\
\text { deg }\end{array}$ & $\begin{array}{c}\text { Gross } \\
\text { liftoff } \\
\text { mass, } \\
\mathrm{kg}\end{array}$ & $\begin{array}{c}\text { Stage 1 } \\
\text { propellant, } \\
\mathrm{kg}\end{array}$ & $\begin{array}{c}\text { Stage 2 } \\
\text { propellant, } \\
\mathrm{kg}\end{array}$ \\
\hline Case 1 & 30 & 180 & 45 & 30 & 343.4 & 203.0 & 66.4 \\
\hline Case 4 & 30 & 180 & 45 & 80 & 275.1 & 152.7 & 48.3 \\
\hline
\end{tabular}




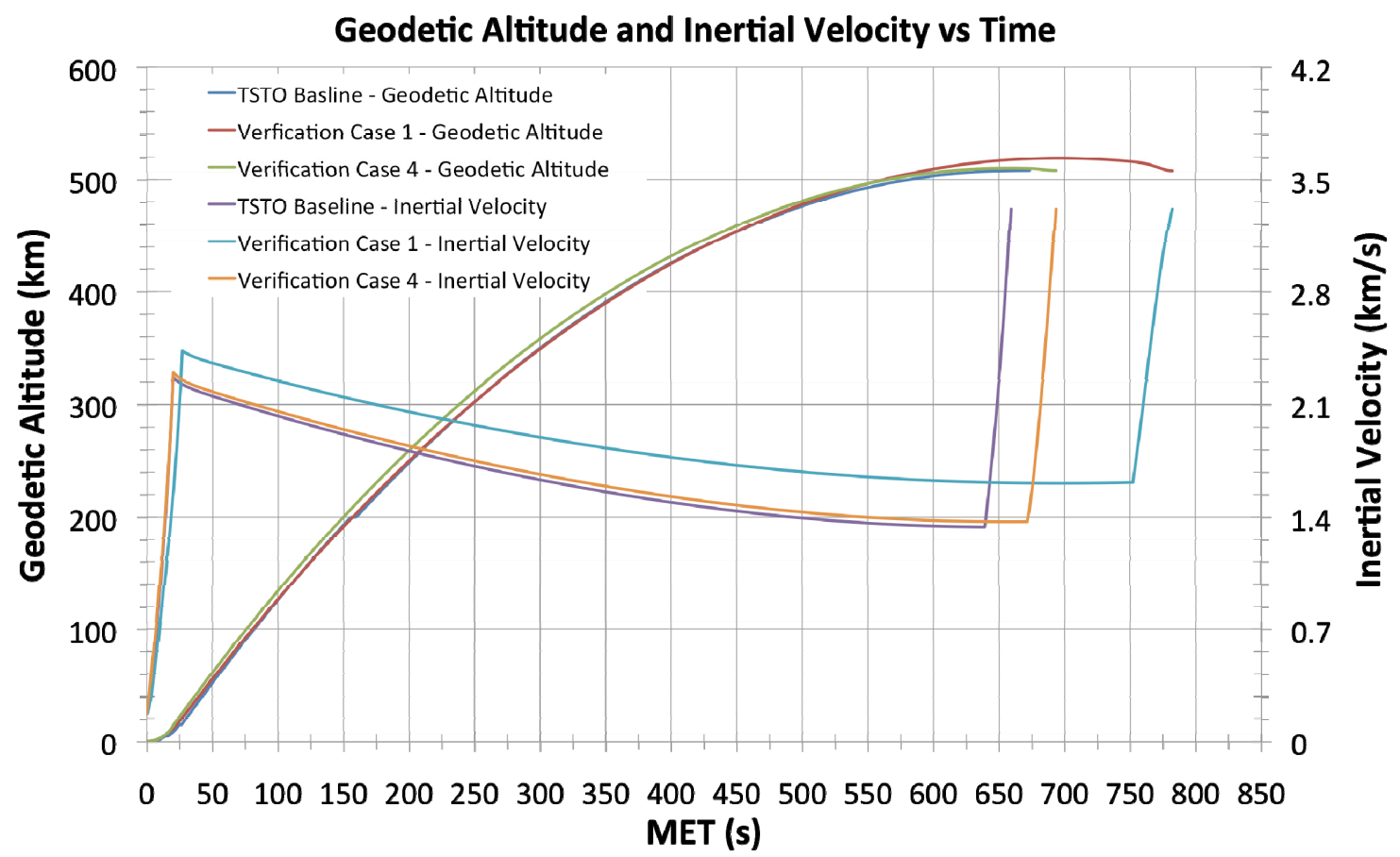

Figure 43.-Geodetic altitude and inertial velocity of large GLOM MAV, flown on a nominal mission.

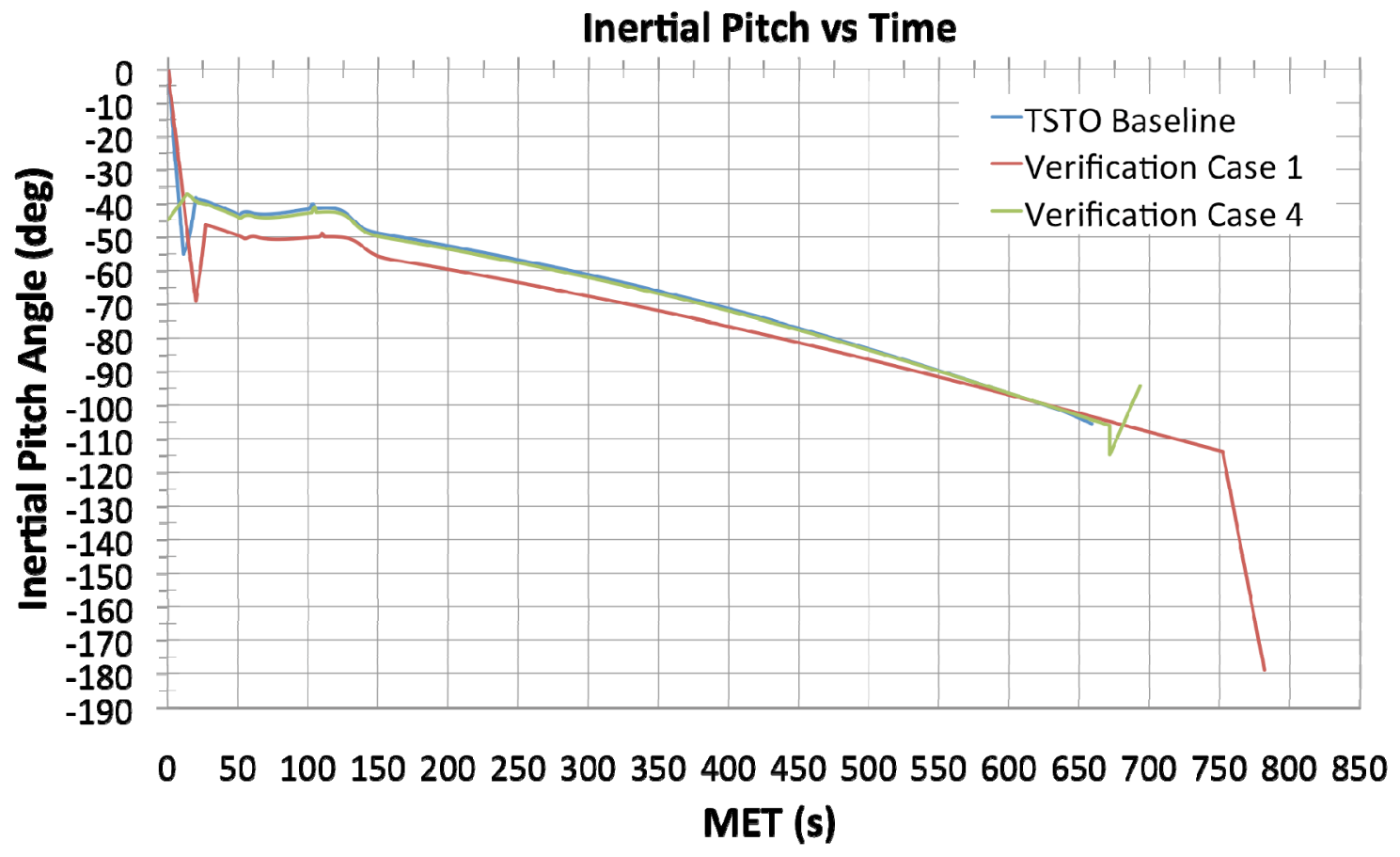

Figure 44.- Inertial Euler pitch history of large GLOM MAV, flown on a nominal mission. 


\section{Inertial Yaw vs Time}

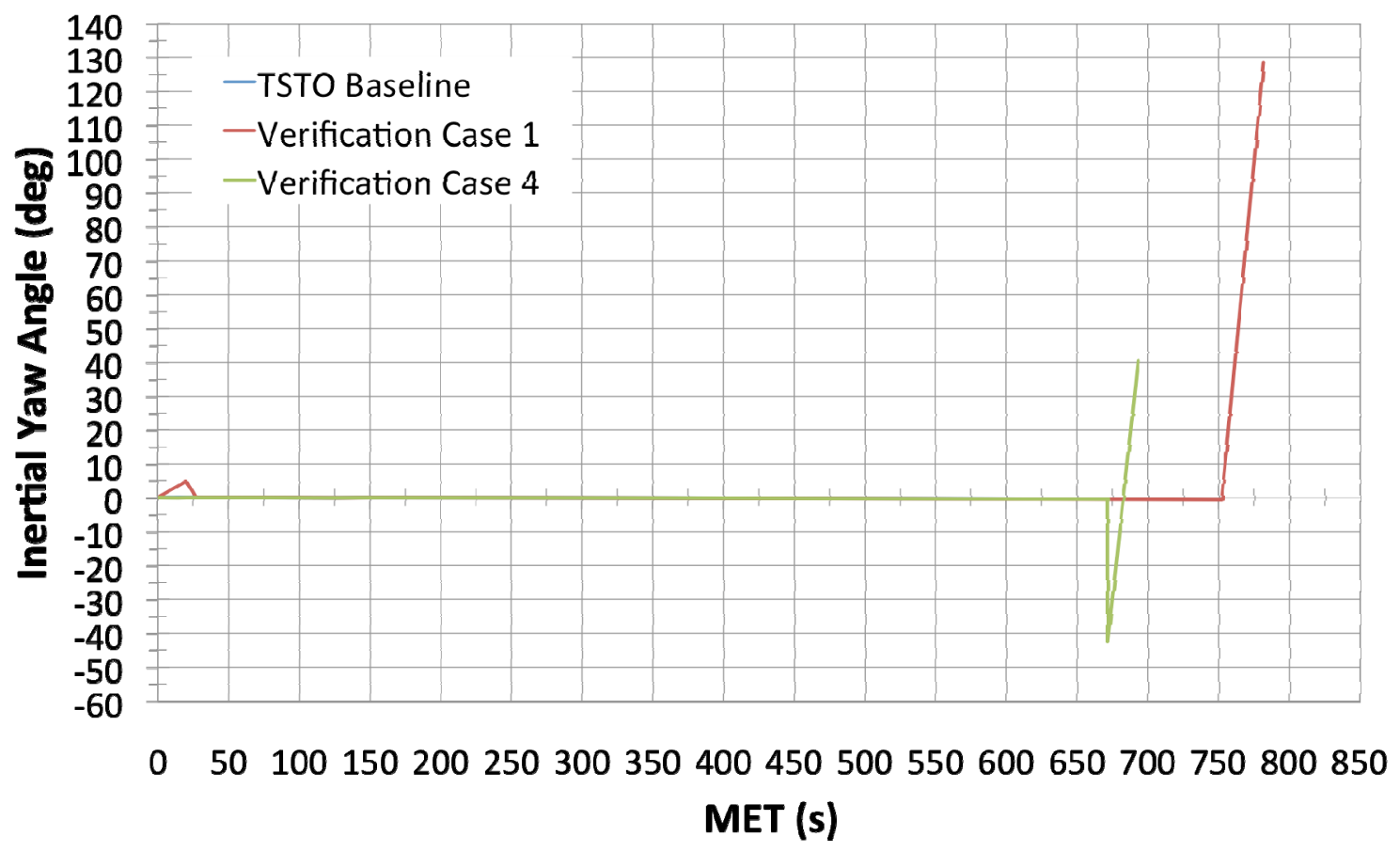

Figure 45.--Inertial Euler yaw history of large GLOM MAV, flown on a nominal mission.

\subsection{SSTO Performance Sensitivities}

\subsection{Engine Thrust and Isp}

Only a small subset of the TSTO sensitivities were run for the SSTO vehicle. This was done to get a better understanding of the validity of using a SSTO for this mission, without committing resources to a study of the full set of launch site sensitivities analyzed for the current baseline TSTO design. The SSTO baseline description noted that thrust optimization was used to establish the SSTO baseline. In addition to the optimal thrust value of 4425 Newtons, the SSTO GLOM corresponding to thrust values up to the TSTO baseline of 21576 Newtons were calculated. Results are shown for a trajectory without wind modeling as the curve with diamond markers in Figure 46. All points in Figure 46 were run by varying thrust only, with all other vehicle parameters, launch conditions and mission targets set to SSTO baseline values as described in Table 5, Table 6, and Table 7. Additionally, GLOM sensitivities over the same thrust range were completed using the wind profile modeled in the TSTO case with results in Figure 46 plotted with square markers.

Three important conclusions are drawn from this data. First, is that the difference in GLOM with and without wind modeling over the same thrust range is less than $0.5 \mathrm{~kg}$. Using an optimized thrust for the SSTO case a larger GLOM reduction is observed when compared to the TSTO thrust sensitivities. For the TSTO case, shown in Figure 40, a reduction in GLOM of approximately $4.4 \mathrm{~kg}$ is observed when using an optimized thrust value. Figure 46 clearly shows that for the SSTO case, the use of an optimal thrust value reduces GLOM by $21.6 \mathrm{~kg}$, almost five times the TSTO results. Although an overall optimal thrust was established, which corresponds to the minimum GLOM SSTO case, the curve is very flat near this optimal thrust with only $0.4 \mathrm{~kg}$ of GLOM growth at thrust level up to $5300 \mathrm{~N}$. This allows for a broader array of thrust design solutions, with minimal penalty to GLOM. This has important design ramifications for the SSTO design. If a near optimal thrust vehicle design cannot be used for an SSTO MAV, a significant increase in GLOM would be necessary. 


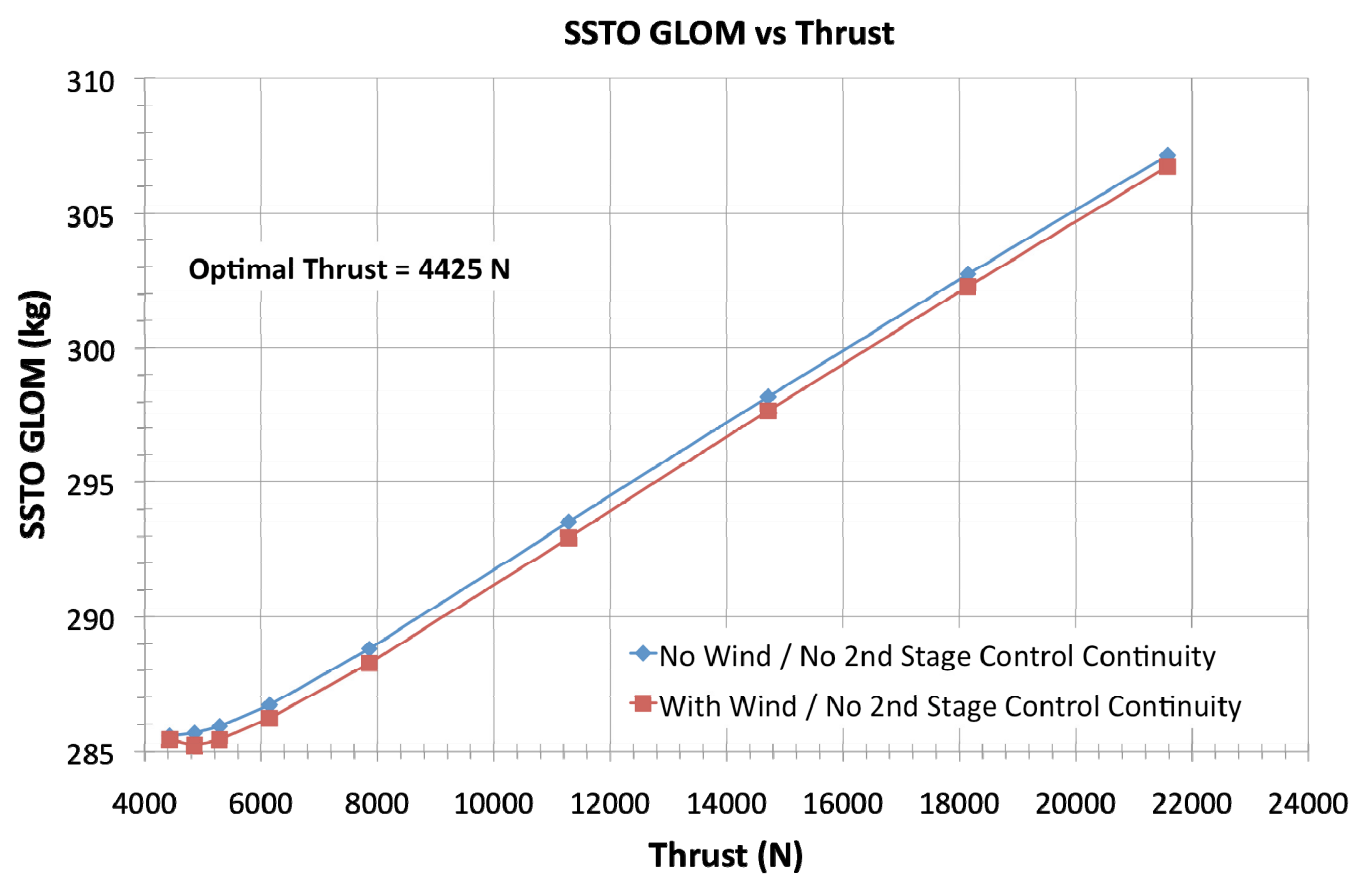

Figure 46.-SSTO GLOM sensitivity to thrust with and without wind modeling.

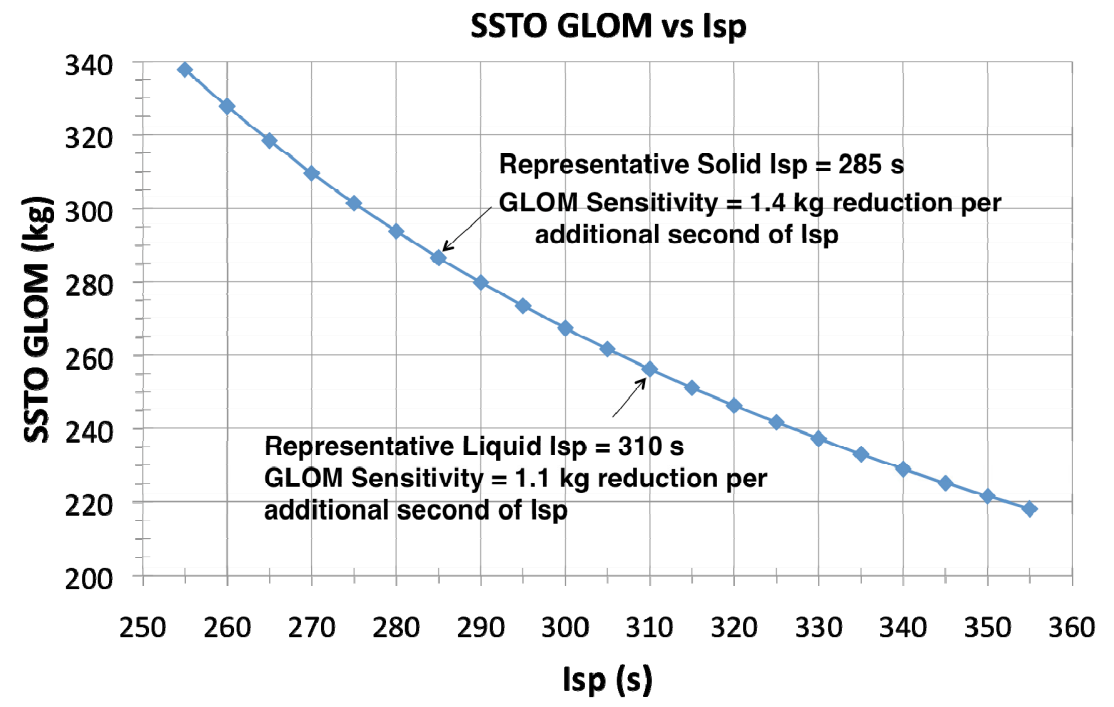

Figure 47.-SSTO GLOM sensitivity to engine Isp.

GLOM values for variations in Isp were also calculated; again holding thrust at the optimal values with all other vehicle parameters set to the SSTO baseline values. Figure 47 shows GLOM sensitivities to Isp from 255 to $355 \mathrm{sec}$. Similar to the TSTO Isp sensitivity two average Isp values were established for solid and liquid systems: 285 for solid motors and $310 \mathrm{sec}$ for liquid rocket systems. Around these Isp values, approximate linear slopes were established with $1.4 \mathrm{~kg}$ of GLOM reduction found for every second of solid motor Isp increase and $1.1 \mathrm{~kg}$ of GLOM reduction predicted for every second of liquid rocket engine Isp increase. These values are very similar to the TSTO Isp results and are important to note that GLOM reductions possible may allow higher Isp engines to trade very well into the MAV system. 


\subsection{Stage Mass Sensitivities}

The SSTO stage mass, including payload fairing, was varied between an absolute minimum of $25 \mathrm{~kg}$ to a maximum of $70 \mathrm{~kg}$. As in other sensitivities, all other parameters were held to SSTO baseline values. A linear trend of approximately $3.9 \mathrm{~kg}$ of GLOM growth per $\mathrm{kg}$ of additional dry stage mass was calculated and shown in Figure 48.

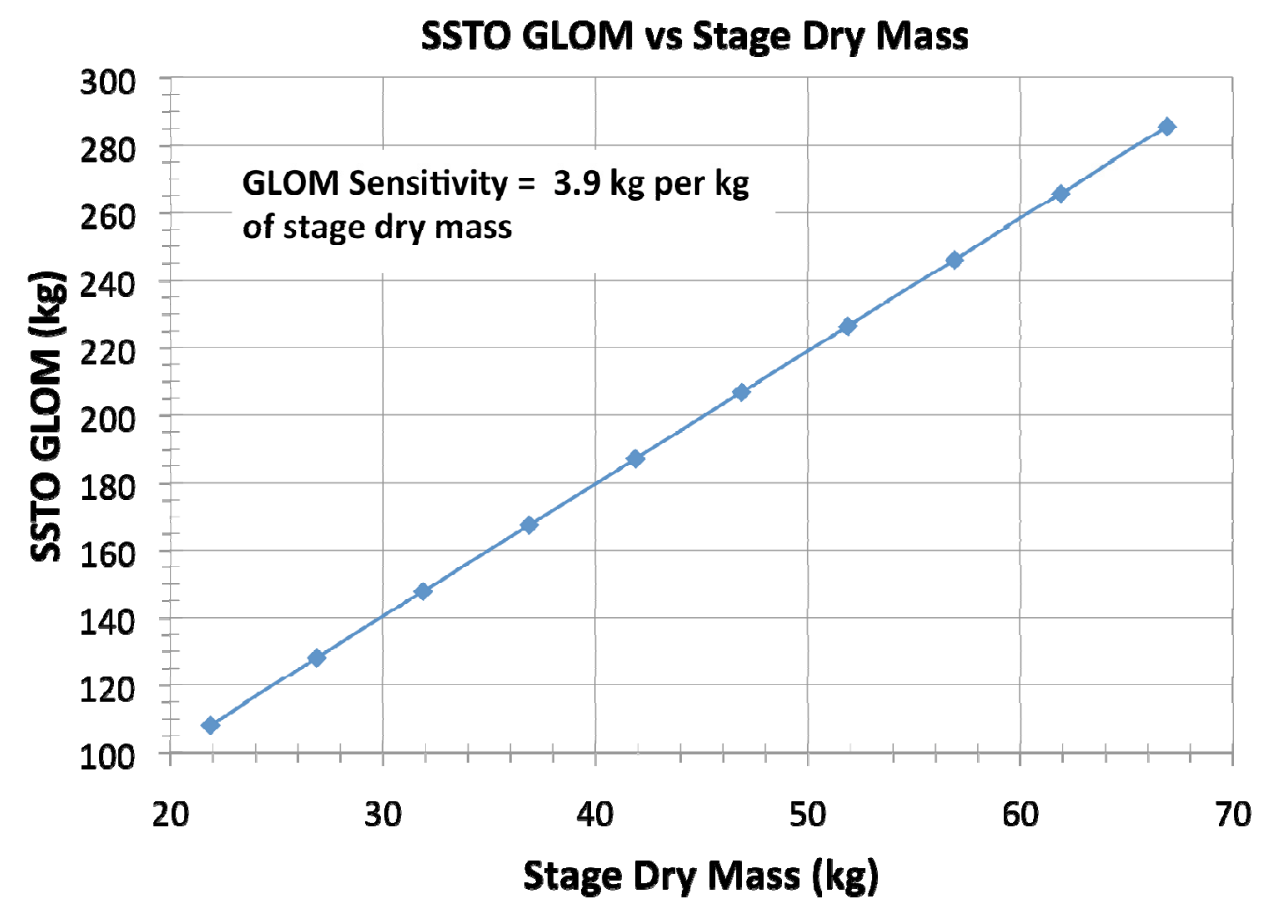

Figure 48.-SSTO GLOM sensitivity to dry mass.

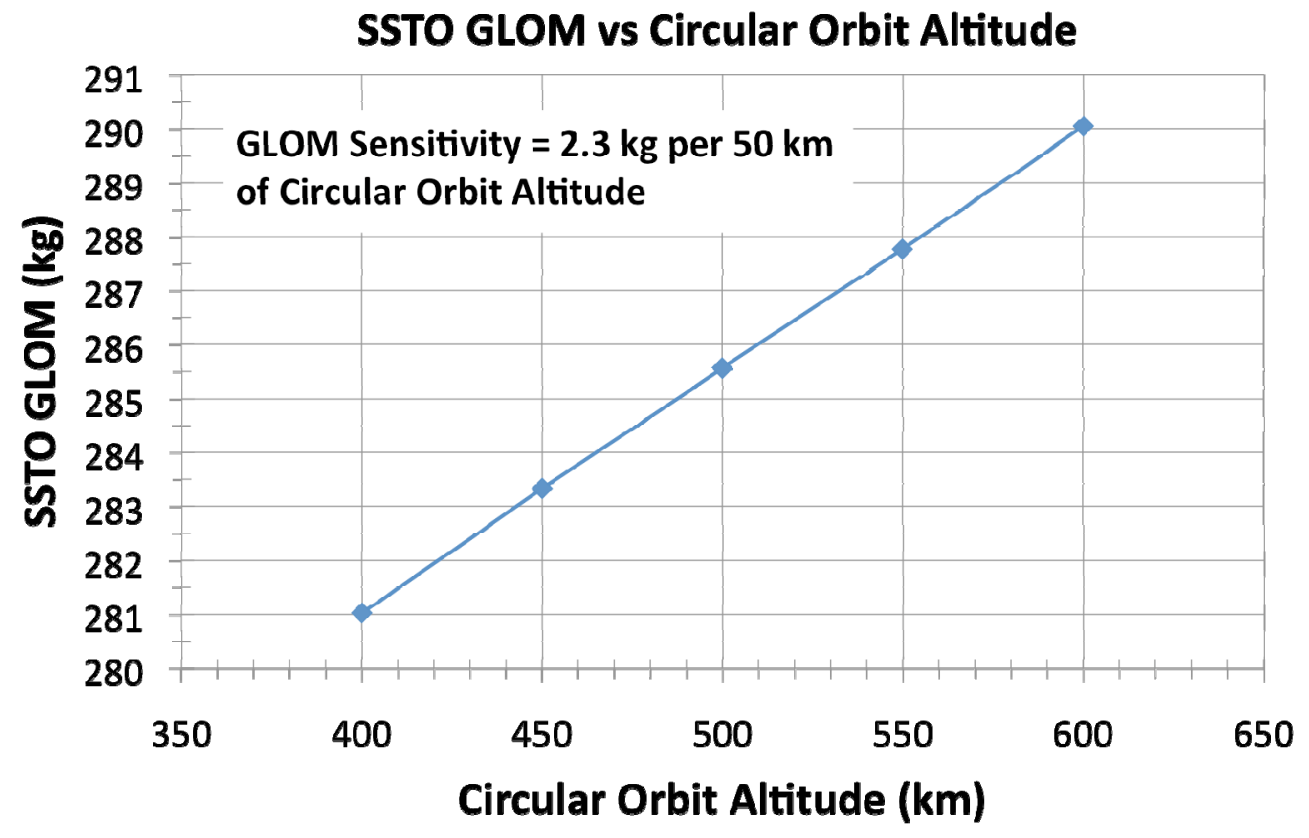

Figure 49.-SSTO GLOM sensitivity to circular orbit altitude. 


\subsection{Circular Orbit Altitude Sensitivity}

The circular orbit altitude trade was run for the SSTO vehicle design, to determine the additional benefit of using a SSTO design in combination with a lower altitude circular orbit. The results, found in Figure 49, show that the sensitivity of the SSTO design to circular orbit altitude is smaller than that of the TSTO design. A slope was calculated of approximately $2.3 \mathrm{~kg}$ of GLOM for every $50 \mathrm{~km}$ of additional orbital altitude, compared to the $5.1 \mathrm{~kg}$ slope for the TSTO vehicle. This difference is largely due to the lower thrust used in the SSTO case, allowing for adjustments in the trajectory to be made without large changes in the SSTO GLOM.

\subsection{Conclusions}

A large number of vehicle sensitivities were completed for both the TSTO and SSTO MAV designs. When possible simple numerical sensitivities, commonly referred to as vehicle partial derivatives, were established to directly relate GLOM growth with the design parameter of interest. These design relationships have been highlighted throughout this paper and are summarized below for the TSTO and SSTO vehicles in Table 15.

Two areas of the MAV trade space were found to have very little effect on the resulting vehicle GLOM: launch latitude for inclination targets greater than that latitude (when using an optimized launch azimuth) and the second stage engine thrust for the TSTO orbit vehicle. While other vehicle parameters cannot be classified as insensitive, the results show very small GLOM growth over the ranges analyzed. This is the case for GLOM growth due to circular orbit altitude in both the TSTO and SSTO vehicle designs. The TSTO GLOM also shows very little effect over a large range of first stage thrust values. This allows for a wide range of thrust solutions for either stage of the TSTO MAV design.

The greatest impact to GLOM is observed in the launch site orientation sensitivities run for the TSTO vehicle. If azimuth cannot be controlled within a small range around the optimal launch azimuth, large growth in GLOM can be expected for off azimuth cases unless a near vertical launch can be guaranteed. It is also obvious from the relationships presented in Table 15 that the system mass and propulsion performance of the MAV could also have a large effect on GLOM, especially if large changes from the current baseline are made.

TABLE 15.-MAV QUANTITATIVE VEHICLE SENSITIVITIES

\begin{tabular}{|c|c|}
\hline TSTO Vehicle Design Sensitivities: \\
$\circ$ & Approximately $5.1 \mathrm{~kg}$ of GLOM increase per $50 \mathrm{~km}$ of circular orbit \\
$\circ$ & Approximately $4.6 \mathrm{~kg}$ of GLOM increase per kg of second stage dry mass \\
$\circ$ & Approximately $1.9 \mathrm{~kg}$ of GLOM increase per kg of first dry stage \\
$\circ$ & Approximately $2.7 \mathrm{~kg}$ of GLOM decrease per $\mathrm{kg}$ of second stage dry mass shifted to the first stage \\
$\circ$ & Approximately $0.23 \mathrm{~kg}$ of GLOM per $10^{\circ}$ of launch latitude, for constant launch elevation angle \\
and constant target inclination
\end{tabular}




\subsection{System Implications}

The primary intention of the results presented was to help guide decisions on the investments necessary to produce a MAV capable of launching in a variety of conditions and still remain small enough to fit into the landed mass restrictions. As these sensitivities were completed, the authors have developed a set of recommendations that could allow GLOM savings and still support a variety of launch site locations and conditions.

First, if the landing system can guarantee the launch azimuth within approximately $40^{\circ}$ of the optimal launch azimuth, the MAV should be designed to launch at a $45^{\circ}$ elevation and incorporate the resulting reduction in GLOM. A change in the baseline launch elevation to $45^{\circ}$, from vertical, could result in additional benefits to the launch platform as a $45^{\circ}$ launch angle may be easier to achieve. It should be noted, that if azimuth cannot be guaranteed within $40^{\circ}$ but could be guaranteed to within approximately $70^{\circ}$ of the optimal launch azimuth, a $45^{\circ}$ launch elevation could be used while maintaining the current TSTO baseline mass. If azimuth restrictions are not possible, a launch elevation near $90^{\circ}$ is necessary to minimize GLOM growth.

The current analysis demonstrates the impact of launching at elevations of up to $30^{\circ}$ from the design point. Due to the large GLOM variations that result from changes in launch elevation, it is recommended that launch elevation accuracy be restricted to approximately $10^{\circ}$ from the design point. This would allow additional GLOM savings and provide more flexibility in the launch azimuth constraints necessary to utilize a lower baseline launch elevation.

The final recommendation is related to the physical design of the TSTO MAV. Functionality could be moved from the second stage to the first with a GLOM savings of $2.7 \mathrm{~kg}$ per kilogram moved with no impact to performance due to the ability to jettison the first stage just before second stage ignition. Reconfiguring the distribution of important systems between both stages, could allow significant GLOM savings without a major change to the current MAV propulsion and mission assumptions.

\subsection{Future Work}

Further work is needed in three key areas to refine the current data: MAV body control rate limits, TSTO nonoptimal azimuth launches at low latitudes and SSTO launch orientation sensitivities. The existing 2001 TSTO baseline design, utilized body control rates of $20^{\circ}$ per second; a rate believed to be unsuitable for the current vehicle design. For the sensitivities presented in this paper a $5^{\circ}$ per second body control rate was assumed, as it is currently well within historically used limits. However, it was shown that off azimuth GLOM sensitivities could be mitigated to some extent with the use of a higher body control rate. Therefore, a more detailed study is necessary to determine what control rates could be used for MAV. It would be necessary to model the MAV using a six-degree of freedom simulation, which would allow the interaction of a gimbaled engine with the relatively small MAV to be studied in greater detail. With a six-degree of freedom model, differing vehicle body rates could be imposed to determine when, and if, the MAV becomes uncontrollable or exceeds structural design limits.

The verification results presented indicate that further study of nonoptimal azimuth launches at lower launch latitudes is required to more accurately predict GLOM trends. This would include further analysis using the models already completed for this study and a more extensive trade matrix of inclination and launch latitudes for the off azimuth angles analyzed. The current data provides an adequate initial GLOM estimate for launches at latitudes lower than $45^{\circ}$, but does not incorporate all necessary effects of launching from those latitudes. This is especially true if a higher Isp or lower thrust MAV design is under consideration, as errors could grow quite high for off optimal azimuth launches due to differences in burn time caused by engine parameters changes. 
Finally, if the SSTO vehicle design is to be strongly considered, launch site and launch orientation sensitivities need to be completed similar to those shown here for the TSTO design. These could be completed with the previously developed models using the analysis methodology described for the TSTO sensitivities. It is assumed that trends will be similar to the TSTO design, but the magnitude of SSTO GLOM growth could far exceed the TSTO design for some cases. 



\section{Appendix A.-Gross Lift-off Mass Sensitivities for Launch Elevations From $0^{\circ}$ to $90^{\circ}$ Targeting Inclinations from $0^{\circ}$ to $90^{\circ}$ for \\ Launch Latitudes From $0^{\circ}$ to $90^{\circ}$}

\section{TSTO GLOM vs Inclination for All Launch Elevations \\ Launch Latitude $=\mathbf{5} \mathrm{deg}$}

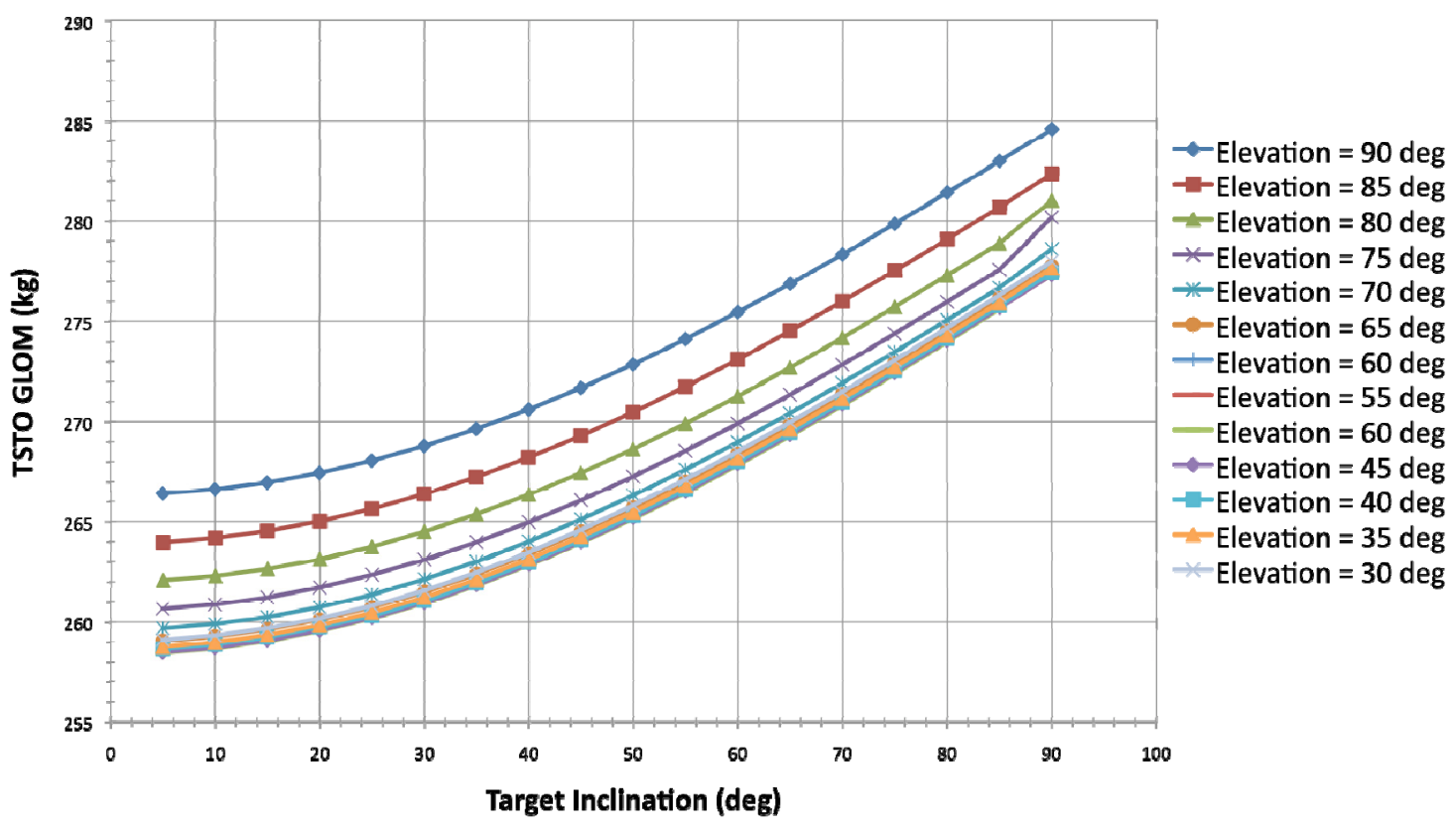

Figure 50.-TSTO GLOM sensitivities for a launch latitude of $5^{\circ}$.

\section{TSTO GLOM vs Inclination for All Launch Elevations Launch Latitude $=10 \mathrm{deg}$}

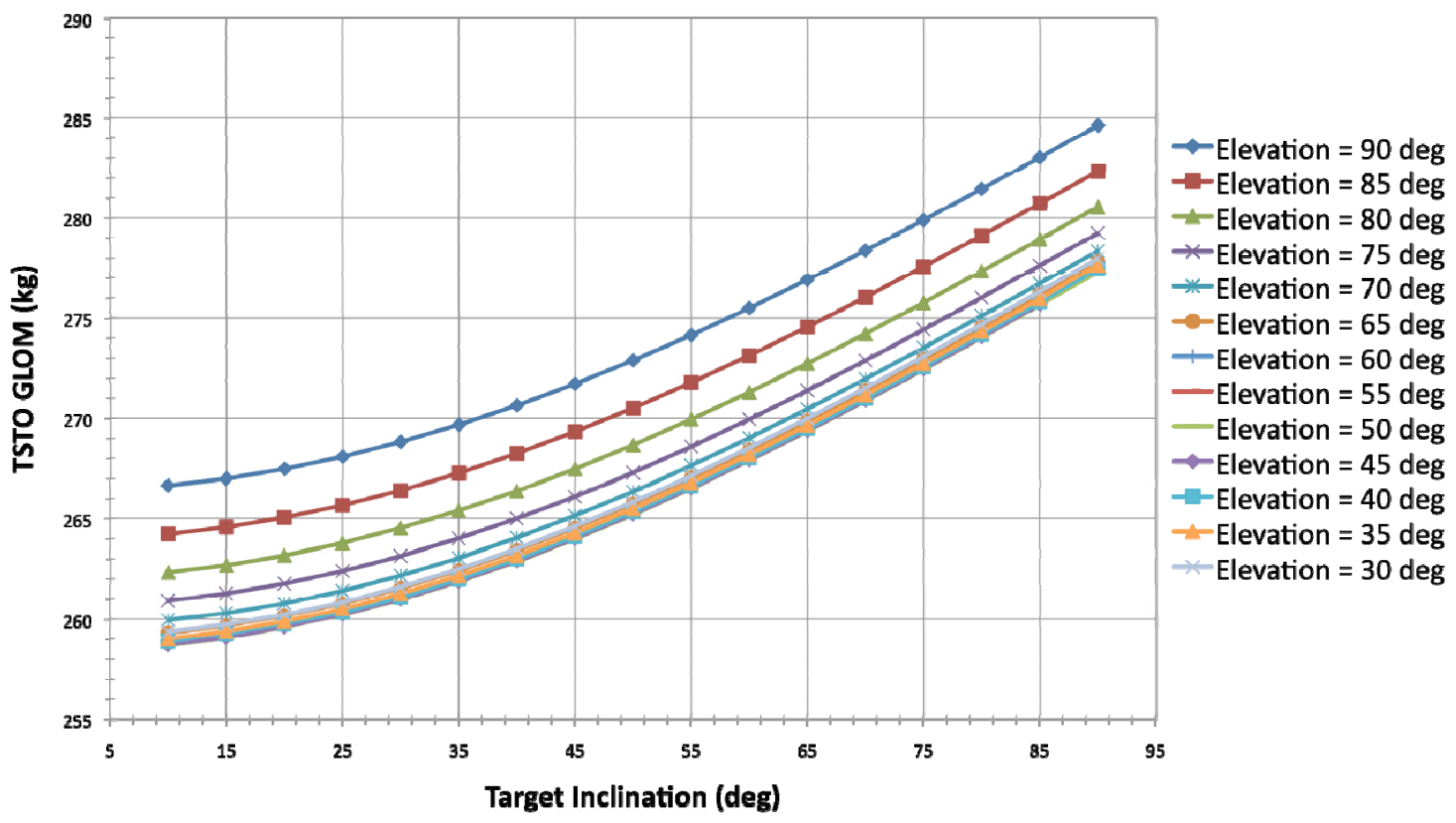

Figure 51.-TSTO GLOM sensitivities for a launch latitude of $10^{\circ}$. 


\section{TSTO GLOM vs Inclination for All Launch Elevations Launch Latitude $=15 \mathrm{deg}$}

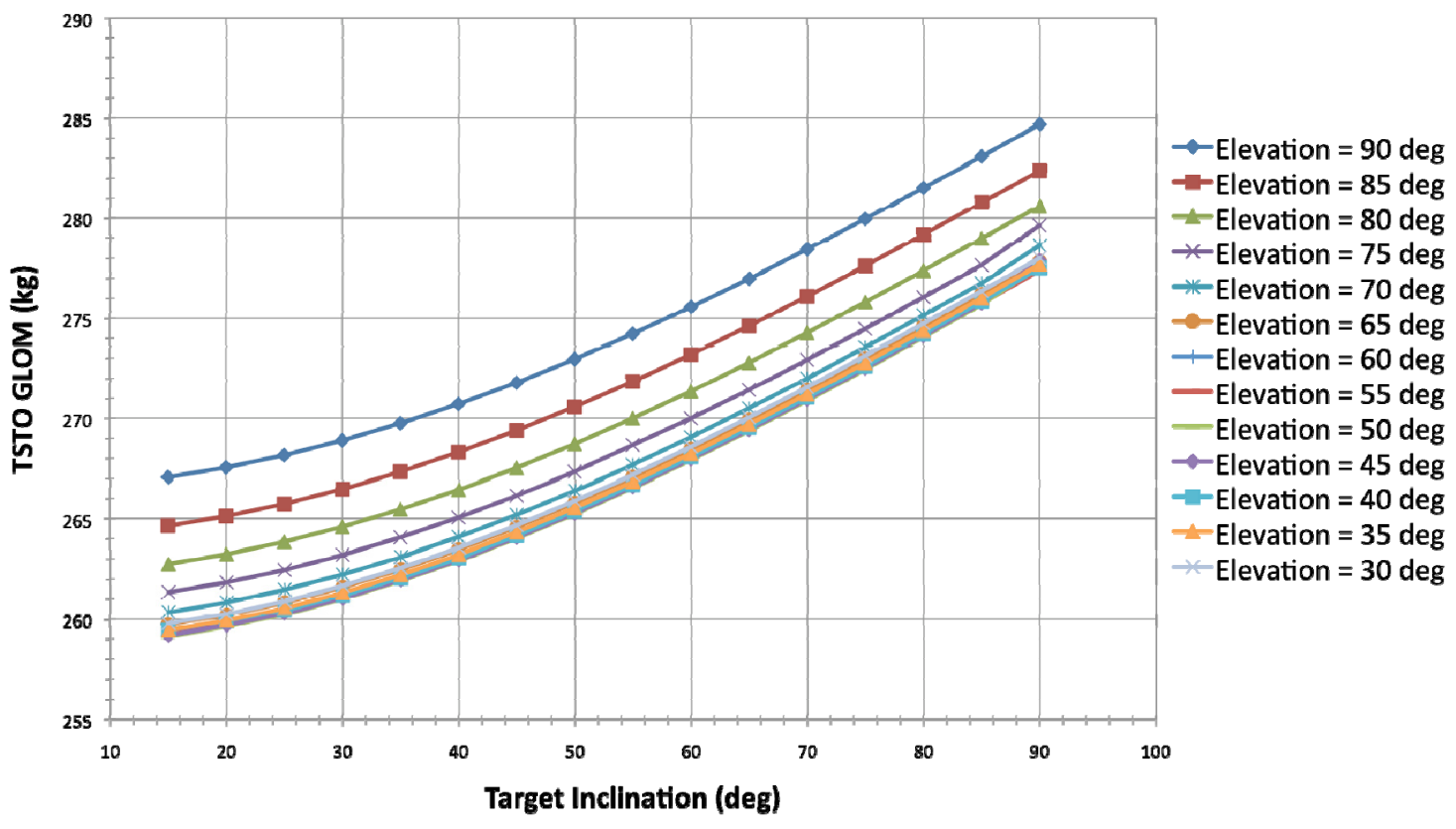

Figure 52.-TSTO GLOM sensitivities for a launch latitude of $15^{\circ}$.

\section{TSTO GLOM vs Inclination for All Launch Elevations Launch Latitude $=\mathbf{2 0} \mathrm{deg}$}

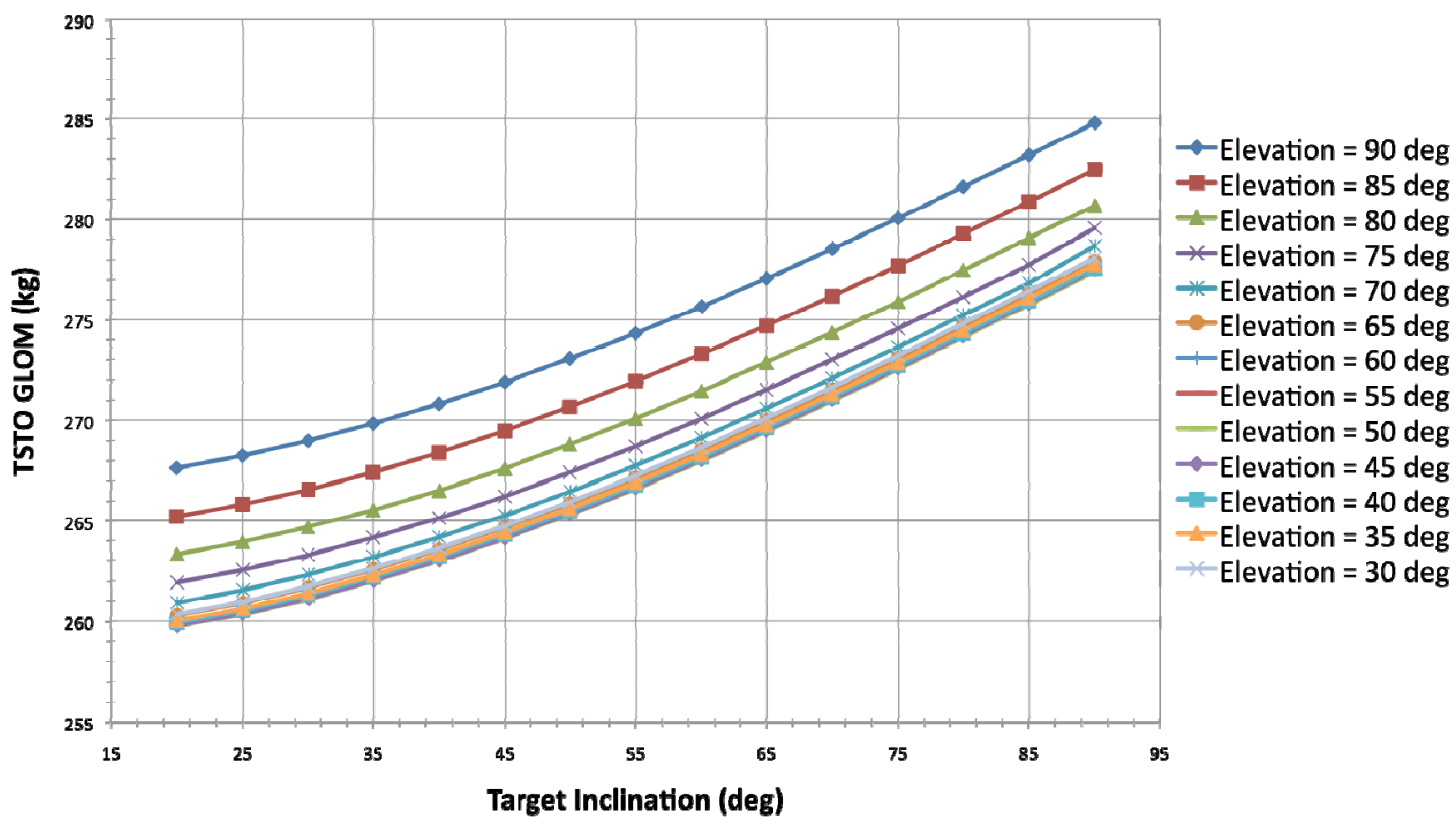

Figure 53.-TSTO GLOM sensitivities for a launch latitude of $20^{\circ}$. 


\section{TSTO GLOM vs Inclination for All Launch Elevations Launch Latitude = $25 \mathrm{deg}$}

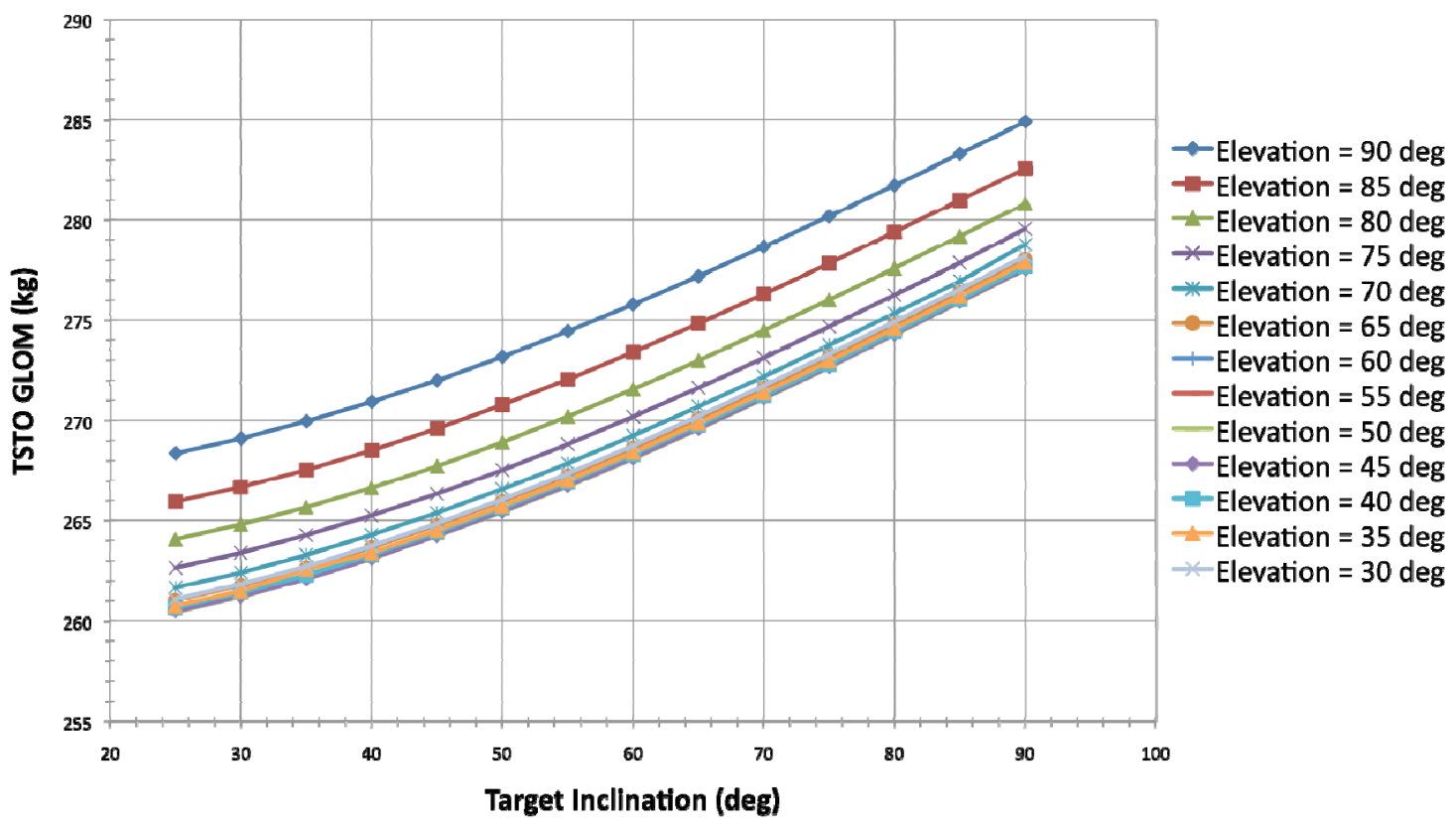

Figure 54.-TSTO GLOM sensitivities for a launch latitude of $25^{\circ}$.

\section{TSTO GLOM vs Inclination for All Launch Elevations Launch Latitude $=\mathbf{3 0} \mathrm{deg}$}

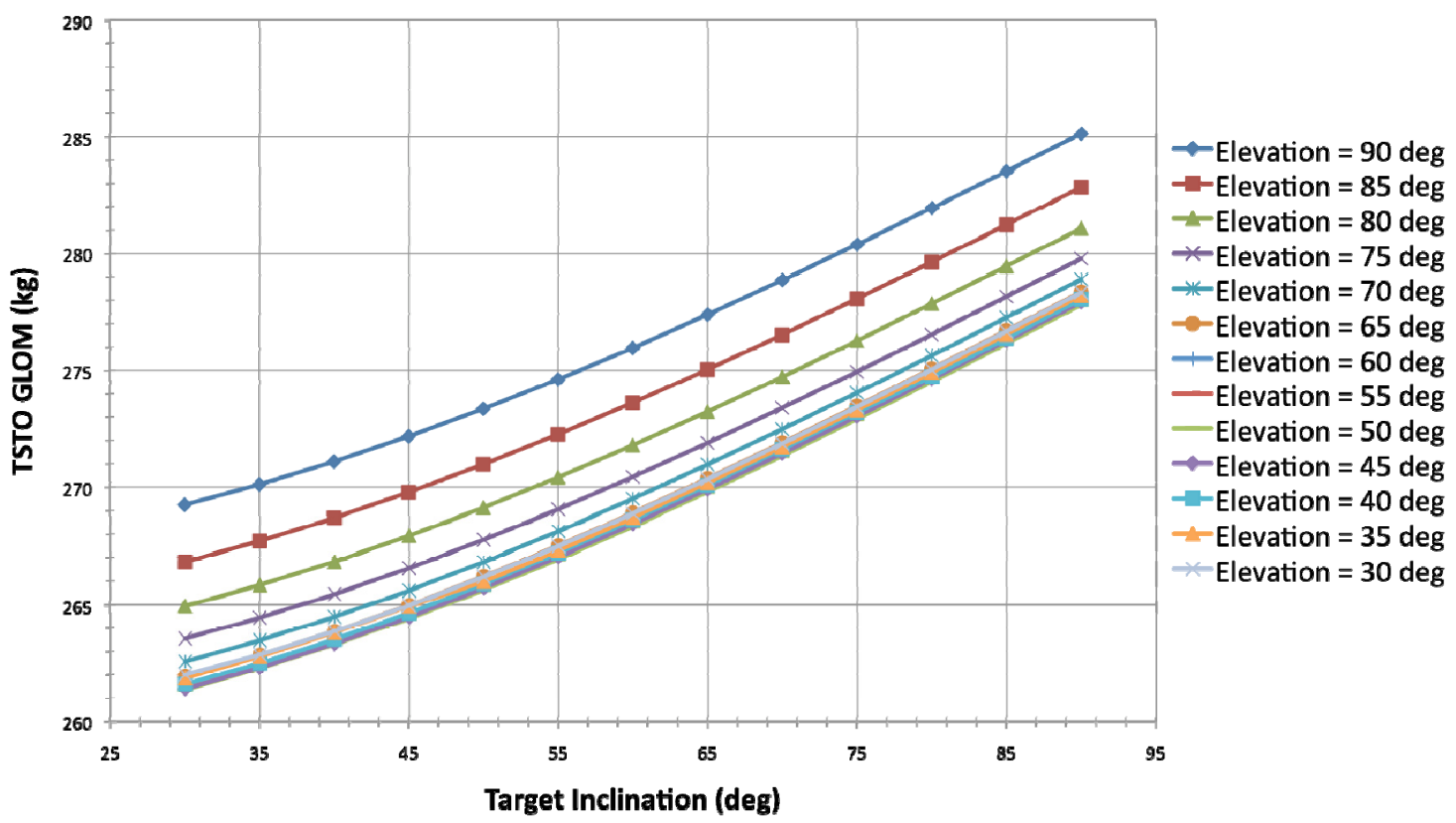

Figure 55.-TSTO GLOM sensitivities for a launch latitude of $30^{\circ}$. 


\section{TSTO GLOM vs Inclination for All Launch Elevations Launch Latitude $=\mathbf{3 5} \mathrm{deg}$}

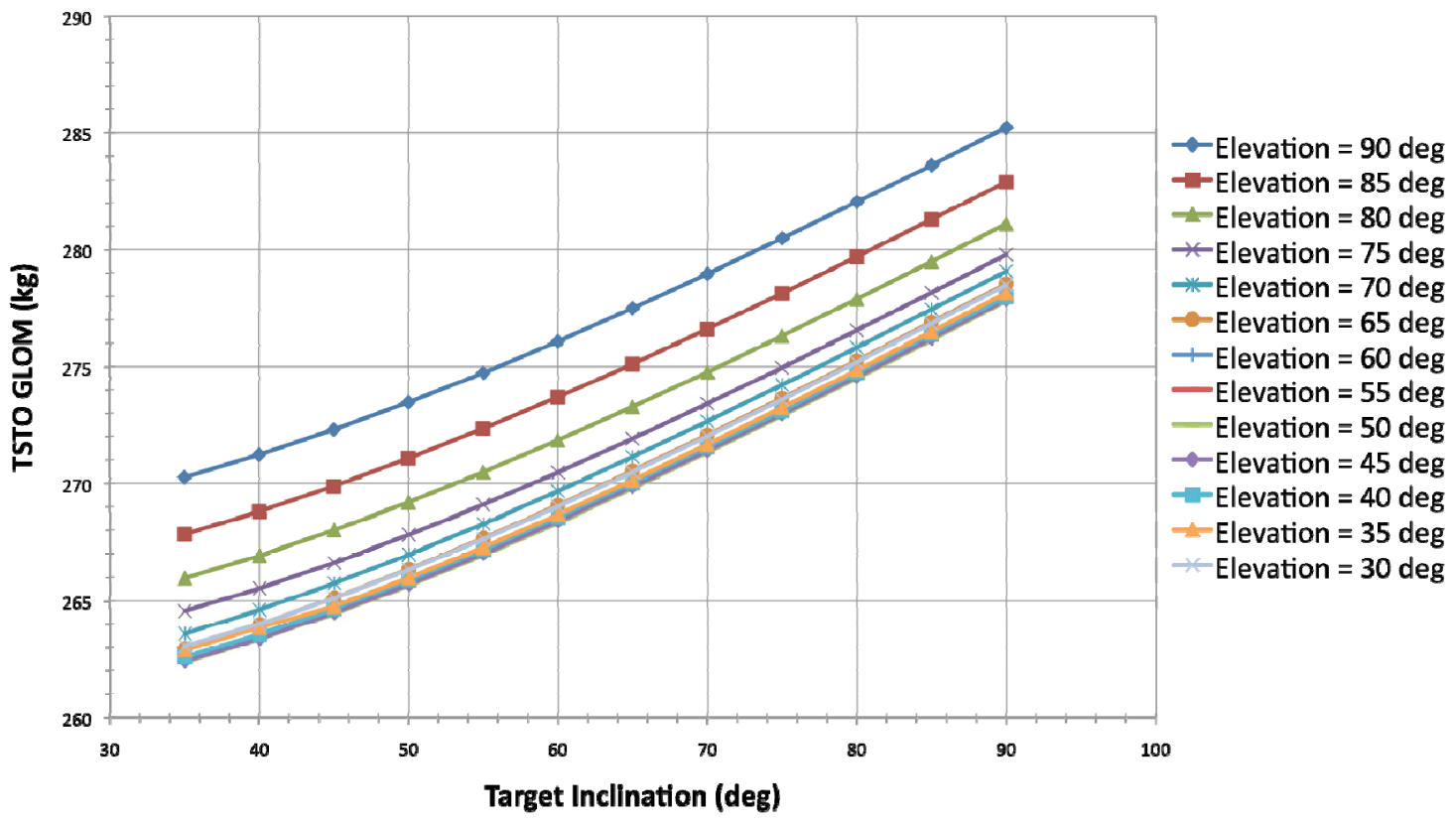

Figure 56.-TSTO GLOM sensitivities for a launch latitude of $35^{\circ}$.

\section{TSTO GLOM vs Inclination for All Launch Elevations Launch Latitude $=\mathbf{4 0} \mathrm{deg}$}

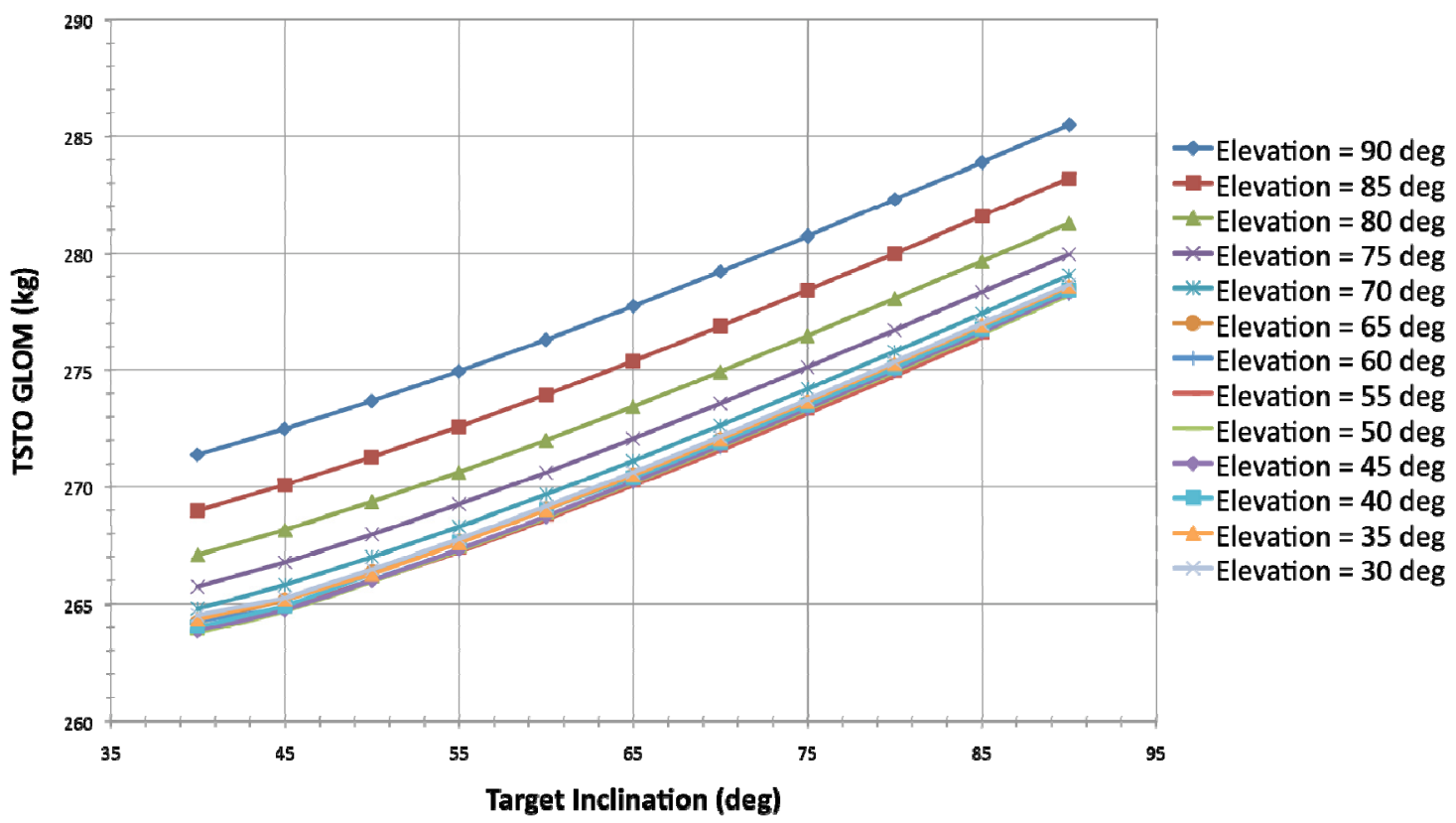

Figure 57.-TSTO GLOM sensitivities for a launch latitude of $40^{\circ}$. 


\section{TSTO GLOM vs Inclination for All Launch Elevations Launch Latitude $=\mathbf{4 5} \mathrm{deg}$}

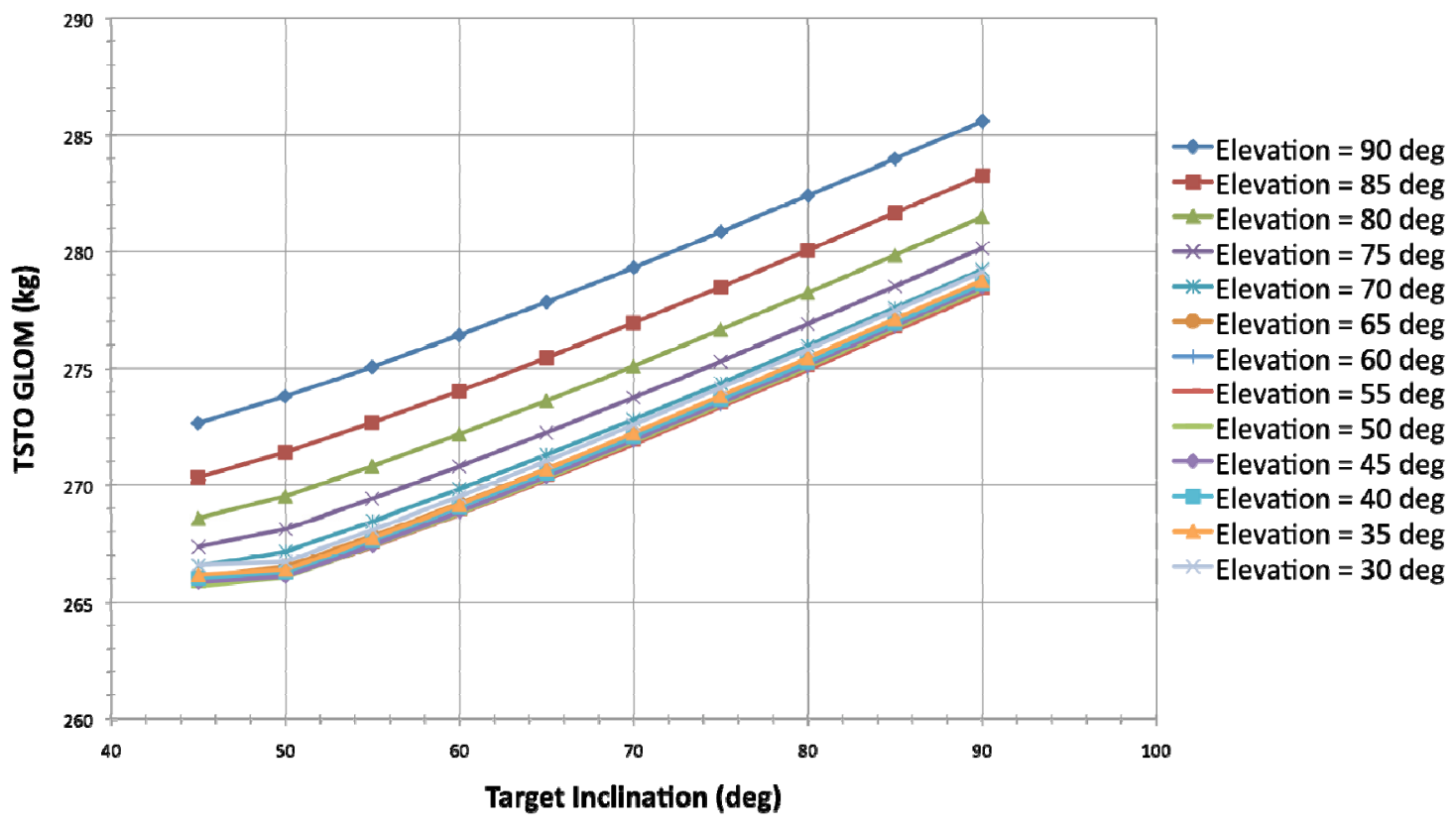

Figure 58.-TSTO GLOM sensitivities for a launch latitude of $45^{\circ}$.

\section{TSTO GLOM vs Inclination for All Launch Elevations Launch Latitude $=\mathbf{5 0} \mathbf{~ d e g}$}

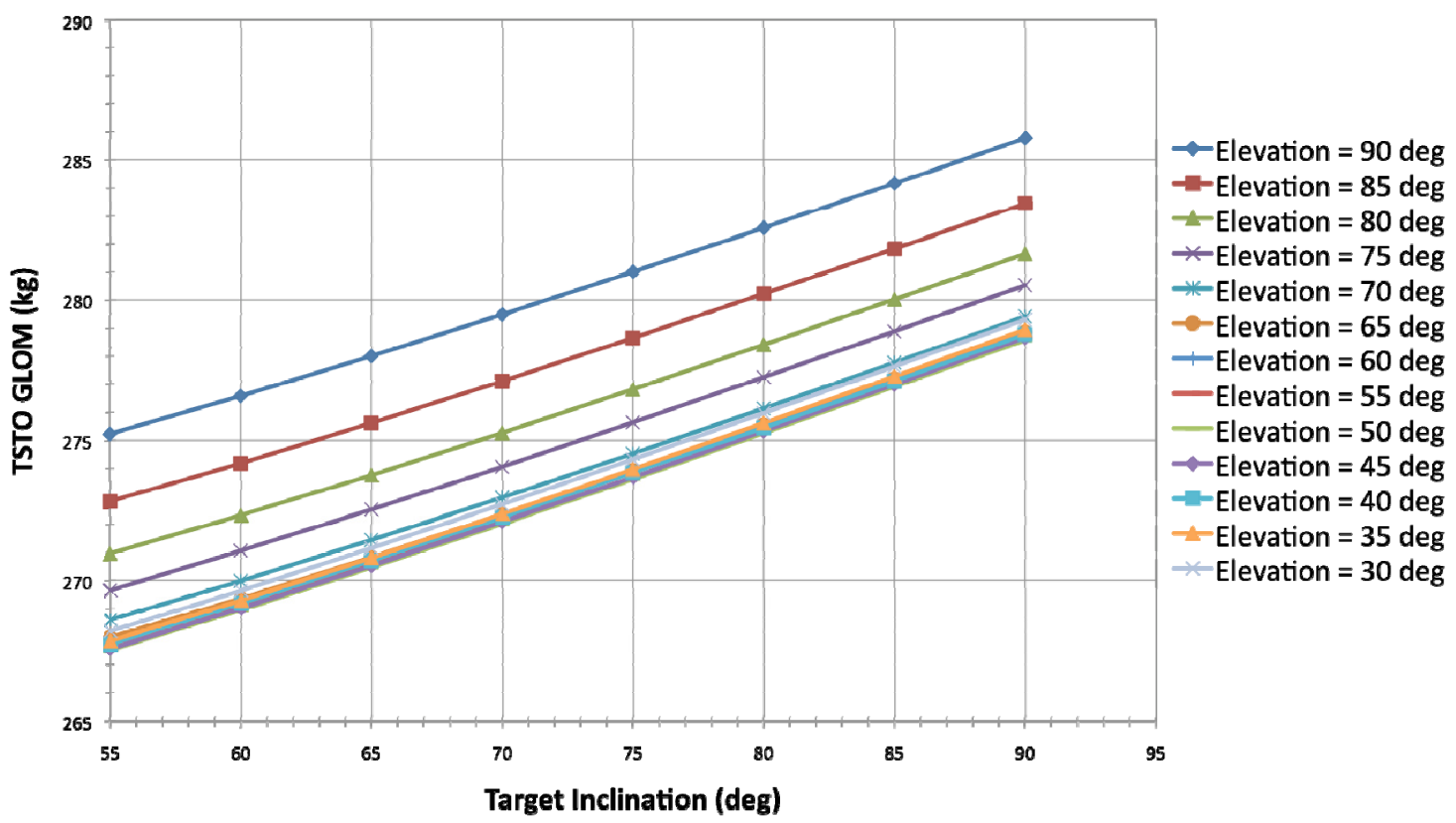

Figure 59._-TSTO GLOM sensitivities for a launch latitude of $50^{\circ}$. 


\section{TSTO GLOM vs Inclination for All Launch Elevations Launch Latitude $=55 \mathrm{deg}$}

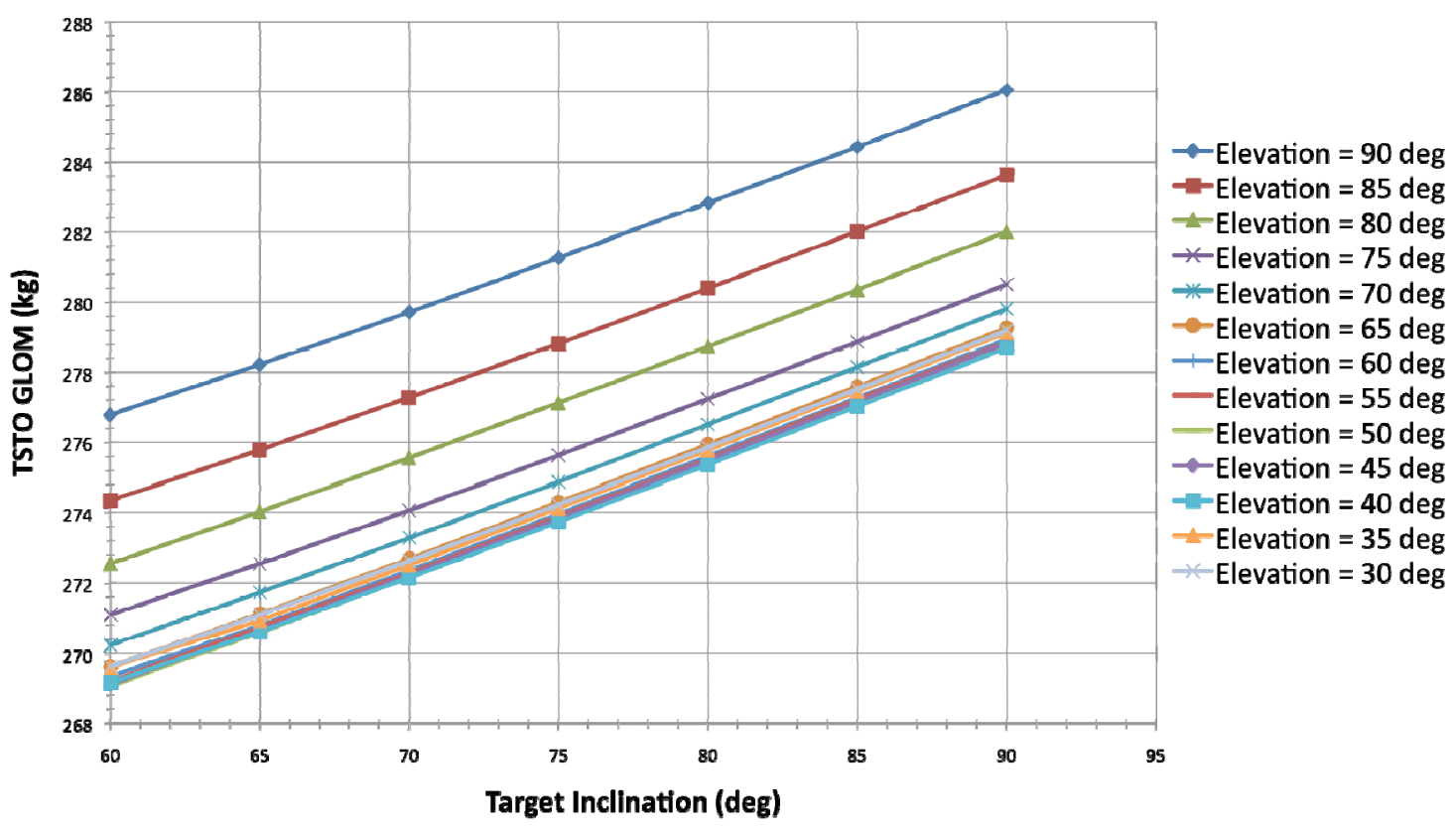

Figure 60.-TSTO GLOM sensitivities for a launch latitude of $55^{\circ}$.

\section{TSTO GLOM vs Inclination for All Launch Elevations Launch Latitude $=60 \mathrm{deg}$}

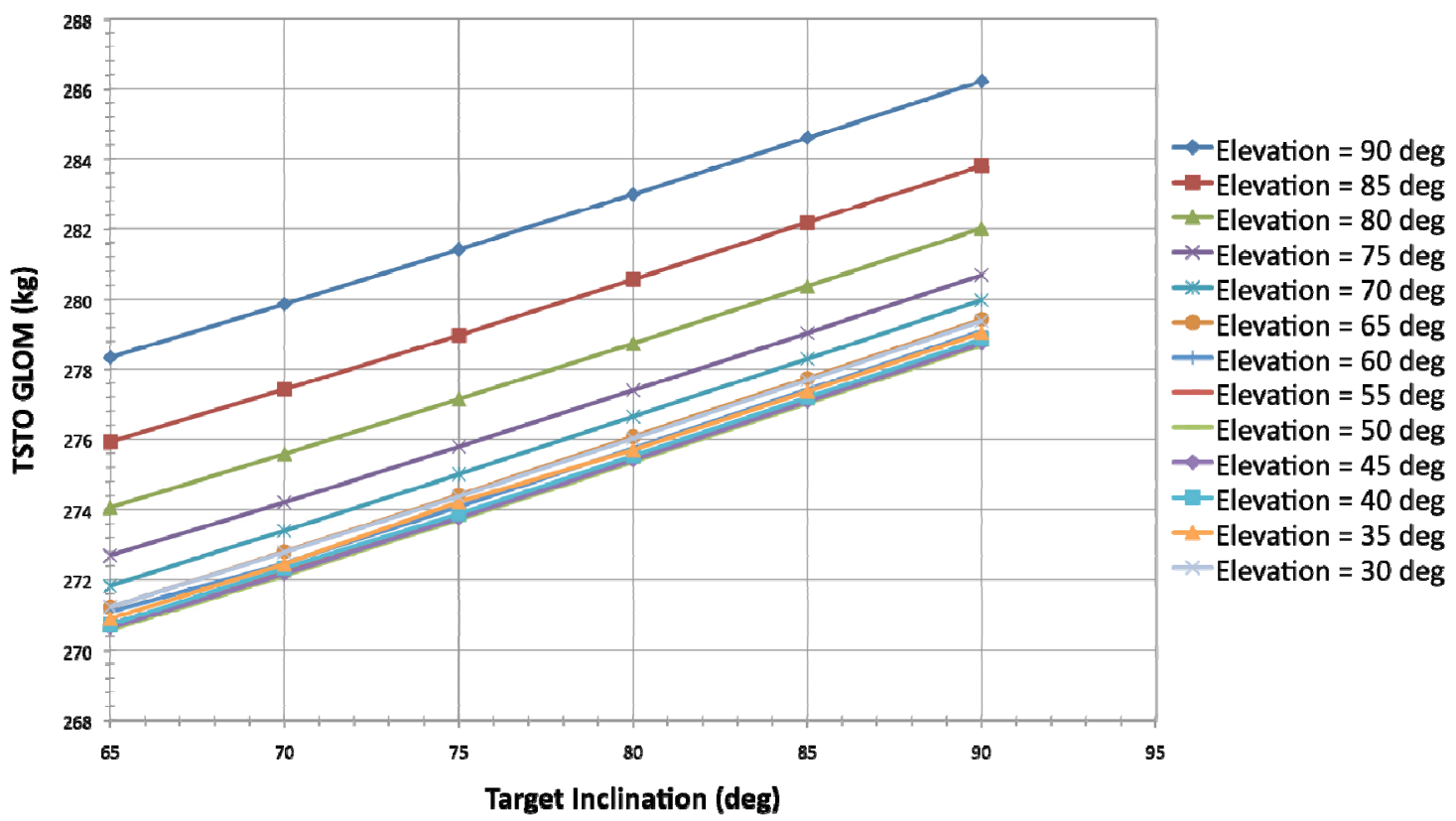

Figure 61.-TSTO GLOM sensitivities for a launch latitude of $60^{\circ}$. 


\section{TSTO GLOM vs Inclination for All Launch Elevations Launch Latitude $=65 \mathrm{deg}$}

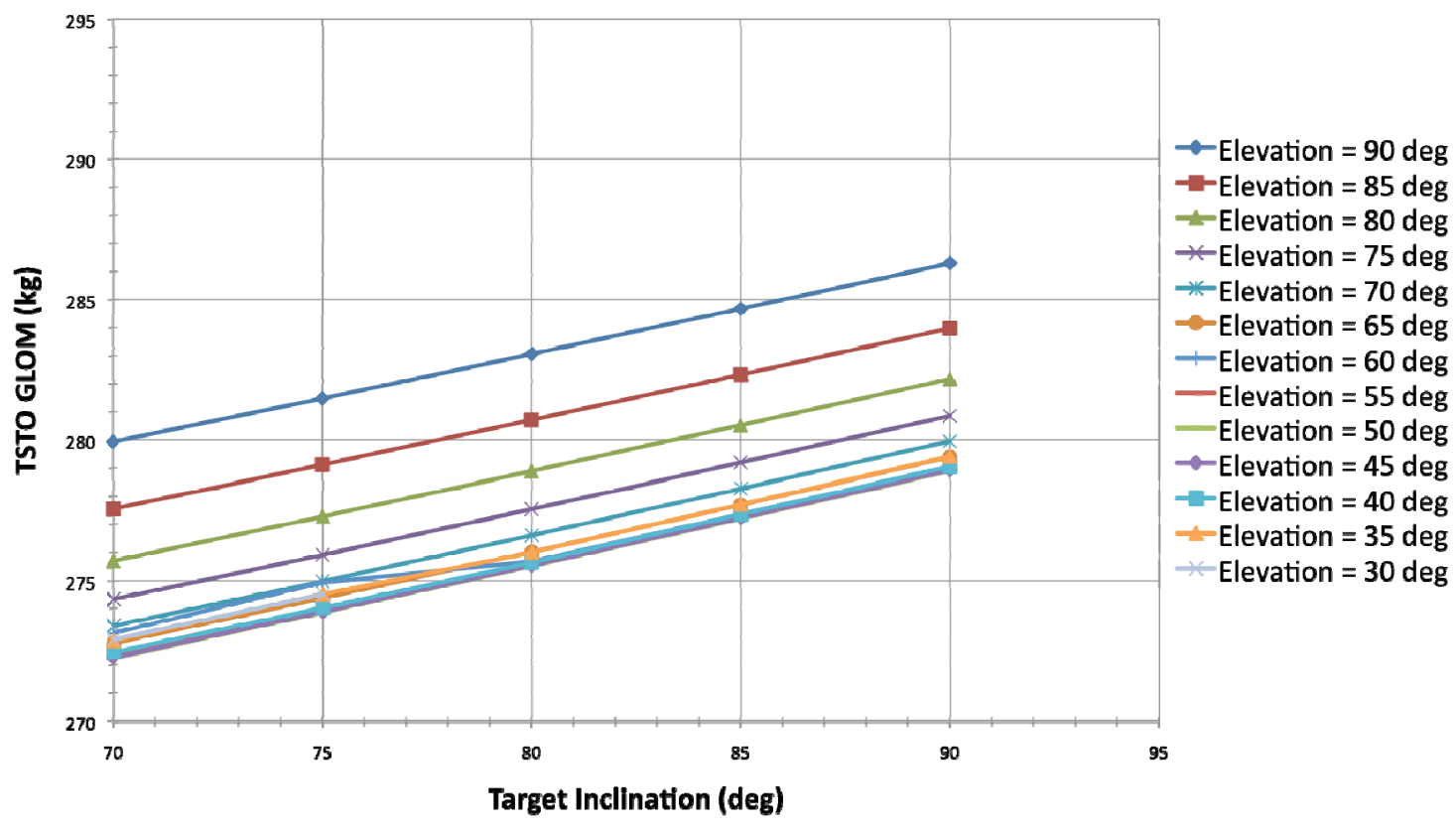

Figure 62.-TSTO GLOM sensitivities for a launch latitude of $65^{\circ}$.

\section{TSTO GLOM vs Inclination for All Launch Elevations Launch Latitude $=\mathbf{7 0} \mathrm{deg}$}

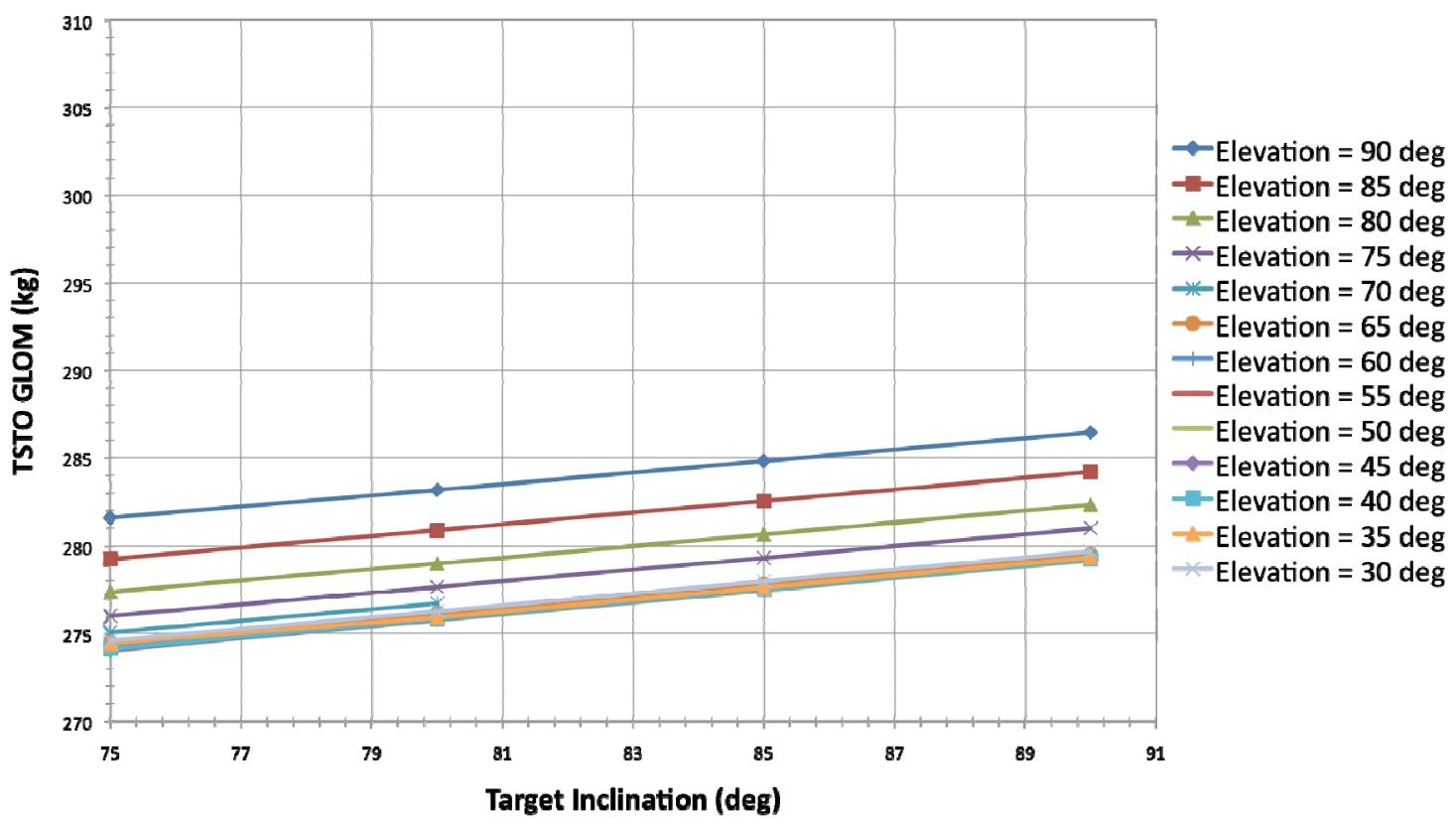

Figure 63.-TSTO GLOM sensitivities for a launch latitude of $70^{\circ}$. 
TSTO GLOM vs Inclination for All Launch Elevations Launch Latitude $=75 \mathrm{deg}$

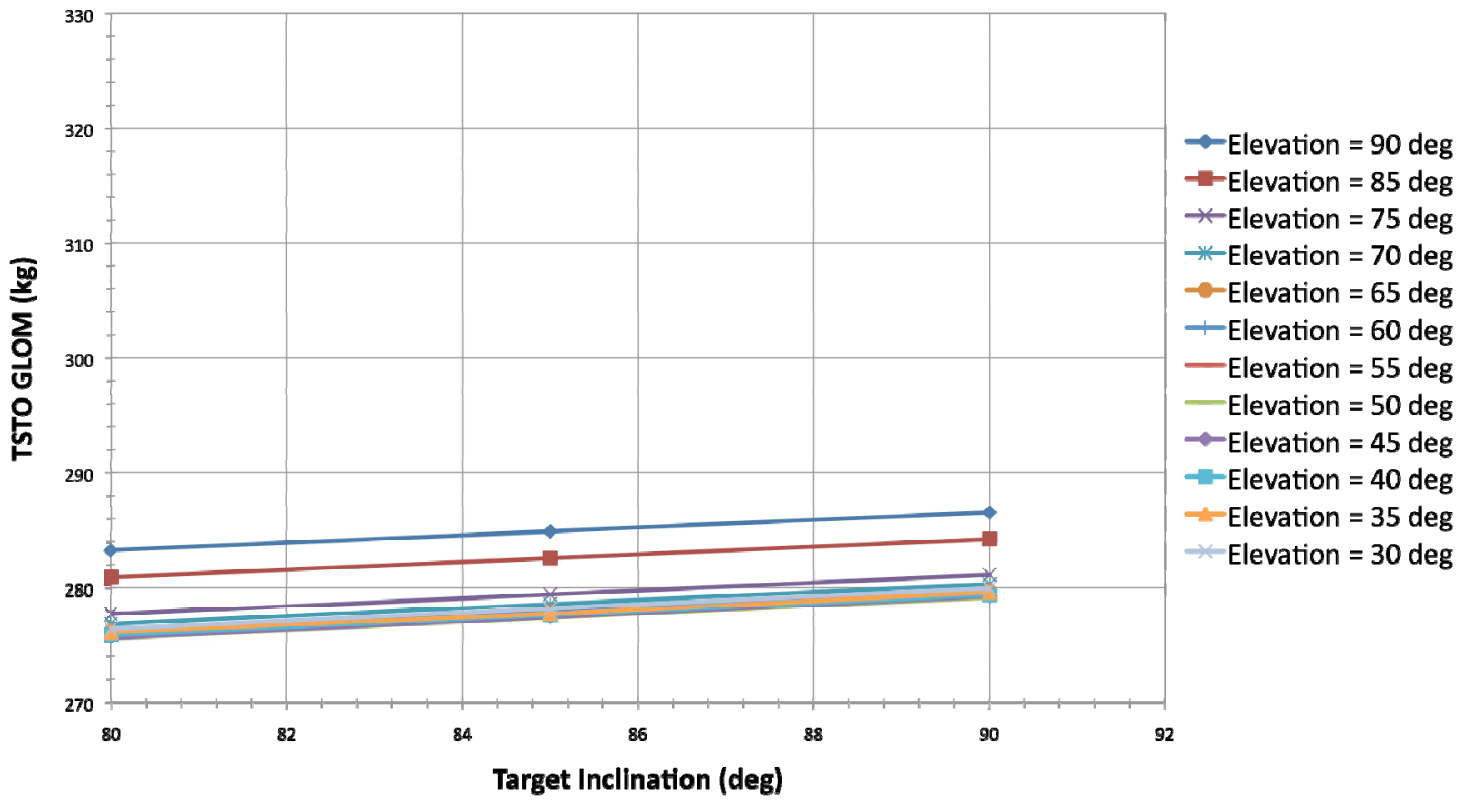

Figure 64.-TSTO GLOM sensitivities for a launch latitude of $75^{\circ}$. 


\section{References}

1. Mattingly, R., Matousek, S., and Jordan, F., "Continuing Evolution of Mars Sample Return,” 2004 IEEE Aerospace Conference, March 2004, Paper \#1392.

2. Sherwood, B., Pearson, D., Smith, D.B., Greeley, R., Whittaker, W., Woodcock, G., Barton, G., "Mars Sample Return: Architecture and Mission Design," 2002 IEEE Aerospace Conference, Paper \#515.

3. Evanyo, J.A., Delamere, A., Gulick, D., Horsley, B. et al., "Mars Sample Return A Robust Mission Approach for "Getting the Right Sample," 2002 IEEE Aerospace Conference, March 2002.

4. Mattingly, R., Hayati, S., and Udomkesmalee, G., "Technology Development Plans for the Mars Sample Return Missions," 2005 IEEE Aerospace Conference, Big Sky, MT, March 2005.

5. Way, D. W, et al., "Mars Science Laboratory: Entry, Descent, and Landing System Performance," 2007 IEEE Aerospace Conference, Big Sky, MT, March 2007.

6. Dankanich, J.W., "Mars Ascent Vehicle Technology Planning," 2009 IEEE Aerospace Conference, Big Sky, MT, March 2009.

7. Stephenson, D., "Mars Ascent Vehicle - Concept Development," AIAA-2002-4318, 38th Joint Propulsion Conference, July 2002.

8. Hargraves, C.R., Paris, S.W., and Vlases, W.G., "OTIS Past, Present, and Future," AIAA 92-4530 1992.

9. Brauer, G.L., Cornick, D.E., and Stevenson, R., "Capabilities and Applications of the Program to Optimize Simulated Trajectories,” NASA CR-2770, Feb. 1977.

10. Nelson, D., "Qualitative and Quantitative Assessment of Optimal Trajectories by Implicit Simulation (OTIS) and Program to Optimize Simulated Trajectories (POST)," Masters Individual Research Project, School of Aerospace Engineering, Georgia Institute of Technology, Atlanta, GA, 2001. 


\begin{tabular}{|c|c|c|c|c|c|}
\hline \multicolumn{5}{|c|}{ REPORT DOCUMENTATION PAGE } & $\begin{array}{c}\text { Form Approved } \\
\text { OMB No. 0704-0188 }\end{array}$ \\
\hline \multicolumn{6}{|c|}{$\begin{array}{l}\text { The public reporting burden for this collection of information is estimated to average } 1 \text { hour per response, including the time for reviewing instructions, searching existing data sources, gathering and maintaining the } \\
\text { data needed, and completing and reviewing the collection of information. Send comments regarding this burden estimate or any other aspect of this collection of information, including suggestions for reducing this } \\
\text { burden, to Department of Defense, Washington Headquarters Services, Directorate for Information Operations and Reports (07004-0188), } 1215 \text { Jefferson Davis Highway, Suite } 1204 \text {, Arlington, VA } 22220-4302 \text {. } \\
\text { Respondents should be aware that notwithstanding any other provision of law, no person shall be subject to any penalty for failing to comply with a collection of information if it does not display a currently valid OMB } \\
\text { control number. } \\
\text { PLEASE DO NOT RETURN YOUR FORM TO THE ABOVE ADDRESS. }\end{array}$} \\
\hline \multicolumn{2}{|c|}{$\begin{array}{l}\text { 1. REPORT DATE (DD-MM-YYYY) } \\
01-04-2011\end{array}$} & \multicolumn{3}{|c|}{$\begin{array}{l}\text { 2. REPORT TYPE } \\
\text { Technical Memorandum }\end{array}$} & 3. DATES COVERED (From - To) \\
\hline \multirow{3}{*}{\multicolumn{5}{|c|}{$\begin{array}{l}\text { 4. TITLE AND SUBTITLE } \\
\text { Mars Ascent Vehicle Gross Lift-off Mass Sensitivities for Robotic Mars Sample Return }\end{array}$}} & 5a. CONTRACT NUMBER \\
\hline & & & & & 5b. GRANT NUMBER \\
\hline & & & & & 5c. PROGRAM ELEMENT NUMBER \\
\hline \multirow{3}{*}{\multicolumn{5}{|c|}{$\begin{array}{l}\text { 6. AUTHOR(S) } \\
\text { Dux, Ian, J.; Huwaldt, Joseph, A.; McKamey, R., Steve, P.E.; Dankanich, John, W. }\end{array}$}} & 5d. PROJECT NUMBER \\
\hline & & & & & 5e. TASK NUMBER \\
\hline & & & & & $\begin{array}{l}\text { 5f. WORK UNIT NUMBER } \\
\text { WBS } 346620.04 .09 .01 .01 .01\end{array}$ \\
\hline \multicolumn{5}{|c|}{$\begin{array}{l}\text { 7. PERFORMING ORGANIZATION NAME(S) AND ADDRESS(ES) } \\
\text { National Aeronautics and Space Administration } \\
\text { John H. Glenn Research Center at Lewis Field } \\
\text { Cleveland, Ohio 44135-3191 }\end{array}$} & $\begin{array}{l}\text { 8. PERFORMING ORGANIZATION } \\
\text { REPORT NUMBER } \\
\text { E-17594 }\end{array}$ \\
\hline \multirow{2}{*}{\multicolumn{5}{|c|}{$\begin{array}{l}\text { 9. SPONSORING/MONITORING AGENCY NAME(S) AND ADDRESS(ES) } \\
\text { National Aeronautics and Space Administration } \\
\text { Washington, DC 20546-0001 }\end{array}$}} & $\begin{array}{l}\text { 10. SPONSORING/MONITOR'S } \\
\text { ACRONYM(S) } \\
\text { NASA }\end{array}$ \\
\hline & & & & & $\begin{array}{l}\text { 11. SPONSORING/MONITORING } \\
\text { REPORT NUMBER } \\
\text { NASA/TM-2011-216968 }\end{array}$ \\
\hline \multicolumn{6}{|c|}{$\begin{array}{l}\text { 12. DISTRIBUTION/AVAILABILITY STATEMENT } \\
\text { Unclassified-Unlimited } \\
\text { Subject Categories: } 91,15 \text {, and } 20 \\
\text { Available electronically at http://www.sti.nasa.gov } \\
\text { This publication is available from the NASA Center for AeroSpace Information, 443-757-5802 }\end{array}$} \\
\hline \multicolumn{6}{|c|}{ 13. SUPPLEMENTARY NOTES } \\
\hline \multicolumn{6}{|c|}{$\begin{array}{l}\text { 14. ABSTRACT } \\
\text { The Mars ascent vehicle is a critical element of the robotic Mars Sample Return (MSR) mission. The Mars ascent vehicle must be developed } \\
\text { to survive a variety of conditions including the trans-Mars journey, descent through the Martian atmosphere and the harsh Martian surface } \\
\text { environments while maintaining the ability to deliver its payload to a low Mars orbit. The primary technology challenge of developing the } \\
\text { Mars ascent vehicle system is designing for all conditions while ensuring the mass limitations of the entry descent and landing system are } \\
\text { not exceeded. The NASA In-Space Propulsion technology project has initiated the development of Mars ascent vehicle technologies with } \\
\text { propulsion system performance and launch environments yet to be defined. To support the project's evaluation and development of various } \\
\text { technology options the sensitivity of the Mars ascent vehicle gross lift-off mass to engine performance, inert mass, target orbits, and launch } \\
\text { conditions has been completed with the results presented herein. }\end{array}$} \\
\hline \multicolumn{6}{|c|}{$\begin{array}{l}\text { 15. SUBJECT TERMS } \\
\text { Ascent; Mars Sample Return (MSR) mission; Mars landing; Mars surface; Optimal Trajectories by Implicit Simulation program } \\
\text { (OTIS); Mars ascent vehicle; Mars surface samples; Descent }\end{array}$} \\
\hline \multicolumn{3}{|c|}{ 16. SECURITY CLASSIFICATION OF: } & $\begin{array}{l}\text { 17. LIMITATION OF } \\
\text { ABSTRACT }\end{array}$ & $\begin{array}{l}\text { 18. NUMBER } \\
\text { OF }\end{array}$ & $\begin{array}{l}\text { 19a. NAME OF RESPONSIBLE PERSON } \\
\text { STI Help Desk (email:help@sti.nasa.gov) }\end{array}$ \\
\hline $\begin{array}{l}\text { a. REPORT } \\
\text { U }\end{array}$ & $\begin{array}{l}\text { b. ABSTRACT } \\
\text { U }\end{array}$ & $\begin{array}{l}\text { C. THIS } \\
\text { PAGE } \\
\text { U }\end{array}$ & UU & $\begin{array}{l}\text { PAGES } \\
63\end{array}$ & $\begin{array}{l}\text { 19b. TELEPHONE NUMBER (include area code) } \\
443-757-5802\end{array}$ \\
\hline
\end{tabular}



